\title{
Estimating the Geothermal Electricity Generation Potential of Sedimentary Basins using genGEO (the generalizable GEOthermal techno-economic simulator)
}

\author{
Benjamin M. Adams ${ }^{1 *}$, Jonathan D. Ogland-Hand ${ }^{1}$, Jeffrey M. Bielicki ${ }^{2,3}$, Philipp Schädle ${ }^{1}$, and \\ Martin O. Saar ${ }^{1,4 *}$ \\ ${ }^{1}$ Geothermal Energy and Geofluids Group, Department of Earth Sciences, ETH-Zürich, Sonneggstrasse 5, 8092 Zürich, Switzerland \\ ${ }^{2}$ Department of Civil, Environmental, and Geodetic Engineering, 2070 Neil Avenue, Columbus, OH 43210, USA \\ 3John Glenn College of Public Affairs, 1810 College Road, Columbus, OH 43210, USA \\ ${ }^{4}$ Department of Earth and Environmental Sciences, University of Minnesota, Minneapolis, MN, USA \\ "Corresponding Authors: badams@ethz.ch and saarm@ethz.ch
}

\begin{abstract}
Sedimentary basins are ubiquitous, naturally porous and permeable, and the geothermal heat in these basins can be extracted with geologic water or $\mathrm{CO}_{2}$ and used to generate electricity. Despite this, the broad potential that these formations may have for electricity generation is unknown. Here we investigate this potential, which required the creation of the generalizable GEOthermal techno-economic simulator (genGEO). genGEO is built with only publicly available data and uses five standalone, but integrated, models that directly simulate all components of geothermal power plants to estimate electricity generation and cost. As a result of this structure, genGEO, or a portion of it, can be applied or extended to study any geothermal power technology. In contrast, the current techno-economic tools for geothermal power plants rely on characterizations of unpublished ASPEN results and are thus not generalizable enough to be applied to sedimentary basin geothermal power plants which use subsurface $\mathrm{CO}_{2}$.
\end{abstract}

In this study, we present genGEO as open-source software, validate it with industry data, and compare its estimates to other geothermal techno-economic tools. We then apply genGEO to sedimentary basin geothermal resources and find that using $\mathrm{CO}_{2}$ as a subsurface heat extraction fluid compared to water decreases the cost of geothermal electricity across most geologic conditions that are representative of sedimentary basins. Using genGEO results and p50 geologic data, we produce supply curves for sedimentary basin geothermal power plants in the U.S., which suggests that there is present-day potential to profitably increase the capacity of geothermal power by $\sim 10 \%$ using water as the subsurface heat extraction fluid. More capacity is available at lower cost when $\mathrm{CO}_{2}$ is used as the subsurface fluid, but realizing this capacity requires geologically storing between $\sim 2$ and $\sim 7 \mathrm{MtCO}_{2} / \mathrm{MW}_{\mathrm{e}}$. But developing sedimentary basin resources in the short-term using subsurface water may not eliminate options for $\mathrm{CO}_{2}$-based power plants in the long-term because the least-cost order of sedimentary basins is not the same for both $\mathrm{CO}_{2}$ and water. With sufficient geologic $\mathrm{CO}_{2}$ storage, developing sedimentary basins using $\mathrm{CO}_{2}$ - and water-based power plants may be able to proceed in parallel.

\section{Broader Context}

Geothermal power plants can provide dispatchable and renewable electricity but are not widely deployed because they require specific geologic resources. To this end, much geothermal energy research is focused on identifying new and existing geologies that can be developed for power generation. Sedimentary basins can be used to generate electricity, but the geothermal potential 
of these formations is unknown and typically excluded without justification from geothermal power resource assessments. In order to address this gap, we developed genGEO and applied it to sedimentary basin geothermal resources. Our findings broadly suggest that sedimentary basin geothermal resources should not be excluded anymore and may thus be relevant to anyone concerned with meeting energy decarbonization or climate change mitigation goals. Independent of these findings, the generalizability and optimization options offered with genGEO are novel improvements to geothermal techno-economic tools. We release genGEO implemented in python as open-source software as part of this publication, thus enabling future researchers to robustly study geothermal energy resources and to further develop their own custom geothermal technoeconomic assessment tools.

Keywords: Geothermal Power Plants; Sedimentary Basins; Geothermal Resource Assessment; Techno-economic Assessment Tools; Renewable Energy; genGEO

\section{Introduction}

Geothermal energy is the thermal energy contained within the crust of the earth and can be used to generate electricity. Geothermal power plants are comprised of similar components as coal or natural-gas power plants (e.g. turbines, compressors, heat-exchangers), but are driven from energy derived from the subsurface instead of burning fossil-fuels. This subsurface energy is accessed by producing geothermally-heated fluids from a well. As a result, geothermal power plants emit substantially less carbon dioxide $\left(\mathrm{CO}_{2}\right)$ compared to coal or natural gas power plants, but can still provide on-demand, or dispatchable, electricity, unlike other renewable energy technologies (e.g. solar photovoltaics). The importance of these distinctions cannot be overstated because dispatchable low-carbon energy technologies are valuable to electricity system decarbonization, ${ }^{1,2}$ which is an essential component of climate change mitigation. ${ }^{3-5}$ For example, even with a levelized cost approximately double that of solar photovoltaics, geothermal power plants may still be deployed in least-cost decarbonized electricity systems because they can provide dispatchable low-carbon electricity. ${ }^{6}$

Despite its value, the contribution of geothermal power to decarbonization efforts may be limited because the majority of identified conventional low-cost geothermal energy resources in the developed world are already in use. For example, there are only about $6 \mathrm{GW}_{\mathrm{e}}$ of discovered conventional, or "hydrothermal", resources that are not yet being used to generate electricity in the U.S., ${ }^{7}$ which is equivalent to $0.5 \%$ of all installed generation capacity in the country in $2019 .{ }^{8}$ For this reason, investigating the use of non-hydrothermal geologies for geothermal electricity production is a primary research focus.

Hot dry rock resources are the most studied alternative to hydrothermal geologies, with an estimated potential capacity of approximately $5,000 \mathrm{GW}_{\mathrm{e}}$ in the U.S. alone. ${ }^{9}$ Hydrothermal resources provide access to hot brine or steam through naturally permeable geologic structures, such as pores or faults in the subsurface. In contrast, accessing the heat within hot dry rock resources requires artificially increasing permeability by hydraulic stimulation and then pumping an external fluid through the enhanced-permeability system. ${ }^{10}$ Water is typically considered as the external fluid, but $\mathrm{CO}_{2}$ has been shown to extract heat more efficiently due to its advantageous 
thermophysical properties. ${ }^{11,12}$ Because the fluid and fracture network are unnatural, hot dry rock is typically referred to as an "enhanced" geothermal system (EGS) resource.

Due to their generally high temperatures, EGS resources are an enticing option for low-cost geothermal power because, holding everything else constant, cost decreases as the temperature of the subsurface increases. But everything else is not held constant between EGS and hydrothermal resources, managing induced seismicity during hydraulic stimulation is challenging, ${ }^{13-15}$ and only a small fraction of the vast EGS resource potential is viable to be developed from a cost perspective without the development of novel technologies that reduce the cost of drilling and hydraulic stimulation. ${ }^{7,16,17}$

Sedimentary basins are another option for expanding the geothermal resource base. In contrast to EGS resources, low-cost development of sedimentary basins for power generation is not contingent on advances in drilling and fracturing technology because these formations are naturally porous and permeable and do not require artificial stimulation. Additionally, sedimentary basins are ubiquitous, underlying approximately half of all land on Earth. ${ }^{18}$ Despite these advantages and a lack of research justifying their exclusion, sedimentary basins are typically not considered for electricity generation. For example, without providing any reasoning for doing so, the 2019 U.S. Department of Energy GeoVision study excluded sedimentary basins when estimating the geothermal electricity generation potential in the U.S. ${ }^{7}$

While typically excluded, it is possible to generate electricity with sedimentary basin geothermal resources using either in-situ brine or geologically stored $\mathrm{CO}_{2}$ as the heat extraction fluid. ${ }^{19,20}$ And because sedimentary basins are also the primary targets for geologic $\mathrm{CO}_{2}$ storage ${ }^{21}$ sedimentary basin $\mathrm{CO}_{2}$-geothermal power plants, typically referred to a $\mathrm{CO}_{2}$-Plume Geothermal (CPG) power plants ${ }^{22-24}$, may have beneficial synergies with $\mathrm{CO}_{2}$ capture and storage (CCS) processes that increase their value to decarbonization efforts. Despite this potential, the cost of generating electricity with sedimentary basins has not been robustly studied and the potential that sedimentary basins have for expanding the geothermal resource base is unknown.

In this study, we address this knowledge gap by developing and using the generalizable GEOthermal simulator (genGEO), which can estimate the electricity generation and cost of geothermal power plants. genGEO is built from the bottom-up using publicly available data and is comprised of five standalone, but integrated, models: 1) a geologic model to simulate reservoir pressure and temperature change, 2) a well model that simulates the energy and pressure loss (or gain) of fluid flowing to and from the subsurface, 3) a power cycle model that thermodynamically simulates electricity generation, 4) a capital cost model that estimates the capital cost of the geothermal power plant, and 5) a levelized cost of electricity (LCOE) model that estimates the LCOE of the geothermal power plant, which is a standard metric for cost throughout the electricity sector.

Prior work created Geothermal Electricity Evvaluation Model (GETEM) ${ }^{25}$ and GEOthermal energy

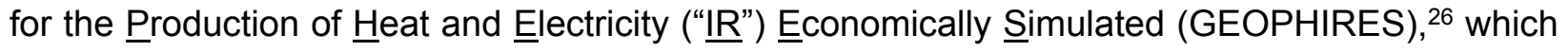
have played a pioneering role in techno-economic geothermal resource assessment. For example, GEOPHIRES was developed out of the MIT-EGS model, which was used for technoeconomic assessments of EGS geothermal power plants starting in the 1980 s. ${ }^{26}$ Further, GETEM 
supply curves also are the default cost and capacity relationships used to define geothermal power plants within NEMS, MARKAL, ReEDS, SEDS, and GCAM, ${ }^{27,28}$ which are all energy systems models that can be used to inform policy decisions. Recently, GETEM was used to create U.S.-wide supply curves for all hydrothermal and EGS geothermal power plants in the 2019 U.S. DOE GeoVision report. ${ }^{7}$ Despite this reputability, neither GETEM nor GEOPHIRES were generalizable enough to be applied for this study because they fundamentally rely on characterizations of results from unpublished ASPEN simulations to estimate electricity generation and cost. This reliance limits the applicability of these tools to any power plants besides traditional indirect power plants that use water as the subsurface heat extraction fluid. In contrast, the generalizability of genGEO means that nearly any geothermal energy system may be investigated, including sedimentary basin power plants that use $\mathrm{CO}_{2}$ as the subsurface heat extraction fluid.

Because genGEO is first-of-its-kind, we provide multiple contributions in this paper. First, in Section 2 and in the Supplemental Information (SI), we provide a detailed description of genGEO, which we implemented in python to release as open-source software concurrently with this publication. Second, we validate genGEO using publicly available data from the Tungsten Mountain geothermal power plant in Nevada, U.S. This validation is part of a larger comparison between genGEO, GETEM, and GEOPHIRES that we conduct to display the improvements that genGEO makes to the field of geothermal techno-economic assessment (Section 3.1). Third, we use genGEO to compare using $\mathrm{CO}_{2}$ versus water as a heat extraction fluid in sedimentary basin geothermal power plants from an electricity generation and cost perspective over a large geologic parameter space (Section 3.2). Fourth, we use these large parameter space cost and generation results along with publicly available sedimentary basin data to produce supply curves for sedimentary basins geothermal power plants in the U.S. (Section 3.2). Finally, we provide the conclusions from this study (Section 4). While this study is not a review paper, we uncovered findings that have not yet been clearly documented within the geothermal energy community during the literature review that we conducted to create genGEO. As a result, we also include these literature review findings at the end of our conclusion section.

\section{Methods}

In addition to using some features of genGEO to extend the scientific understanding of sedimentary basin geothermal power plants, this paper also introduces and validates genGEO as an open-source software tool that can be applied to various geothermal systems as needed. As a result, we first present an overview of genGEO before describing how we applied genGEO to study sedimentary basin geothermal power plants.

\subsection{Description of the "Out of the Box" genGEO}

Figure 1 shows the model couplings within genGEO that allow users to simulate the use of geothermal resources for heat or electricity generation and estimate associated cost. Each of these models, which are briefly discussed below and completely described in the SI, are standalone and transparent. Additionally, aside from common mathematic libraries, the only thirdparty software used within genGEO is the open-source thermophysical fluid library CoolProp, ${ }^{29}$ which is used to calculate fluid properties. 


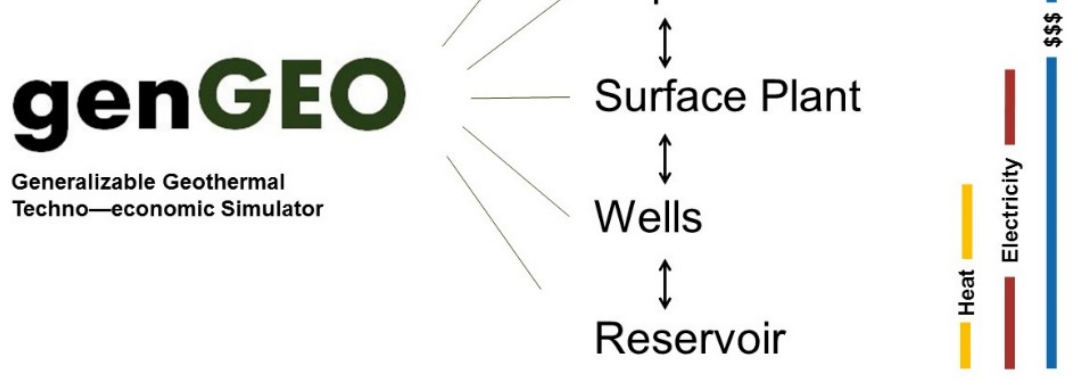

Figure 1: genGEO coupled model approach

The object-oriented and transparent nature of genGEO enables generalizability because it allows any model within of genGEO to be applied to any given geothermal technology. For example, because the genGEO capital cost model estimates the cost of each individual component of a geothermal surface plant separately (e.g. turbine, heat exchanger, etc.) and then combines them, it can be applied to estimate the capital cost of geothermal energy system that provides heat instead of electricity. Similarly, the same code used to find the capital cost of an ORC is used to find the capital cost of a CPG surface plant, which is thermodynamically very different. Further, the user could modify the power plant model to investigate novel power cycles or implement conditions representative of any geologic resource in the reservoir model.

In addition to its generalizability, the optimization options implemented within genGEO are also methodological contributions to the field of geothermal techno-economic assessment. For example, when investigating geothermal surface plants, the user can specify to minimize cost or maximize power production. Based on the user inputs, genGEO can also determine the heat extraction production flowrate that minimizes cost or maximizes electricity generation (Section S5.1). And if used to investigate an ORC surface plant, genGEO will also determine the optimal boiling pressures and heat exchanger pinch temperature difference, which are degrees of freedom in every ORC surface plant (Section S5.3).

\subsubsection{Reservoir Model (Sections S7 and S8 of the SI)}

The standard reservoir model in genGEO is a 1-D Darcy analytical solution for simulating the pressure decline in homogeneous, isotropic, and porous reservoir. We use this model because it provides a relatively precise solution for reservoir impedance while substantially reducing the computational requirements compared to reservoir simulators (e.g. TOUGH2) that have been extensively used to study geothermal energy. ${ }^{30}$ But similar to GEOPHIRES, the user can apply results they generated with separate reservoir simulators to genGEO by modifying the relevant python models, if desired (Section S7). Similarly, the pressure drop through EGS or hydrothermal resources may be simulated by calculating an effective transmissivity, as is the case of the Tungsten Mountain simulations we performed to validate genGEO in this study (Section 3.1.3). 
There are two well-pattern reservoir model options in genGEO. The user can either use an inverted 5-spot pattern ${ }^{19,22,23,31,32}$ or a simpler source-sink pair (i.e. "doublet") (Section S8).

\subsubsection{Well Model (Section S6 of the SI)}

The wellbore model is taken from prior work. ${ }^{19,33}$ The substantive change between Ref. 19 and Ref. 33 is the inclusion of heat loss (or addition) from the wellbore to the surrounding rock.

\subsubsection{Surface Plant Model (Section S5 of the SI)}

There are two surface plant types implemented in genGEO: 1) an ORC that uses water as the subsurface heat extraction fluid and 2) a power cycle that directly uses geologically stored $\mathrm{CO}_{2}$ to generate electricity (i.e. a CPG power plant). These power cycles are modeled following the method used in Ref. 19, except that tower parasitic load fractions have been re-regressed for a better fit of the raw data.

\subsubsection{Capital Cost Model (Section S3 of the SI)}

The genGEO capital cost model has six primary components:

- Surface Plant (Section S3.2)

- Well (Section S3.3)

- Surface Piping (Section S3.4)

- Wellfield (Section S3.5)

- Exploration (Section S3.6)

- Well Stimulation (Section S3.7)

The capital cost model calculates the cost of all primary components of the power plant and then determines the total cost using multipliers that account for construction, labor, etc. This bottom-up process ensures modifications to the cost of any equipment or component can be propagated. For instance, the cost of the turbine or cooling towers is determined as a function of the thermodynamic data produced with the power cycle model. As a result, when the turbine power generation increases, or the cooling tower approach temperature increases, the cost reflects those changes.

\subsubsection{Levelized Cost of Electricity (LCOE) Model (Section S2 of the SI)}

The LCOE is the price at which electricity must be sold for revenue from electricity sales to equal the levelized capital and operating cost and can be calculated in multiple ways (Section S2).

The LCOE is a function of the financing assumptions, which are inputs in genGEO. For reference, Table 1 shows the LCOE financing assumptions of genGEO and prior work. ${ }^{34}$ The "LIKELY" values represent values likely expected in industry. For example, the Ormat 2019 annual report 35 provides sufficient information to estimate their financing assumptions: $1536 \mathrm{M} \$$ debt at an average interest rate of $5.1 \%$ and $1524 \mathrm{M} \$$ equity at an average rate of $2.1 \%$ for a weighted average cost of capital (WACC) of 3.6\%. The "O\&M-Only" financing parameters can be used to estimate an older power plant, financed only through debt, that completed paying off capital cost. 
Table 1: LCOE Financing Assumptions

\begin{tabular}{|c|c|c|c|c|c|}
\hline LCOEX & LAZARD & LIKELY & O\&M-Only & GETEM & GEOPHIRES \\
\hline Capacity Factor & 0.85 & 0.95 & 0.95 & 0.95 & 0.90 \\
\hline $\begin{array}{l}\text { Financial } \\
\text { Lifetime [years] }\end{array}$ & 25 & 25 & -- & 30 & 30 \\
\hline WACC [\%] & 9.6 & 4 & -- & 7 & 7.5 \\
\hline $\begin{array}{l}\text { O\&M Fraction } \\
\text { [\% of capital } \\
\text { cost/year] }\end{array}$ & 4.5 & 5.5 & 5.5 & $3.0^{* *}$ & $5.6^{* *}$ \\
\hline $\begin{array}{l}\text { Rate Factor (RF) } \\
{\left[\mathrm{W} / \mathrm{MW}_{\mathrm{e}}-\mathrm{h}\right]}\end{array}$ & 20 & 14 & 6.6 & 13 & 18 \\
\hline
\end{tabular}

The LCOE can be found by multiplying the specific capital cost by the rate factor (RF), which is a coefficient we developed to easily convert specific capital cost to the LCOE (Section S2.2). As demonstrated in Figure 2, the rate factor is primarily a function of the O\&M cost fraction and the WACC. The solid blue lines represent a capacity factor of $90 \%$.

Figure 2 shows that for the same capital cost, the LCOE can vary by $\sim 40 \%$ due only to the LCOE financing assumptions in Table 1. Also, the slope of the blue lines in Figure 2 is about $-11 / y r$, which illustrates that the O\&M cost fraction has an approximately equivalent effect on the LCOE as the WACC. Lastly, the "O\&M-Only" rate factor is approximately half the LIKELY value. The rate factor increases to approximately $60 \%$ of the LIKELY value when $40 \%$ indefinite equity financing is assumed (Section S2.1). In other words, Figure 2 demonstrates that O\&M costs are an important consideration of the cost of geothermal power plants and that the LCOE can still be substantial after debt financing is complete.

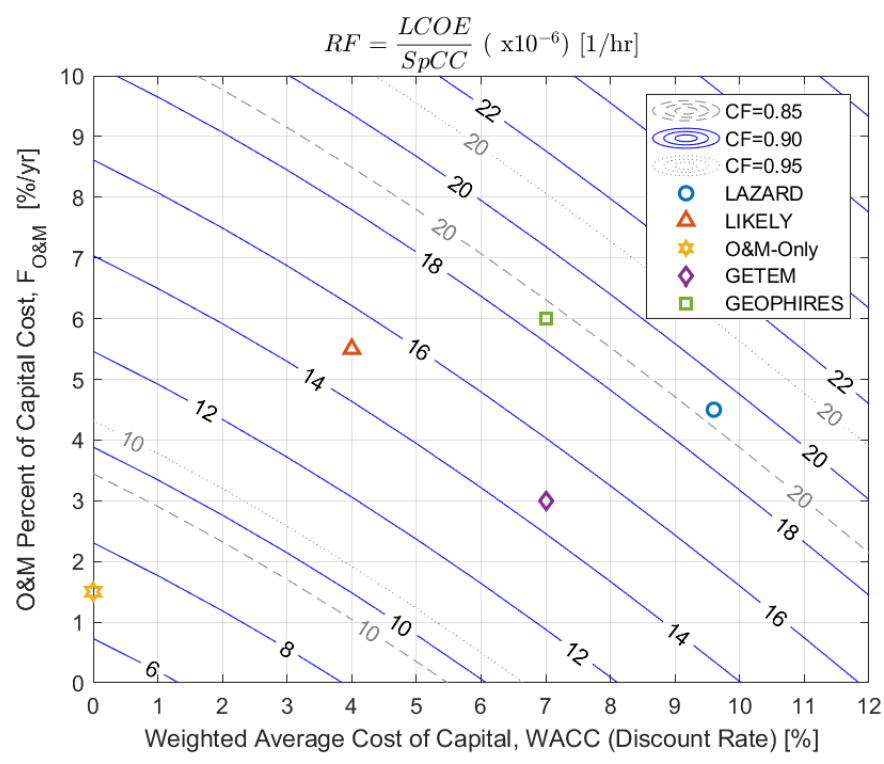

Figure 2: Ratio of LCOE to Specific Capital Cost (i.e. rate factor, RF) for a range of weighted average cost of capital, WACC, and O\&M cost fraction, Fo\&M. The solid blue lines represent a $90 \%$ capacity factor. 
Additionally, users investigating geothermal energy resources for heat may be interested in calculating the levelized cost of heat $(\mathrm{LCOH})$, which is also described in the SI.

\subsection{Using genGEO}

\subsubsection{Comparing genGEO to GETEM and GEOPHIRES}

We make three comparisons between genGEO, GETEM, and GEOPHIRES in Section 3.1 to display the methodological contributions of genGEO. We validate genGEO using industry data in Section 3.1.3. In all comparisons, unless otherwise specified, we use the geologic and power cycle inputs shown in Table 2. As the rate factor varies widely depending on financing assumptions (Figure 2), we report costs primarily using the specific capital cost $\left(\$ / \mathrm{MW}_{\mathrm{e}}\right)$ instead of LCOE. All capital costs are reported in 2019 dollars and include indirect costs and contingency (Section S1.2). When LCOE is reported, the financing assumptions of Table 1 are given.

Table 2: Study Base-case Parameters

\begin{tabular}{|l|l|}
\hline $\begin{array}{l}\text { Parameter } \\
\text { Geologic Temperature }\end{array}$ & $35 \mathrm{C} / \mathrm{km}$ \\
\hline Reservoir Depth & $2.5 \mathrm{~km}$ \\
\hline Reservoir Permeability & $50 \mathrm{mD}$ \\
\hline Reservoir Thickness & $300 \mathrm{~m}$ \\
\hline Reservoir Conductivity & $2.1 \mathrm{~W} / \mathrm{m}-\mathrm{C}$ \\
\hline Reservoir Specific Heat & $1000 \mathrm{~J} / \mathrm{kg}-\mathrm{C}$ \\
\hline Reservoir Rock Density & $2650 \mathrm{~kg} / \mathrm{m}^{3}$ \\
\hline Well Diameter & $0.41 \mathrm{~m}$ \\
\hline Well Roughness & $55 \mu \mathrm{m}$ \\
\hline Well Spacing & $707 \mathrm{~m}$ \\
\hline Well Configuration & $\begin{array}{l}\text { Inverted } 5-s p o t \\
(\text { Shared- }\end{array}$ \\
\hline Surface Air Temperature & $15^{\circ} \mathrm{C}$ \\
\hline Surface Rock Temperature & $15^{\circ} \mathrm{C}$ \\
\hline Geologic Fluid & Water or $\mathrm{CO}_{2}$ \\
\hline Geologic Fluid Flowrate & Cost Minimized \\
\hline Heat Depletion Time & Year-1 \\
\hline Cooling Tower Technology & Wet \\
\hline $\begin{array}{l}\text { Cooling Tower Approach } \\
\text { Temperature }\end{array}$ & $7^{\circ} \mathrm{C}$ \\
\hline CPG Turbine Efficiency & 0.78 \\
\hline
\end{tabular}

\begin{tabular}{|l|l|}
\hline CPG Pump Efficiency & 0.9 \\
\hline $\begin{array}{l}\text { CPG Monitoring Well } \\
\text { Diameter }\end{array}$ & $0.22 \mathrm{~m}$ \\
\hline ORC Fluid & $\begin{array}{l}\text { R245fa } \\
\text { Subcritical, } \\
\text { Single-pressure }\end{array}$ \\
\hline ORC Type & 0.8 \\
\hline ORC Turbine Efficiency & 0.9 \\
\hline ORC Pump Efficiency & Cost Minimized \\
\hline ORC Boiling Pressure & $5^{\circ} \mathrm{C}$ \\
\hline $\begin{array}{l}\text { ORC Heat Exchanger Pinch } \\
\text { Minimum Temperature }\end{array}$ & Cost Minimized \\
\hline $\begin{array}{l}\text { ORC Heat Exchanger } \\
\text { Temperature Difference }\end{array}$ & $500 \mathrm{~W} / \mathrm{m}^{2}$-C \\
\hline $\begin{array}{l}\text { ORC Heat Exchanger } \\
\text { Overall Heat Transfer } \\
\text { Coefficient }\end{array}$ & 0.75 \\
\hline $\begin{array}{l}\text { Water Downhole Pump } \\
\text { Efficiency }\end{array}$ & $500 \mathrm{~m}$ \\
\hline $\begin{array}{l}\text { Water Downhole Pump } \\
\text { Depth }\end{array}$ & $10 \mathrm{MPa}$ \\
\hline $\begin{array}{l}\text { Water Downhole Pump } \\
\text { Maximum Pressure } \\
\text { Difference }\end{array}$ & $95 \%$ \\
\hline Well Drilling Success Rate & \\
\hline
\end{tabular}

Our first comparison (Section 3.1.1) is of the cost and generation as a function of mass flowrate and is made to demonstrate the contributions of the optimization options available within genGEO. In geothermal power plants, the production mass flowrate can be set to maximize power or minimize cost. For this reason, the default setting in genGEO is to optimize the heat extraction mass flowrate based on the user inputs. This feature is an improvement upon the method used within GEOPHIRES or GETEM, which respectively require the user to specify the mass flowrate as an input or use a default value of $110 \mathrm{~kg} / \mathrm{s}$ per well that can be changed if desired. 
Our second comparison (Section 3.1.2) is for the specific cost of a $10 \mathrm{MW}_{\mathrm{e}} \mathrm{ORC}$ power cycle. We make this comparison primarily to contrast the genGEO ORC power cycle model to that of the characterizations of ASPEN results that GETEM and GEOPHIRES use. GETEM and GEOPHIRES do not directly simulate a power cycle, but rather have built-in functions which provide power generation and cost as a function of resource temperature. Thus, a comparison of the specific cost of ORC power cycles is the smallest level by which the three models may be compared.

An ORC in genGEO can be designed to either minimize cost or maximize power, which result in different power generation and cost (Section S5.3). As this optimization process can be computationally expensive, genGEO provides lookup tables of simulation design parameters to accomplish these optimizations; however, the code could be modified to perform this optimization during a simulation. This robust and transparent optimization feature of genGEO is an improvement upon the methods used within GETEM and GEOPHIRES. GETEM uses an EXCEL macro to find the second-law efficiency input into the ASPEN-derived characterizations of cost and electricity generation that minimize cost. GEOPHIRES does not optimize for cost and instead uses the same ASPEN-derived equation that provides the maximum electricity generation as a function of production temperature for all simualtions. ${ }^{16}$

In our third comparison (Section 3.1.3), we use data from the Tungsten Mountain geothermal power plant in Nevada, U.S., along with two other cases of realistic but hypothetical geologic conditions to compare the capital costs of an entire geothermal power plant facility across these three tools and to validate genGEO.

To avoid confusion across comparisons, we provide more details on the methodology used in each comparison immediately before presenting the results (Sections 3.1.1, 3.1.2, and 3.1.3).

\subsubsection{Expanding the Understanding of $\mathrm{CO}_{2}$ vs Water Heat Extraction Fluid Tradeoffs and Estimating the Potential for Sedimentary Basin Geothermal Resources in the United States}

In prior work, ${ }^{19}$ we compared power generation estimates between sedimentary basin power plants using $\mathrm{CO}_{2}$ as a subsurface heat extraction fluid versus water for a few different scenarios of subsurface conditions. In this study, we use genGEO to expand the parameter space across which we make this comparison by finding the generation for 5,000 unique combinations of reservoir depth (between $1 \mathrm{~km}$ and $7 \mathrm{~km}$ ) and transmissivity (between 100 and 10,000,000 $\mathrm{mD}-\mathrm{m})$. Transmissivity is the product of reservoir thickness and permeability $\left(1 \mathrm{mD}-\mathrm{m}=10^{-15} \mathrm{~m}^{3}\right)$. All scenarios assume a $35^{\circ} \mathrm{C} / \mathrm{km}$ geologic temperature gradient and one inverted 5 -spot well pattern power plant.

We calculate the LCOE over the parameter space using the LIKELY financing assumptions and the production well flowrate that minimizes cost. We assume two $\mathrm{CO}_{2}$-geothermal cases for these calculations: brownfield and greenfield. In a brownfield case, the cost of $\mathrm{CO}_{2}$ injection wells and wellfield are not included because this cost is assumed to have been paid for by a geologic $\mathrm{CO}_{2}$ storage developer. In contrast, greenfield scenarios assume all costs are included. Power plants that use water as the heat extraction fluid are always greenfield cases. In both greenfield and 
brownfield $\mathrm{CO}_{2}$-geothermal power plants, we do not assume a cost for acquiring $\mathrm{CO}_{2}$ nor any financial benefit (e.g. revenue) for sequestering it in the subsurface.

We combine the 5,000 cost and power generation results with p50 geological data from the United States Geological Survey (USGS) ${ }^{36}$ to estimate supply curves for sedimentary basin geothermal power plants in the US. The p50 value is the value where $50 \%$ of the estimates are above that value, and $50 \%$ are below. In other words, p50 data can be thought of as median values.

We use the USGS dataset for p50 depth, permeability, porosity, and thickness data for each sedimentary basin, which are identified by their unique "SAU code" (e.g. C50360101). Additionally, we also use the provided map-view area of a basin (i.e. the "footprint") and the p50 $\mathrm{CO}_{2}$ storage potential is used to estimate $\mathrm{CO}_{2}$-geothermal resource potential.

For water-based power plants, we divide the map-view area of the basin by $1 \mathrm{~km}^{2}$ to obtain the total number of 5-spots in that basin and then multiply the electricity generated by a single 5-spot by the total number of 5 -spots to obtain the basin-wide electricity generation capacity.

For $\mathrm{CO}_{2}$-geothermal power plants, we estimate the amount of $\mathrm{CO}_{2}$ required for a 5-spot by multiplying the 5-spot pore space volume by the density of $\mathrm{CO}_{2}$ in the basin and the $36 \%$ storage factor, which is the approximate percentage of the pore space volume that is required to be saturated with $\mathrm{CO}_{2}$ for $\mathrm{CO}_{2}$-geothermal (i.e. $\mathrm{CPG}$ ) power generation. ${ }^{30,37}$ The pore space volume is the product of the basin porosity, surface area $\left(1 \mathrm{~km}^{2}\right)$, and basin thickness. We then divide the $\mathrm{CO}_{2}$ storage potential for each basin, as calculated by the USGS, by the $\mathrm{CO}_{2}$ required per 5-spot to obtain the number of 5-spots which can be built in a basin. Finally, we multiply the electricity generated by a single 5-spot by the number of $1 \mathrm{~km}^{2}$ footprint 5 -spots in that basin to find the basin-wide $\mathrm{CO}_{2}$ electricity generating capacity. This supply curve assessment assumes using only saline aquifers, but it is possible that depleted oil/gas fields may also be used for $\mathrm{CO}_{2-}$ geothermal sedimentary basin power plants. ${ }^{38}$

\section{Results and Discussion}

We first discuss our comparison of genGEO to GETEM and GEOPHIRES (Section 3.1) before presenting the electricity generation and cost of sedimentary basin geothermal power plants across our large parameter space and the resulting p50 supply curves for the U.S. (Section 3.2).

\subsection{Comparing genGEO to GETEM and GEOPHIRES}

\subsubsection{Optimization Strategy Comparison}

In our first comparison, we compare the electricity generated and cost for a geothermal power plant with the same base-case parameters (Table 2) between genGEO, GETEM, and GEOPHIRES. This comparison illustrates different optimization strategies: system mass flowrate and cost-minimization versus electricity-maximization.

Figure $3 \mathrm{~A}$ shows the generation and specific cost as a function of system mass flowrate. Power plants that use subsurface water as a heat extraction fluid are shown with solid lines while systems that use subsurface $\mathrm{CO}_{2}$ are shown with dashed lines. Only genGEO produced results for nonwater-based geothermal power plants. Figure 3B shows the genGEO ORC specific electric power 
and ORC specific cost as a function of ORC inlet temperature (Section S5.3). The results in Figure 3B are shown both using electricity maximization (solid line) and cost minimization (dashed line) options.
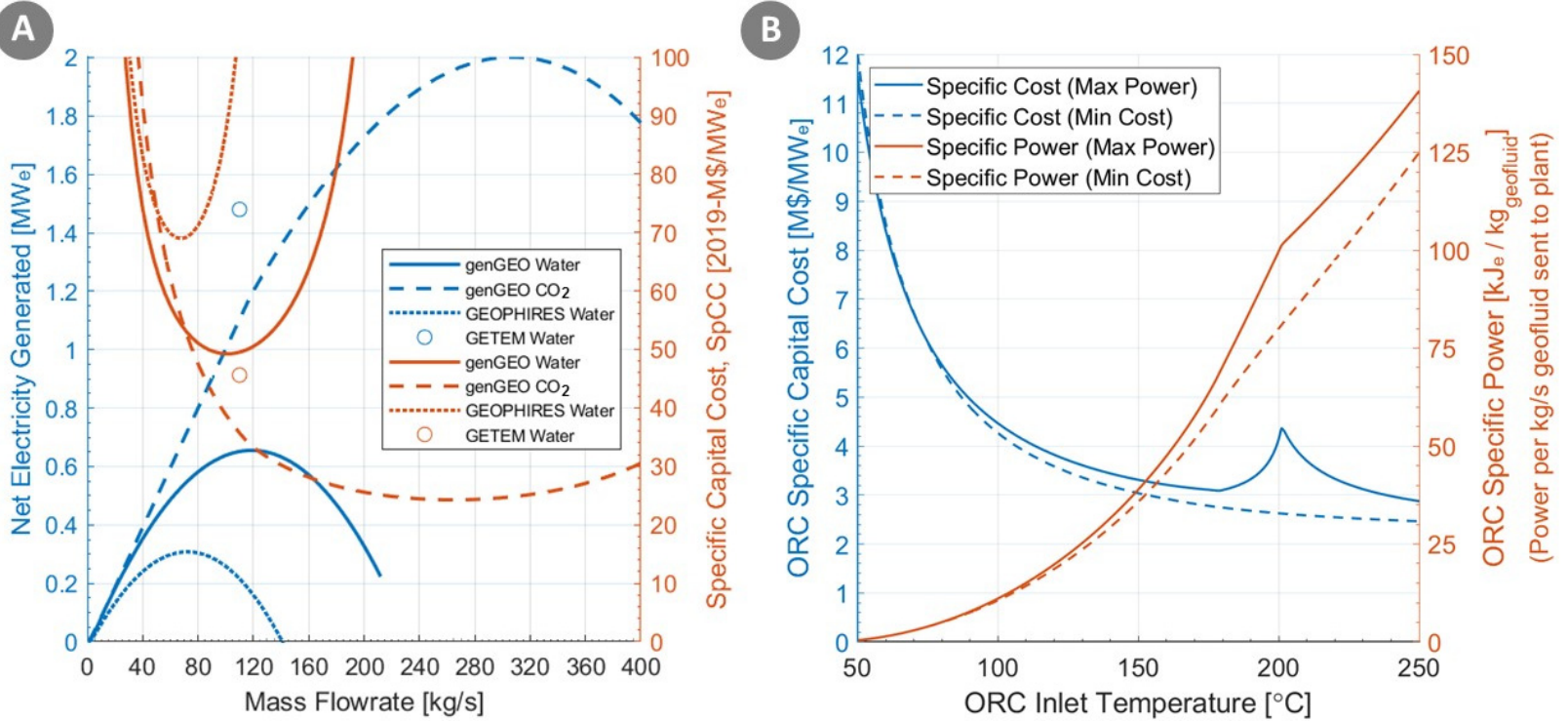

Figure 3: A) a comparison of genGEO, GETEM, and GEOPHIRES electricity generated and specific capital cost as a function of injection or production well mass flowrate, and B) the genGEO ORC specific electricity generated and specific capital cost as a function of ORC inlet temperature.

As shown in Figure $3 \mathrm{~A}$, the genGEO water-based power plant has an electricity generation maximum near $120 \mathrm{~kg} / \mathrm{s}$ per well, while the GEOPHIRES power plant has a maximum at a flowrate of $70 \mathrm{~kg} / \mathrm{s}$, even though identical inputs were used in both tools (Table 2). Further, at their respective flowrates of maximum electricity generation, the GEOPHIRES power plant generates approximately half the electricity of the genGEO power plant and the GETEM power plant generates approximately double the genGEO power plant. These differences are probably the result of different assumptions within GETEM and GEOPHIRES, but it is difficult to examine further without the underlying ASPEN ORC models.

Figure 3A also shows that the cost minima for both genGEO and GEOPHIRES occur at lower mass flowrates than the flowrates that maximize electricity generation. This demonstrates the importance of being able to optimize to either maximize electricity generation or minimize cost. It also demonstrates why there should be an option to determine the heat extraction mass flowrate through optimization, as in genGEO, and not always as an independent variable (i.e. user input). For instance, if the GETEM-default mass flowrate of $110 \mathrm{~kg} / \mathrm{s}$ per well is used in the GEOPHIRES model, the specific capital cost increases by $\sim 40 \%$.

Figure 3B further demonstrates the differences that can result from optimizing to minimize cost versus to maximize electricity generation. For example, at a $200^{\circ} \mathrm{C}$ ORC inlet temperature, the cost-minimized ORC specific capital cost is $2.7 \mathrm{M} \$ / \mathrm{MW}_{\mathrm{e}}$ while the maximized power cost is 4.4 $\mathrm{M} \$ / \mathrm{MW}_{\mathrm{e}}$. In turn, the ORC specific electric power increases from about $80 \mathrm{~kJ} / \mathrm{kg}_{\text {geofluid }}$ to about $100 \mathrm{~kJ} / \mathrm{kg}_{\text {geofluid. }}$ These differences decrease with decreasing ORC inlet temperature, but still illustrate that the optimization strategy has non-negligible implications to the results. 


\subsubsection{Surface-Plant-Only Simulator Comparison}

In our second comparison, we compare the cost of only the surface power plant (i.e. excluding wellfield, wells, production pumps, and surface piping) using base-case inputs (Table 2).

The $10 \mathrm{MW}_{\mathrm{e}}$ GETEM surface plant specific capital cost is not only a function of geofluid (i.e. water) production temperature, but also the second-law "utilization" efficiency. Higher second-law efficiencies generate more electricity, but at a higher specific cost (i.e. cost per $\mathrm{kW}_{\mathrm{e}}$ generated). At runtime, a GETEM EXCEL macro determines the second-law efficiency needed to minimize the system cost. Thus for this comparison, we use a representative range of second-law efficiencies, from $29 \%$ and greater. We use a second-law efficiency of $29 \%$ as the minimum because that was the GETEM-optimized efficiency of the Tungsten Mountain power plant, which has a very high resource temperature and shallow well depth (Section 3.1.3). The upper-bound second-law efficiency is determined by GETEM for the same set of conditions as genGEO (Section S5.3). We do not follow the same procedure with GEOPHIRES because GEOPHIRES does not perform any optimizations.

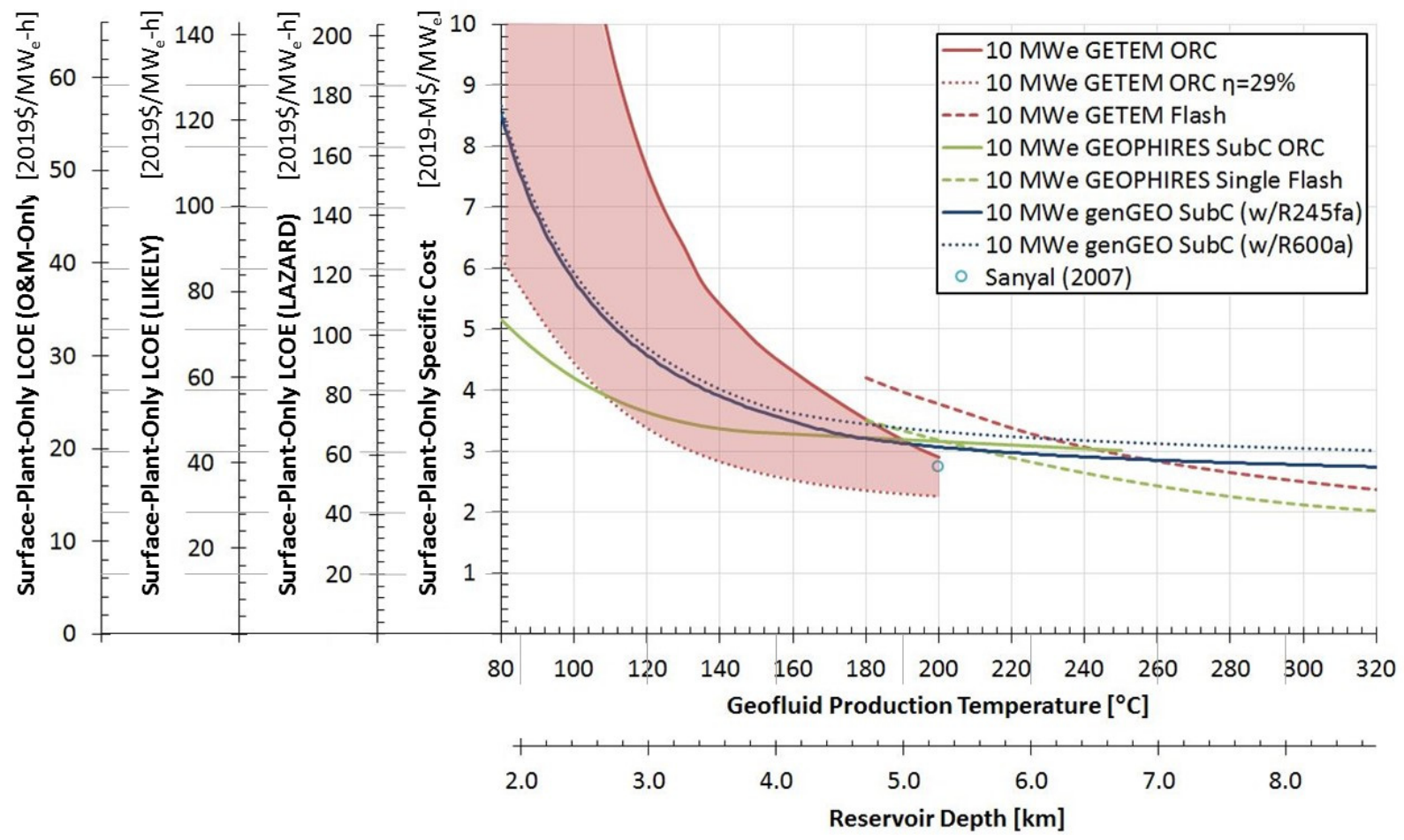

Figure 4: Surface power plant specific capital cost as a function of geofluid inlet temperature for a net $10 \mathrm{MW}$ generating system. The specific capital cost is extended to three different surface-plant-only LCOEs, which exclude all other system components (e.g. wellfield, wells, etc.). Also, the reservoir depth is shown that provides the wellhead geofluid temperature given a $35^{\circ} \mathrm{C} / \mathrm{km}$ temperature gradient and a $15^{\circ} \mathrm{C}$ surface temperature. The GETEM costs are given both using the genGEO cost minimization strategy and for a surface plant $29 \%$ second-law efficiency, which is the GETEM efficiency of the Tungsten Mountain site.

Figure 4 shows the specific capital cost of a $10 \mathrm{MW}_{\mathrm{e}}$ surface power plant as a function of the geofluid (i.e. water) production temperature. This capital cost is converted to a surface-plant-only LCOE using three different sets of financing assumptions (Table 1): LAZARD, LIKELY, and 
O\&M-Only. The reservoir depth necessary to obtain the given geofluid production temperature is shown below the $\mathrm{x}$-axis, assuming a geologic temperature gradient of $35{ }^{\circ} \mathrm{C} / \mathrm{km}$ and a $15^{\circ} \mathrm{C}$ surface temperature. Lastly, the specific capital cost of an EGS surface plant reported by Sanyal $(2007)^{39}$ is plotted.

For production temperatures below $140^{\circ} \mathrm{C}$, there is substantial deviation between the GEOPHIRES, GETEM, and genGEO results. For example, at $100^{\circ} \mathrm{C}$, the GETEM ORC has a specific capital cost as high as $160 \%$ above the genGEO system, while the GEOPHIRES ORC has a specific cost $\sim 30 \%$ lower than genGEO.

The variation of second-law efficiency also has a large effect on the GETEM results. Depending on the capital cost of the other geothermal facility components, the surface plant specific capital cost may vary by a factor of at least three. Also, the GETEM specific capital costs encapsulate the genGEO results, suggesting there is a reasonable second-law efficiency at any given temperature for which the GETEM surface plant will have an equivalent specific cost as a genGEO surface plant.

Overall, the deviations between genGEO, GETEM, and GEOPHIRES, and the variability across GETEM results, cannot be further explained. In contrast, genGEO results can be dissected to a first-principles of thermodynamics level of understanding. For example, Figure 4 suggests that different secondary working fluids can change the specific capital cost of the surface plant by up to $\sim 5 \%$, so it is possible that some of the differences between GETEM and GEOPHIRES could be due to using different secondary working fluids.

At geofluid production temperatures above about $160^{\circ} \mathrm{C}$, the surface-plant-only LCOEs are about $40 \$ / \mathrm{MW}_{\mathrm{e}}$-h with LIKELY financing assumptions and about $60 \$ / \mathrm{MW}_{\mathrm{e}}-\mathrm{h}$ using LAZARD financing assumptions. These differences demonstrate the impact that financing assumptions can have on the levelized cost estimates. Further, these and similar results across different plant capacities (see Figure $A 1$ in the Appendix) also suggest that claims that the LCOE of an entire indirect geothermal facility can fall around or below these costs $\left(\sim 50 \$ / \mathrm{MW}_{\mathrm{e}}-\mathrm{h}\right.$ or $\sim 30 \$ / \mathrm{MW}_{\mathrm{e}}-\mathrm{h}$ for high capacity facilities) should be scrutinized because the surface plant alone may cost at least that amount.

\subsubsection{Validation with Tungsten Mountain Geothermal Power Plant Data}

The Tungsten Mountain, USA, geothermal facility was developed by Ormat and began operation in December 2017.40 Publicly available data for modern operating geothermal power plants are rare, and we chose Tungsten as a case study because Ormat ${ }^{41}$ provided sufficient details to model the power plant and validate cost estimates: the facility has four production and four injection wells, spaced a maximum of $800 \mathrm{~m}$ apart; the well depths are between $500 \mathrm{~m}$ and 1400 $m$ deep, with the injection wells shallower; each well produces $142^{\circ} \mathrm{C}$ water at a flowrate of 250 $\mathrm{L} / \mathrm{s}$; there is negligible temperature depletion in the production wells; the power plant has a parasitic load of $10 \%$ to $15 \%$ of the gross turbine output; net generation is of the facility is between 24-27 $\mathrm{MW}_{\mathrm{e}}$; and the total capital cost of the facility was between 4-5 M\$/MW .

Based off the reported high flowrates, we estimate an equivalent porous medium transmissivity at Tungsten Mountain using doublets spaced $707 \mathrm{~m}$ apart of $10^{-9} \mathrm{~m}^{3}\left(\sim 10^{6} \mathrm{mD}-\mathrm{m}\right)$. We also 
assume a geologic temperature gradient of $127^{\circ} \mathrm{C} / \mathrm{km}$ and $1 \mathrm{~km}$ deep wells because this results in a reservoir temperature of $142^{\circ} \mathrm{C}$. Lastly, we assume that each of the four injection wells and four production wells has a diameter of $31 \mathrm{~cm}(121 / 4$ ") and a mass flowrate of $250 \mathrm{~kg} / \mathrm{s}$. We also include a GETEM scenario in which the flowrate is $110 \mathrm{~kg} / \mathrm{s}$ per well, because that is the default mass flowrate in GETEM.

In the other cases we use base-case inputs (Table 2), but with one injection well and one production well, and two different depths: $2.5 \mathrm{~km}$ (base-case reservoir depth) and $3.6 \mathrm{~km}$ deep. We use $3.6 \mathrm{~km}$ deep reservoirs because this results in the same reservoir temperature as the Tungsten case. In the $2.5 \mathrm{~km}$ and $3.6 \mathrm{~km}$ cases, we report GEOPHIRES and GETEM costs for flowrates that minimized cost, which we found by manually iterating with the tools.

Figure 5 shows the specific capital cost (Figure 5A) and capital cost share of major components (Figure 5B) for each case. The net electricity generated from each plant in $\mathrm{MW}_{\mathrm{e}}$ is shown in black at the top of the bars in Figure 5A. The total capital cost of each power plant in $\$ M$ is shown in white at the top of the bars in Figure 5B. The per-well mass flowrate used is reported after its name.
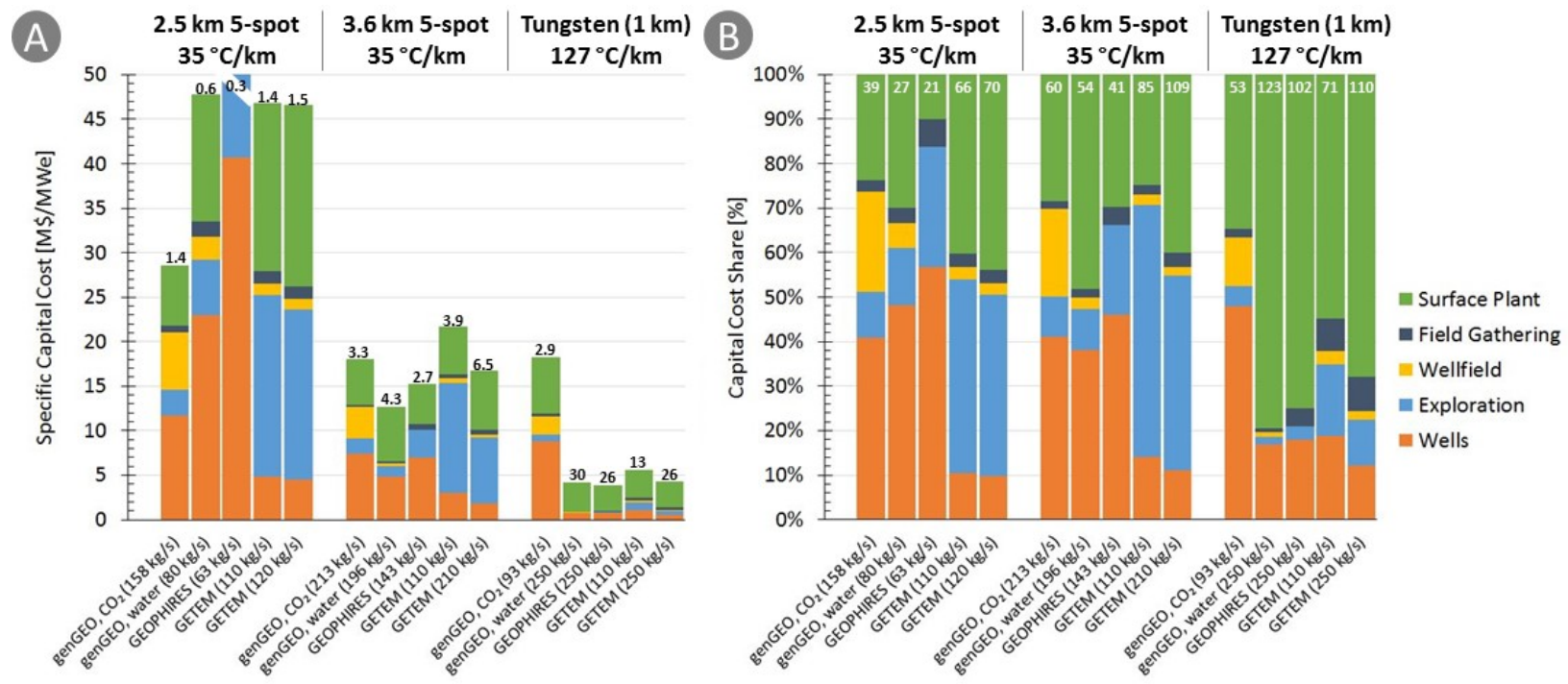

Figure 5: Specific capital cost (A) and the capital cost share of geothermal system components (B) for three cases: a $2.5 \mathrm{~km} 5$-spot and $3.6 \mathrm{~km} 5$-spot, both with a typical $35^{\circ} \mathrm{C} / \mathrm{km}$ geothermal gradient and the Tungsten Mountain case.

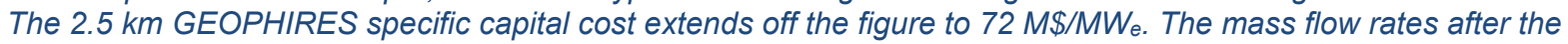
model names are per-well rates.

Figure 5A shows there are large discrepancies across all three tools for the low temperature gradient cases, but in the Tungsten Mountain case, the cost estimates are all relatively similar. The primary reason for this agreement is that the electricity generation is much higher than in the other two cases (i.e. about $30 \mathrm{MW}_{\mathrm{e}}$ vs. $3 \mathrm{MW}_{\mathrm{e}}$ ). There is greater generation in part because the high transmissivity $\left(10^{-9} \mathrm{~m}^{3}\right.$ compared to $\left.10^{-11} \mathrm{~m}^{3}\right)$ permits high mass flowrates in each well, and the Tungsten case uses four well pairs instead of one well pair. As a result, when the cost is divided by high power generation, as in Figure 5A, the tools produce similar specific capital cost estimates even though the total capital costs differ by more than $20 \mathrm{M} \$$. Even in the Tungsten 
scenario, however, the GETEM specific capital costs increase from about $4 \mathrm{M} \$ / \mathrm{MW}_{\mathrm{e}}$ to about 6 $\mathrm{M} \$ / \mathrm{MW}_{\mathrm{e}}$ when the default $110 \mathrm{~kg} / \mathrm{s}$ per-well flowrate is used instead of $250 \mathrm{~kg} / \mathrm{s}$.

The capital cost estimates from the three tools align with the reported actual cost range of the Tungsten Mountain project of between 4 and $5 \mathrm{M} \$ / \mathrm{MW}_{\mathrm{e}} \cdot{ }^{41}$ Additionally, over its entire power plant portfolio, Ormat ${ }^{28}$ reports $50 \$ / \mathrm{MW}_{\mathrm{e}}-\mathrm{h}$ in operating and debt payments and an additional 10 $\$ / \mathrm{MW}_{\mathrm{e}}-\mathrm{h}$ in equity payments, totaling to $61 \$ / \mathrm{MW}_{\mathrm{e}}-\mathrm{h}$. Using the LIKELY financing assumptions (Table 1), this LCOE equates to a specific capital cost of $4.2 \mathrm{M} \$ / \mathrm{MW}_{\mathrm{e}}$. Thus, assuming the operating, debt, and equity payments for the Tungsten Mountain facility are representative of Ormat's generation portfolio, genGEO and GETEM estimate the specific capital cost within $2 \%$ of 4.2 $\mathrm{M} \$ / \mathrm{MW}_{\mathrm{e}}$, while GEOPHIRES estimates the cost within $8 \%$.

The LCOE for the Tungsten Mountain case from genGEO using the LIKELY financing assumptions (Table 1 ) is $59 \$ / \mathrm{MW}_{\mathrm{e}}-\mathrm{h}$, which is broken down in Figure 6.

\section{Tungsten (1 km) Levelized Cost of Electricity (of $59 \$ / \mathrm{MW}_{\mathrm{e}}-\mathrm{h}$ total)}

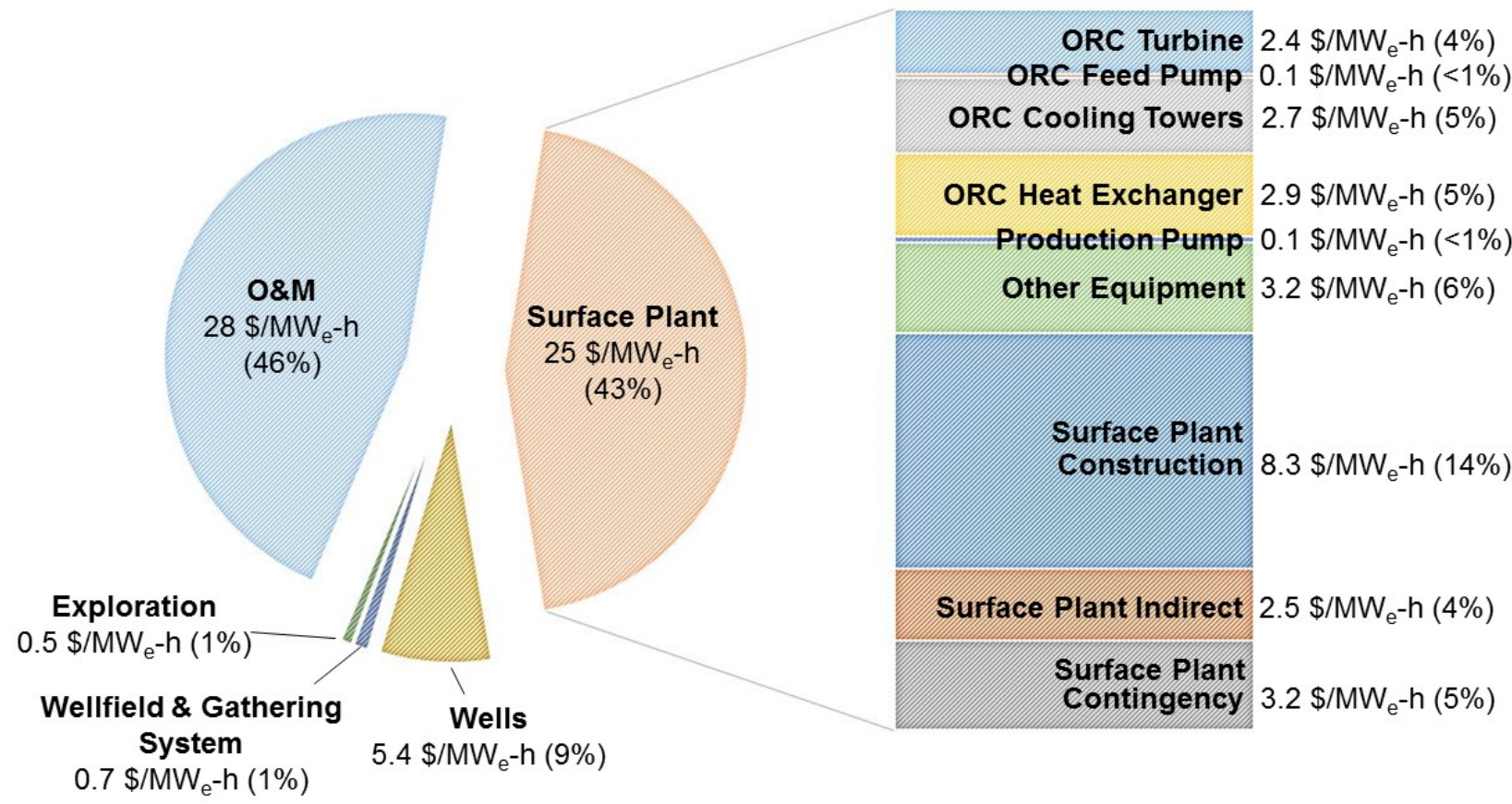

Figure 6: Breakdown of LCOE for the Tungsten Mountain case from genGEO using the LIKELY financing assumptions (Table 1).

The results in Figure 6 suggest that O\&M contributes nearly half of the LCOE: $28 \$ / M W_{e}-h$. This value is within the range for the nearby Steamboat geothermal power plant of 20 to $25 \$ / \mathrm{MW}_{\mathrm{e}}-\mathrm{h} .{ }^{42}$ This is important to note considering the literature review we conducted to create genGEO found a wide variability in O\&M costs, with GETEM underestimating this cost compared to other sources (Section S4). 


\subsection{Expanding the Understanding of Subsurface $\mathrm{CO}_{2}$ vs Water Heat Extraction Fluid Tradeoffs and Estimating the Potential for Sedimentary Basin Geothermal Resources in the United States}

\subsubsection{Parameter Space Results}

Figure 7 shows the electricity generated per $1 \mathrm{~km}^{2}, 5$-spot well pattern (Figure 7A) and LCOE (Figure 7B) across the 5,000 data point parameter space. The orange and black lines are for heat extraction fluids of $\mathrm{CO}_{2}$ (i.e. CPG) and water, respectively. The red threshold line indicates where water-based and $\mathrm{CO}_{2}$-based brownfield geothermal power plants have equivalent values. The greenfield $\mathrm{CO}_{2}$ LCOEs are shown in green and a large dotted green line indicates threshold where water-based and $\mathrm{CO}_{2}$-based greenfield plants have equivalent values. Additional figures for geologic temperature gradients of $30^{\circ} \mathrm{C} / \mathrm{km}$ to $40{ }^{\circ} \mathrm{C} / \mathrm{km}$ are in the Appendix (Figures A2 to A7).

The horizontal lines of the $\mathrm{CO}_{2}$-based power plants in Figure 7 are due to a reservoir constraint where the $\mathrm{CO}_{2}$ production-well downhole pressure must always be hydrostatic. In cases of shallow reservoir depth and high reservoir transmissivity, the $\mathrm{CO}_{2}$ pressure must be throttled downhole to prevent the reservoir from being over-pressurized. This could be mitigated in specific reservoir cases where higher than hydrostatic pressure is allowed.
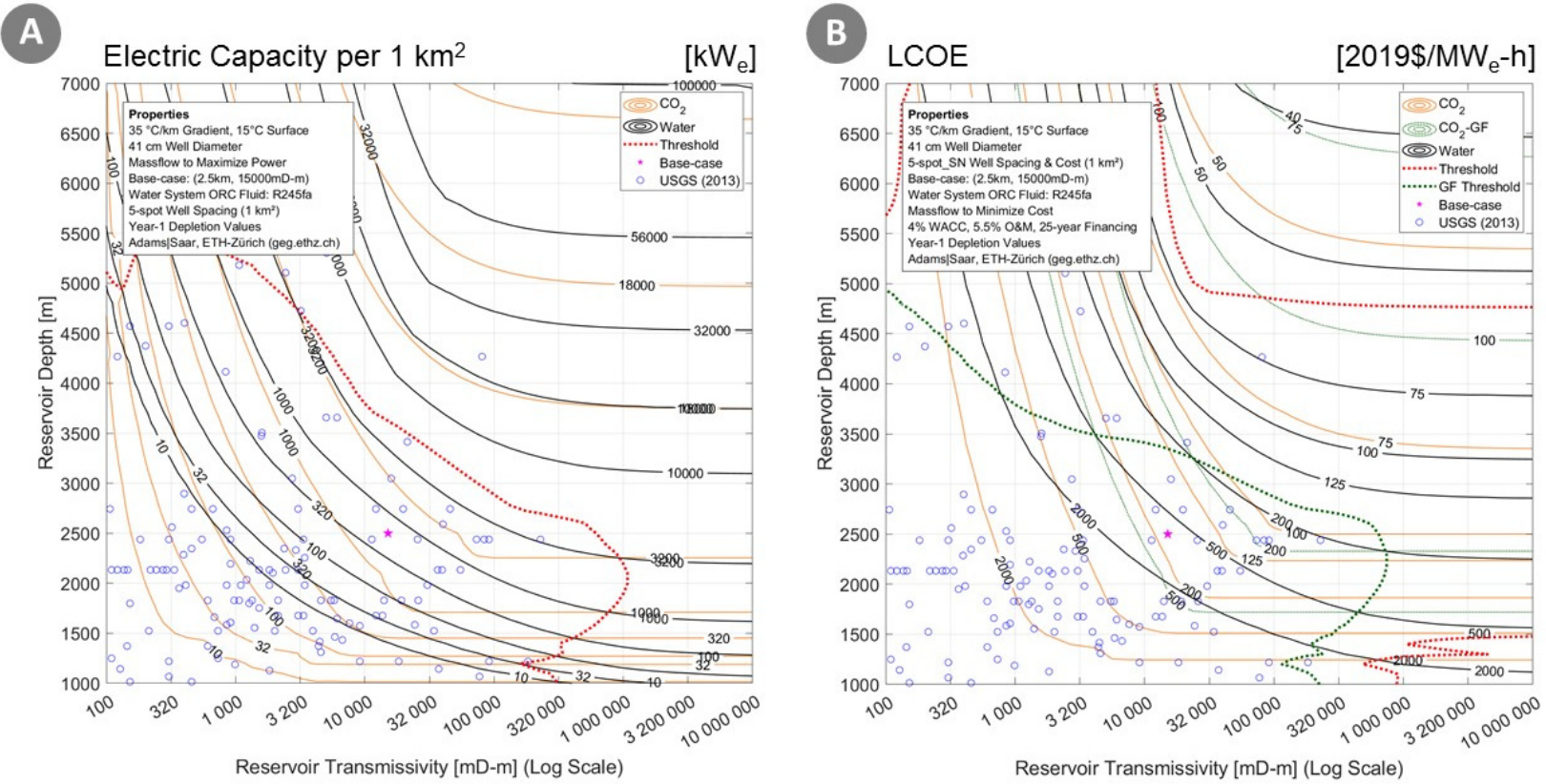

Figure 7: A) Electricity capacity per inverted 5-spot well pattern for $\mathrm{CO}_{2}$ and water geothermal systems as a function of reservoir depth and reservoir transmissivity. B) Levelized Cost of Electricity (LCOELIKELY) for $\mathrm{CO}_{2}$ and water geothermal systems as a function of reservoir depth and reservoir transmissivity. Reservoir transmissivity is plotted logarithmically.

Figure 7A shows that the electricity generated per 5-spot well pattern increases with increasing depth and transmissivity. And as shown by the red threshold line, using $\mathrm{CO}_{2}$ as a heat extraction fluid can generate more electricity than using water at shallower reservoir depths and lower reservoir transmissivities. As discussed in prior work, ${ }^{19}$ this occurs because at low reservoir 
transmissivities and depths, the $\mathrm{CO}_{2}$ viscosity is much lower than water and enables higher geothermal circulation rates. In contrast, at high transmissivities, the reservoir frictional losses are less important, and the higher heat capacity of water can brings more heat to the surface. However, as shown in Figure 7A, the majority of sedimentary basin resources in the U.S. have p50 properties that result in more generation with $\mathrm{CO}_{2}$ compared to water.

Figure 7B shows that the range of parameters in which greenfield $\mathrm{CO}_{2}$-based power plants cost less than water-based power plants (green threshold line in Figure 7B) is similar to the range in Figure 7A where using $\mathrm{CO}_{2}$ to extract heat generates more electricity than using water (red threshold line in Figure 7A).

The LCOE of brownfield $\mathrm{CO}_{2}$-based power plants is less than the LCOE of water-based power plants for almost the entire parameter space, with some small exceptions (e.g., the upper righthand corner of Figure 7B). As a result, Figure 7B demonstrates, for the first time, that using $\mathrm{CO}_{2}$ as the heat extraction fluid in sedimentary basin geothermal power plants (i.e. CPG power plants) has cost advantages compared to using water. Further, the reservoir data of Figure 7B suggests that most sedimentary basins in the U.S. could be used to generate electricity at a lower cost with brownfield $\mathrm{CO}_{2}$-based power plants compared to water-based power plants, and some even with a greenfield $\mathrm{CO}_{2}$-based power plant.

\subsubsection{U.S. Sedimentary Geothermal Supply Curves}

Figure 8 shows the supply curves for sedimentary basin geothermal power plants in the U.S. based on p50 data and a geothermal temperature gradient of $35^{\circ} \mathrm{C} / \mathrm{km}$. The SAU code of each reservoir is listed at the end of the individual reservoir capacity. ${ }^{36}$ The volume of $\mathrm{CO}_{2}$ that is required to realize these supply curves with $\mathrm{CO}_{2}$-power plants is shown on the right $\mathrm{y}$-axis. As references, the current total installed geothermal capacity in the U.S. of $3.8 \mathrm{GW}_{\mathrm{e}}$ is shown at the start of the $\mathrm{x}$-axis, ${ }^{43}$ and the $85 \$ / \mathrm{MW}_{\mathrm{e}}-\mathrm{h}$ line is plotted in red, which is the 2019 average geothermal electricity power purchase agreement (PPA) across Ormat contracts. ${ }^{35}$

Figure 8 suggests that the order of lowest cost sedimentary basin resources may be different when $\mathrm{CO}_{2}$ is used compared to when water is used. For example, the second-lowest cost reservoir when $\mathrm{CO}_{2}$ is used is the Upper Miocene (C50470126), but this reservoir is the third-lowest cost when water is used. As a result, while our discussion has focused on $\mathrm{CO}_{2}$ - versus water-based power plants, it is possible that these two different types of power plants may not compete against one another for sedimentary basins.

Figure 8 also demonstrates that using $\mathrm{CO}_{2}$ as a heat extraction fluid generally increases the available capacity at a given cost. For example, there is over $120 \mathrm{GW}_{\mathrm{e}}$ of potential when $\mathrm{CO}_{2}$ is used under $150 \$ / \mathrm{MW}_{\mathrm{e}}-\mathrm{h}$ but only about $40 \mathrm{GW}$ available for water. While $150 \$ / \mathrm{MW}_{\mathrm{e}}-\mathrm{h}$ is greater than Ormat's average PPA of $85 \$ / \mathrm{MW}_{\mathrm{e}}-\mathrm{h}$, these supply curves were created using p50 data. Considering this assumption and that there is $80+\mathrm{GW}_{\mathrm{e}}$ of potential with $\mathrm{CO}_{2}$ not much costlier than $\$ 100 / \mathrm{MW}_{\mathrm{e}}-\mathrm{h}$, it is possible that using $\mathrm{CO}_{2}$ as a heat extraction fluid may reduce the costs to around $85 \$ / \mathrm{MW}_{\mathrm{e}}-\mathrm{h}$ for $\mathrm{GW}_{\mathrm{e}}$-levels of potential in the US. 


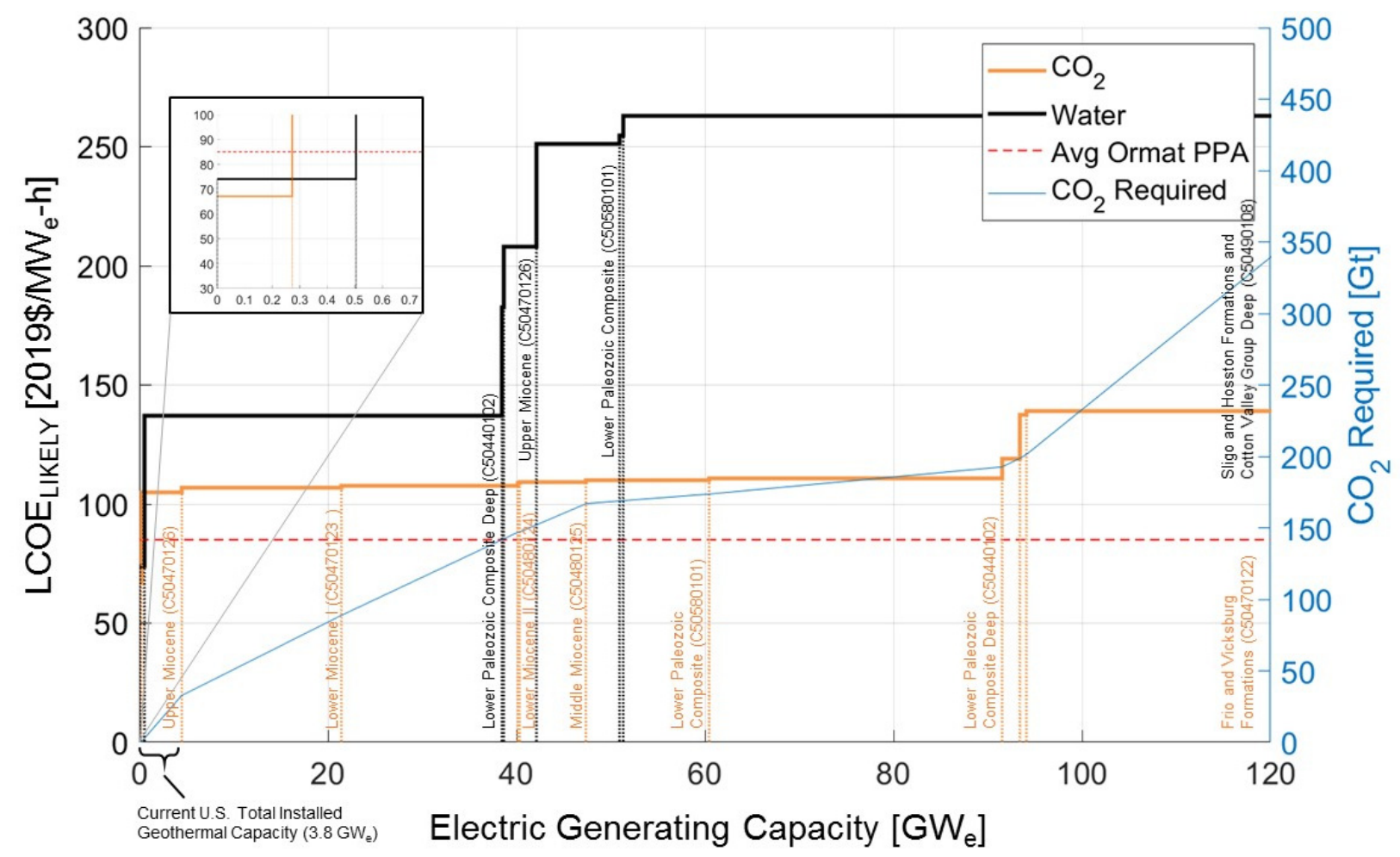

Figure 8: The LIKELY levelized cost of electricity (LCOELIKELY) and electric generating capacity for both brownfield $\mathrm{CO}_{2}$-based and water-based geothermal systems in the U.S assuming p50 data and a geothermal temperature gradient of $35{ }^{\circ} \mathrm{C} / \mathrm{km}$. The target reservoir names are listed with their $\mathrm{SAU}$ code. ${ }^{29}$ The required $\mathrm{CO}_{2}$ for the given electric capacity is also shown.

While the cost of most capacity is above $85 \$ / \mathrm{MW}_{\mathrm{e}}-\mathrm{h}$, there is approximately $500 \mathrm{MW}_{\mathrm{e}}$ of potential using water at about $75 \$ / \mathrm{MW}_{\mathrm{e}}-\mathrm{h}$ and $275 \mathrm{MW}_{\mathrm{e}}$ of potential using $\mathrm{CO}_{2}$ at about $68 \$ / \mathrm{MW}_{\mathrm{e}}-\mathrm{h}$. These capacities are non-negligible percentages of total geothermal capacity in the U.S.: $13 \%$ with water and $7 \%$ with $\mathrm{CO}_{2}$. In other words, Figure 8 suggests that the exclusion of sedimentary basins from geothermal resource assessments has possibly resulted in overlooking substantial opportunities to profitably generate dispatchable renewable electricity. Especially considering that our capacitycost estimates do not assume any technological breakthroughs, like required for EGS facilities. In other words, our results suggest that there may be present-day potential to profitably increase the geothermal power capacity in the U.S. by around $10 \%$ using sedimentary basin geothermal power plants that use water to extract heat.

Developing $\mathrm{CO}_{2}$-based power plants (i.e. CPG power plants) requires a substantial amount of geologic $\mathrm{CO}_{2}$ storage. For example, realizing the lowest cost $5 \mathrm{GW}_{\mathrm{e}}(131 \%$ of current installed U.S. geothermal capacity) of electricity generation capacity in Figure 8 with $\mathrm{CO}_{2}$ would require geologically storing approximately $40 \mathrm{GtCO}_{2}$. The amount of $\mathrm{CO}_{2}$ required for power generation varies across sedimentary basins based on the porosity of the reservoir, and our results suggest this requirement ranges from 0.14 to $0.48 \mathrm{MW}_{\mathrm{e}} / \mathrm{MtCO}_{2}$ (inverse of slope of blue lines in Figure 8). For comparison, all CCS processes in operation as of 2019 have the global capacity to store about $40 \mathrm{MtCO}_{2} / \mathrm{yr}^{44}$ In other words, based on this $\mathrm{CO}_{2}$ storage requirement alone, current geologic $\mathrm{CO}_{2}$ storage efforts are sufficient to support the development of 6 to $19 \mathrm{MW} / \mathrm{yr}$ of 
$\mathrm{CO}_{2}$-geothermal power capacity. But total annual $\mathrm{CO}_{2}$ emissions are much higher, with $33 \mathrm{GtCO}_{2}$ emitted globally in $2017,5 \mathrm{GtCO}_{2}$ of which emitted in the U.S. ${ }^{45}$ And addressing climate change may require geologically storing up to $1,200 \mathrm{GtCO}_{2}$ globally by $2100 .{ }^{46}$ As a result, developing additional $\mathrm{CO}_{2}$-geothermal power plant capacity may be possible in the future.

\section{Conclusions}

Geothermal power plants have the potential to provide value to decarbonizing electricity because they can produce dispatchable and renewable electricity with little to no $\mathrm{CO}_{2}$ emissions. Despite this value, the market penetration of geothermal is low (e.g. generating $\sim 0.3 \%$ of all electricity globally in $2018^{47}$ ) and will not substantially increase if the cost is too high. As cost is largely a function of geology and there are limited identified hydrothermal geothermal resources in the developed world not already in use (e.g. about $\sim 6 \mathrm{GW}_{\mathrm{e}}$ in the U.S. ${ }^{7}$ ), research is investigating using alternative geologic resources for geothermal power generation. Sedimentary basin geothermal resources are one option, ${ }^{19,20}$ but the potential these resources have for expanding the geothermal resource base is unknown.

To address this knowledge gap, we developed and used the generalizable GEOthermal technoeconomic simulator (genGEO). GETEM and GEOPHIRES are the two primary tools that previously existed for techno-economic geothermal power assessments. While reputable and widely used, these tools rely on unpublished ASPEN results and are thus not generalizable or transparent enough to be applied to power plants besides those that use ORC power cycles and water as the heat extraction fluid. In contrast, genGEO transparently uses publicly available data to estimate the generation and cost of geothermal power plants without propriety software, and its generalizability allows it to be applied to sedimentary basin geothermal power plants that use $\mathrm{CO}_{2}$ to extract heat.

In this work, we release, validate, and compare genGEO to present its contributions to geothermal techno-economic assessment. We also apply genGEO to study the potential of sedimentary basin geothermal power plants. As such, we group our conclusions into two categories:

\section{Conclusions from Comparing genGEO to GETEM and GEOPHIRES}

1. The mass flowrate of the heat extraction fluid does not need to be a user input in technoeconomic tools for geothermal power plants because there is an optimal mass flowrate that minimizes cost or maximizes power for a given plant. In geothermal power plants, there are thermodynamic relationships between the reservoir, wells, and power cycle that are functions of the mass flowrate, thus changing the flowrate can substantially increase cost or decrease power (Figure 3; Figure 5). Despite this fact, geothermal resource assessments have used a single mass flowrate across all potential power plants. For example, the default mass flowrate of $110 \mathrm{~kg} / \mathrm{s}$ per well was used within GETEM to create U.S.-wide supply curves for all hydrothermal binary geothermal power plants in the 2019 GeoVision analysis. ${ }^{7}$ Allowing users not to specify the mass flowrate, and instead determining the mass flowrate based on power or cost optimizations, is one of the methodological contributions that genGEO makes to techno-economic assessment tools. 
2. The use of characterized ASPEN simulation results, and of different optimization methods within GETEM and GEOPHIRES, have ramifications on cost and electricity generation estimates. In addition to mass flowrate, there are power cycle design temperatures in every ORC geothermal power plant that minimize cost or maximize power (Section S5.3). While GETEM uses an excel MACRO code to minimize cost, it is difficult to verify or investigate this optimization because it is deeply embedded within the tool and relies on unpublished ASPEN simulations. Further, GEOPHIRES built its characterized ASPEN simulation results using a maximum-power optimization method. Our findings suggest that these differences can result in a wide range of ORC costs, especially at production temperatures below $140^{\circ} \mathrm{C}$ (Figure 4), which could have further ramifications to increased cost estimates for entire facilities (Figure 7).

\section{Conclusions from Using genGEO to Study Sedimentary Basin Geothermal Power Plants}

1. There are more geologic conditions in which the $\mathrm{LCOE}$ of $\mathrm{CO}_{2}$-based power plants are less than water-based power plants. The LCOE for brownfield $\mathrm{CO}_{2}$-based power plants is less than the LCOE for water-based power plants for almost every geologic condition we investigated except for basins with depths greater than about $5 \mathrm{~km}$ and transmissivities above about 10,000 mD-m (Figure 8). Assuming p50 USGS data, all sedimentary basins in the U.S. have conditions in which brownfield $\mathrm{CO}_{2}$-based power plants cost less than water-based power plants and many where greenfield $\mathrm{CO}_{2}$ plants cost less than water-based power plants (Figure 8).

2. The potential for using sedimentary basins for electricity generation is vast and a nonnegligible capacity may be profitably developed. Our supply curves that assumed p50 data and a geothermal temperature gradient of $35^{\circ} \mathrm{C} / \mathrm{km}$ suggest that there are $10 \mathrm{~s}$ of $\mathrm{GW}_{\mathrm{e}}$ of electricity generation potential in the U.S. in deep saline formations alone (Figure 8). Our results also suggest that there is $\sim 500 \mathrm{MW}_{\mathrm{e}}(13 \%$ of current installed US capacity) of additional potential with water or $\sim 275 \mathrm{MW}_{\mathrm{e}}$ ( $7 \%$ of current installed US capacity) with $\mathrm{CO}_{2}$, both below Ormat's 2019 average PPA price of $85 \$ / \mathrm{MW}_{\mathrm{e}}-\mathrm{h}$. While approximately $740 \mathrm{MtCO}_{2}$ of geologically stored $\mathrm{CO}_{2}$ is required to realize this $275 \mathrm{MWe}_{\mathrm{e}}$ capacity with $\mathrm{CO}_{2}$-based power plants, there is nothing constraining the development of this $500 \mathrm{MW}_{\mathrm{e}}$ capacity with water-based power plants. Overall, this finding suggests that sedimentary basin geothermal resources should not be excluded from geothermal resource assessments.

3. Water-based and $\mathrm{CO}_{2}$-based sedimentary basin geothermal power plants may not compete with one another for location or for a particular sedimentary basin resource. Our supply curves suggest that the order of least-cost sedimentary basins was different for brownfield $\mathrm{CO}_{2}$-based power plants than for water-based power plants (Figure 8). Because sedimentary basins are massive, it is possible that this order would be much different when higher spatial resolution geologic data are used. As a result, it is possible that developing sedimentary basins for geothermal power generation using heat extraction fluids of both water and $\mathrm{CO}_{2}$ could proceed in parallel. Or if there are insufficient amounts of geologic $\mathrm{CO}_{2}$ storage, this finding suggests that developing water-based power plants 
in the short term may not eliminate options for $\mathrm{CO}_{2}$-based plants in the long term while waiting for enough $\mathrm{CO}_{2}$ to be geologically stored.

In addition to the above conclusions from our application of genGEO for this specific study, we also include two of primary findings from the literature review that was conducted to create genGEO. While this study is not a review paper, these findings have not yet been clearly documented within the geothermal energy community. As discussed in the SI documentation of genGEO, we find that:

1. All geothermal well cost models derive from the same limited geothermal well cost data. Drilling and completing wells is widely regarded as one of the primary costs of geothermal power plants, but as further discussed in Section S3.3 of the SI, well cost model documentation circularly references itself. As a result, while well cost estimation has likely improved, this improvement appears to be iterative development of a single cost model.

2. There are large discrepancies in the cost of individual components of geothermal LCOE. For example, the GETEM turbine-generator cost is limited to a minimum value with growing capacity which is not consistent with other sources (Figure S1), and the turbine costs substantially contributes to total LCOE (e.g. 4\% in Figure 6). Similarly, GETEM assumes an overall heat transfer coefficient which reduces the heat exchanger cost by a factor of 2 to 4, compared to other sources (Section S3.2.4). We also found a wide variability in reported O\&M costs (see Section S4 in the $\mathrm{SI}$ ) and when we assumed a reasonable estimate of $5.5 \%$ based on these data, O\&M contributed to about half of LCOE (Figure 6). There is generally little discussion of O\&M costs throughout the geothermal energy community broadly, and our findings suggest that this cost, and others (e.g. turbines, cooling towers, etc.), should be more thoroughly examined.

\section{5. genGEO Python Tool and Data Availability}

All genGEO simulator results are available in the Mendeley data repository attached to this paper. The latest version of the genGEO open-source python library is available at https://github.com/GEG-ETHZ/genGEO. The peer-reviewed and archived version of the genGEO library is available at https://doi.org/10.5281/zenodo.4383138. Lastly, electricity generation and cost results for the parameter space of Section 3.2.1 are provided as supplemental spreadsheet files.

\section{Conflicts of Interest}

There are no conflicts to declare.

\section{Acknowledgements}

Many thanks to Kevin Kitz for intellectually stimulating conversations that provided insight into the mindset of geothermal industry professionals. We would also like to thank Geothermal Rising (previously Geothermal Resources Council) and Ormat for providing publicly accessible technoeconomic information on modern geothermal power plants currently in operation. 
The authors gratefully acknowledge funding from Innosuisse (grant 28305.1 PFIW-IW0) and ACT ELEGANCY. We thank SwissGeoPower for their support. The Werner Siemens Foundation (Werner Siemens-Stiftung) is further thanked for its support of the Geothermal Energy and Geofluids (GEG.ethz.ch) Group at ETH Zurich. We also thank the U.S. National Science Foundation Innovations at the Nexus of Food, Energy, and Water Systems (INFEWS) program (1739909), the U.S. National Science Foundation National Research Traineeship Program (1922666), and the Sloan Foundation. Any opinions, findings, conclusions, and/or recommendations expressed in this material are those of the authors and do not necessarily reflect the views of the ETH or The Ohio State University.

ACT ELEGANCY, Project No 271498, has received funding from DETEC (CH), FZJ/PtJ (DE), RVO (NL), Gassnova (NO), BEIS (UK), Gassco AS and Statoil Petroleum AS, and is cofounded by the European Commission under the Horizon 2020 programme, ACT Grant Agreement No 691712.

\section{CRediT Authorship Contribution Statement}

Benjamin M. Adams: Conceptualization, Methodology, Software, Data Curation, Formal Analysis, Writing-Original Draft. Jonathan D. Ogland-Hand: Conceptualization, Methodology, Writing-Original Draft. Jeffrey M. Bielicki: Methodology, Writing-Review \& Editing. Philipp Schaedle: Software, Writing-Review \& Editing. Martin O. Saar: Writing-Review \& Editing, Supervision, Funding Acquisition. 


\section{Appendix}

Figure A1 shows genGEO organic Rankine cycle (ORC) specific capital cost as a function of ORC inlet temperature for ORC capacities of $1 \mathrm{MW}_{\mathrm{e}}$ to $100 \mathrm{MW}_{\mathrm{e}}$.

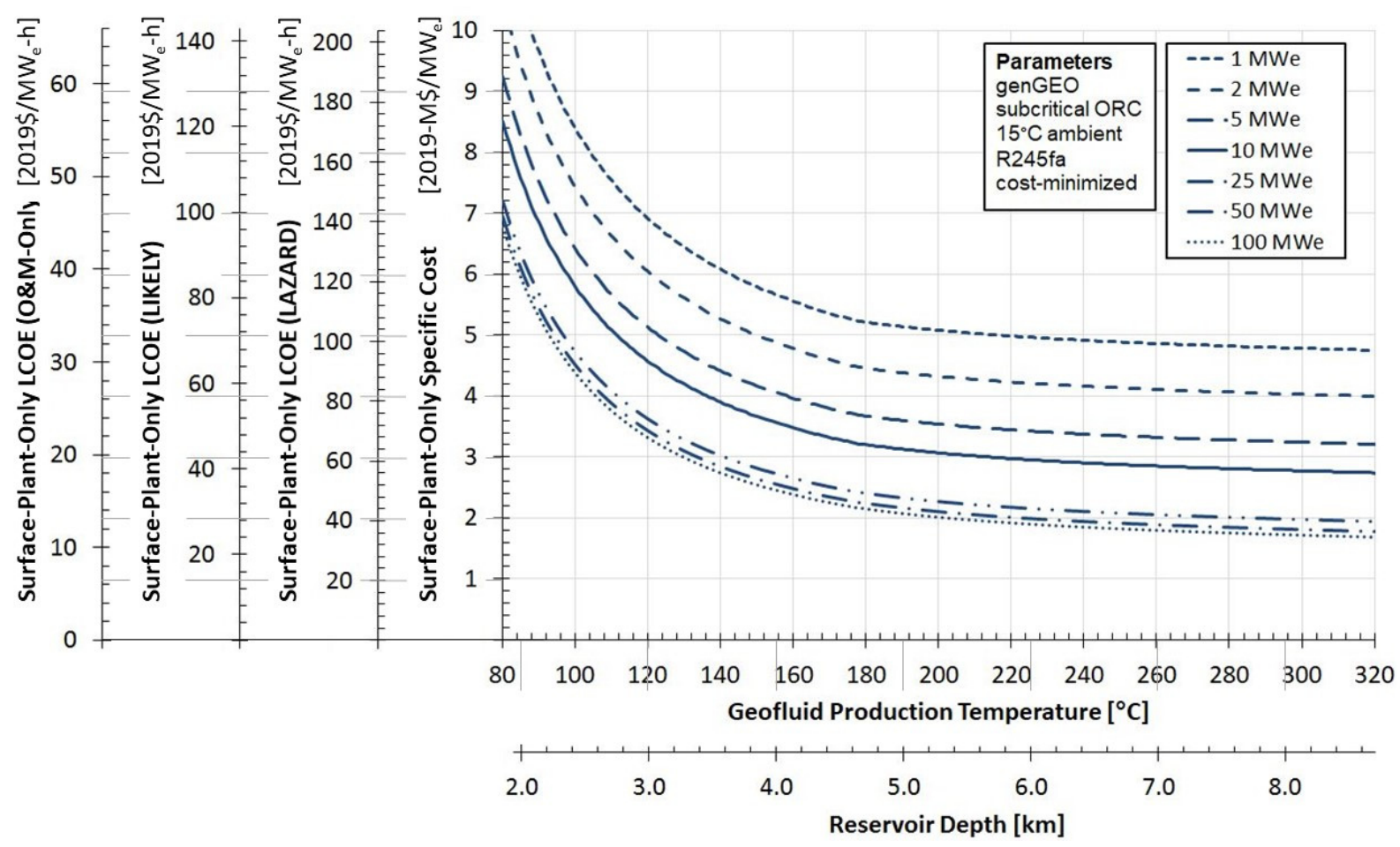

Figure A1: Surface plant only specific capital cost for a genGEO simulated organic Rankine cycle (ORC) as a function of geofluid wellhead temperature. Net plant capacities from $1 \mathrm{MW}$ to $100 \mathrm{MW}$ are given.

Figures $A 2$ to $A 7$ show genGEO simulator results of electric power and LCOE for geologic temperature gradients of $30^{\circ} \mathrm{C} / \mathrm{km}, 35^{\circ} \mathrm{C} / \mathrm{km}$, and $40^{\circ} \mathrm{C} / \mathrm{km}$. 


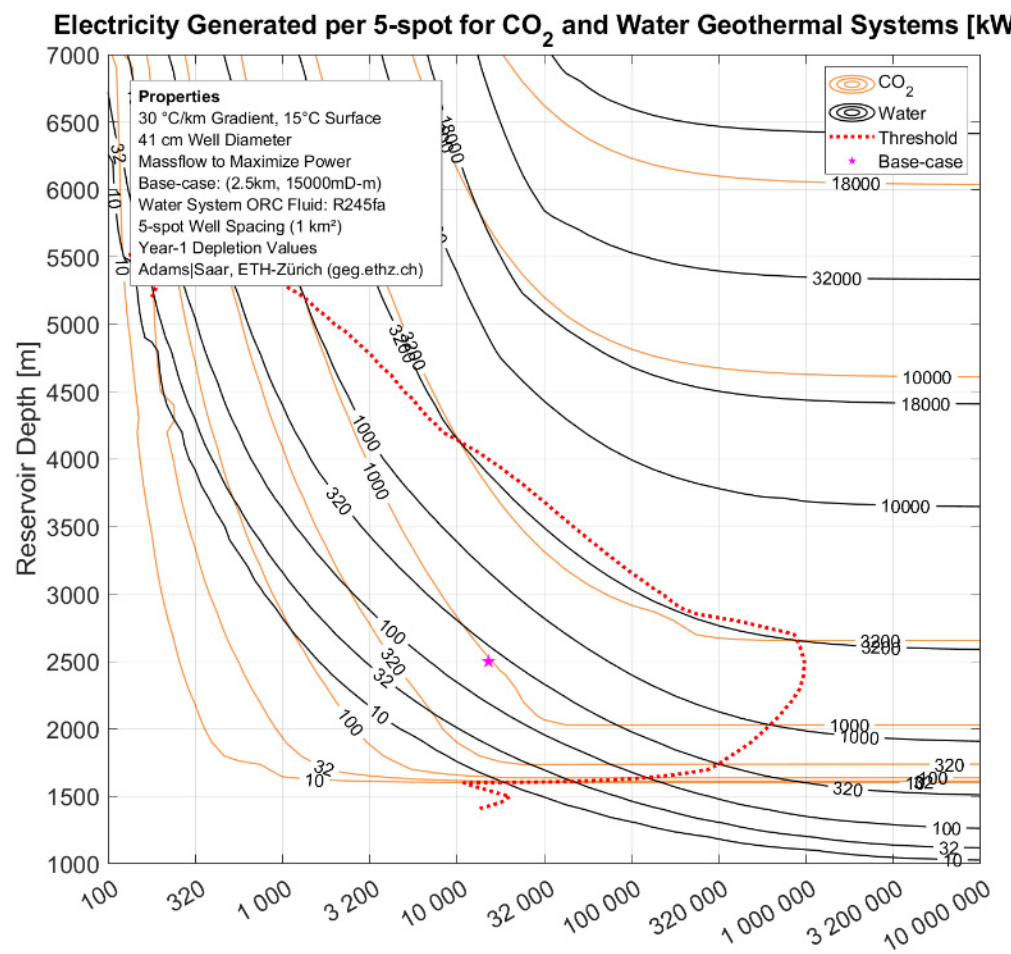

Reservoir Transmissivity [mD-m] (Log Scale)

Figure A2: Electric power generation for a single 5-spot Shared Neighbor for a geologic temperature gradient of $30^{\circ} \mathrm{C} / \mathrm{km}$ as a function of depth and transmissivity.

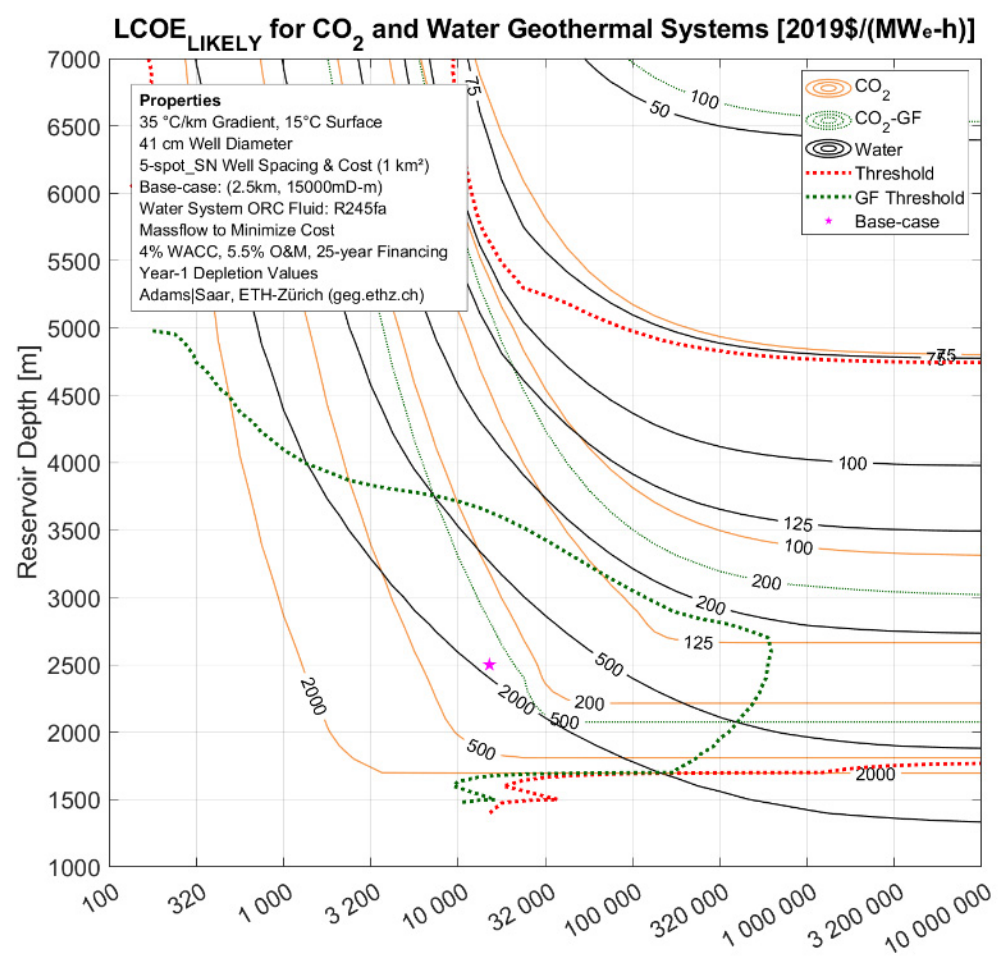

Reservoir Transmissivity [mD-m] (Log Scale)

Figure A3: LCOELIKELY for a geologic temperature gradient of $30^{\circ} \mathrm{C} / \mathrm{km}$ as a function of depth and transmissivity. 


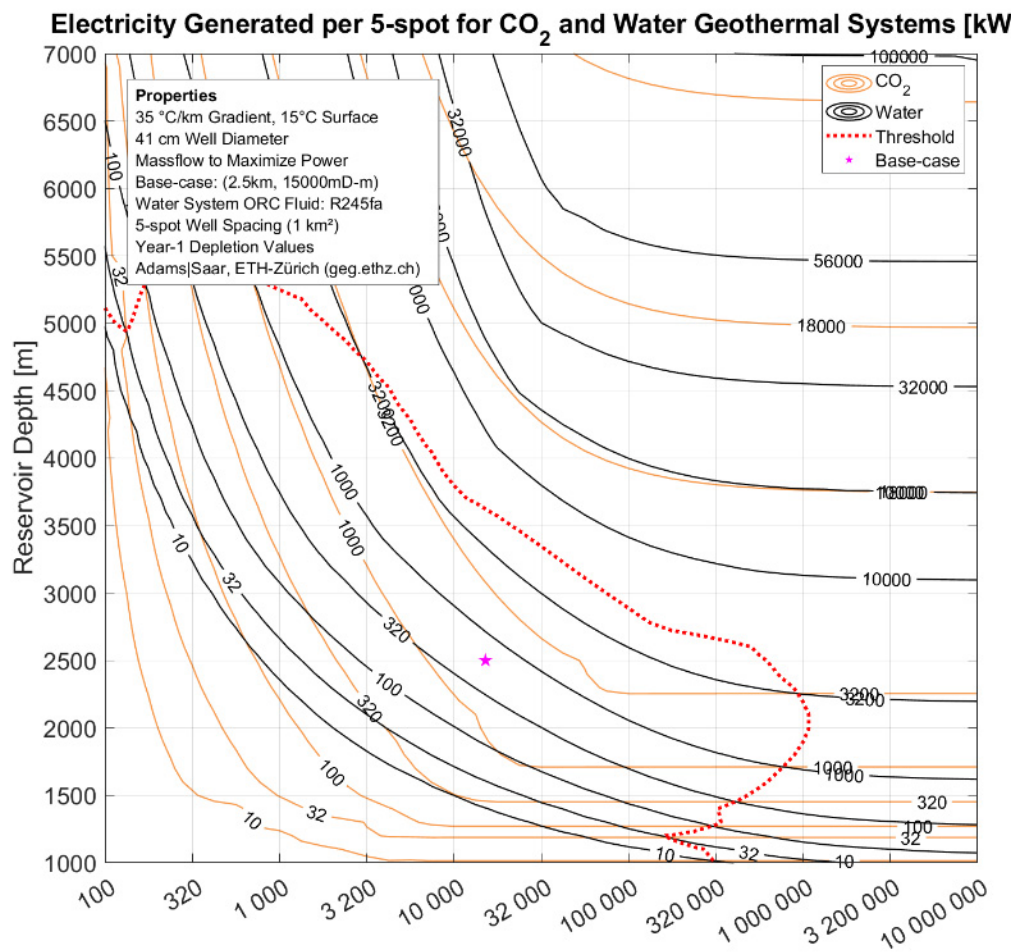

Reservoir Transmissivity [mD-m] (Log Scale)

Figure A4: Electric power generation for a single 5-spot Shared Neighbor for a geologic temperature gradient of $35^{\circ} \mathrm{C} / \mathrm{km}$ as a function of depth and transmissivity.

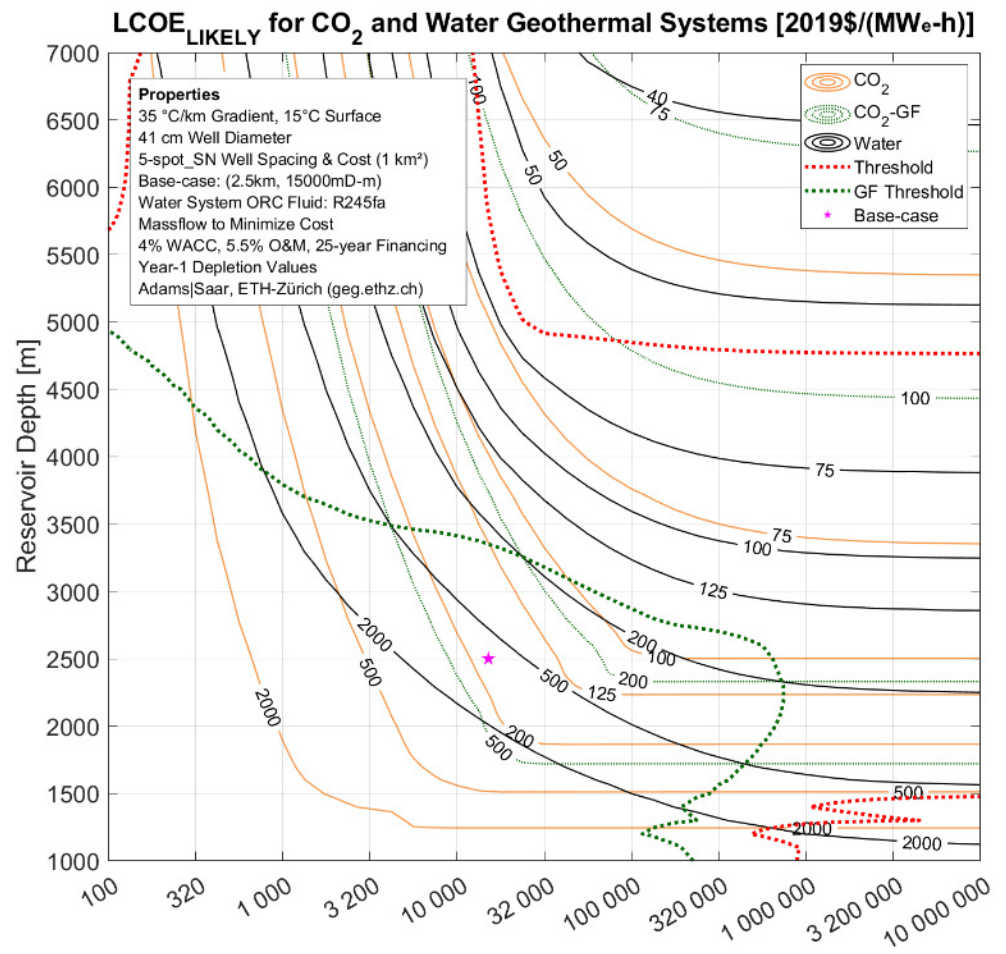

Reservoir Transmissivity [mD-m] (Log Scale)

Figure A5: LCOELIKELY for a geologic temperature gradient of $35^{\circ} \mathrm{C} / \mathrm{km}$ as a function of depth and transmissivity. 


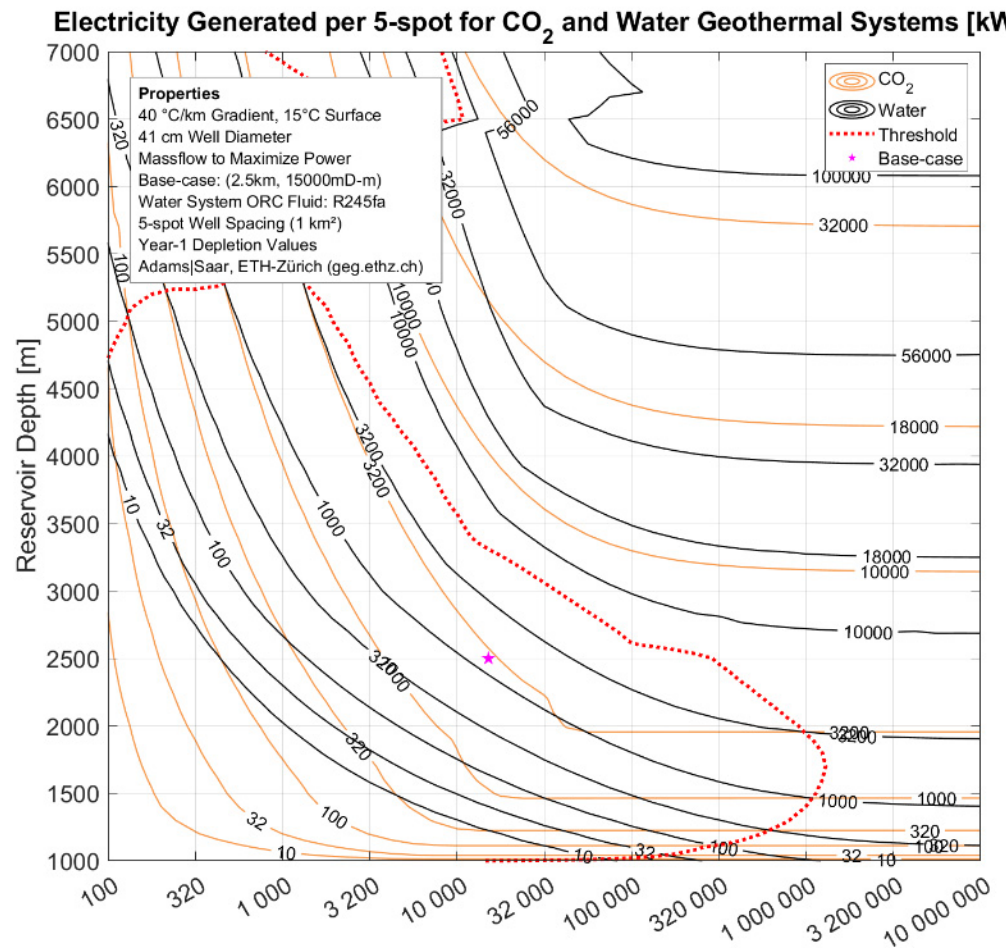

Reservoir Transmissivity [mD-m] (Log Scale)

Figure A6: Electric power generation for a single 5-spot Shared Neighbor for a geologic temperature gradient of $40^{\circ} \mathrm{C} / \mathrm{km}$ as a function of depth and transmissivity.

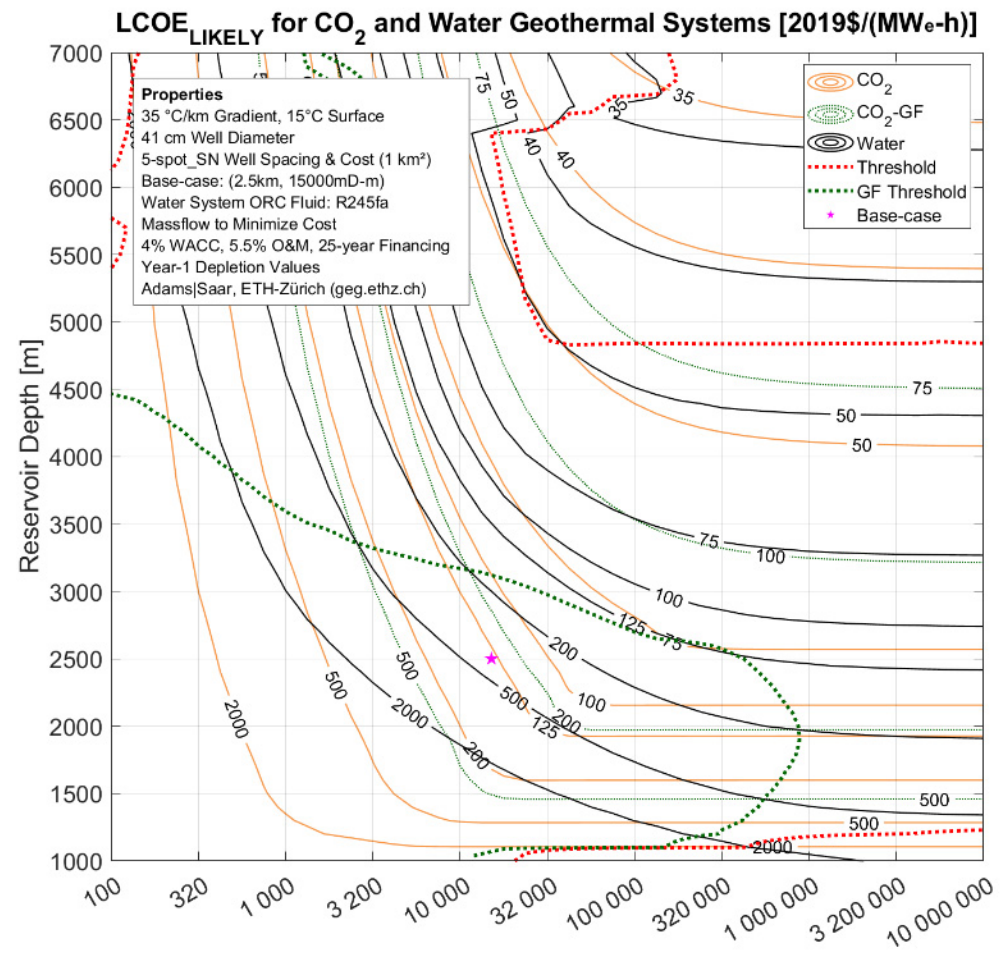

Reservoir Transmissivity [mD-m] (Log Scale)

Figure A7: LCOELIKELY for a geologic temperature gradient of $40{ }^{\circ} \mathrm{C} / \mathrm{km}$ as a function of depth and transmissivity. 


\section{References}

1. Sepulveda, N.A., Jenkins, J.D., Sisternes, F.J., \& Lester, R.K. (2018). The role of firm lowcarbon electricity resources in deep decarbonization of power generation. Joule, 2, 24032420. https://doi.org/10.1016/j.joule.2018.08.006

2. Bistline, J.E.T. \& Blanford, G.J. (2020). Value of technology in the U.S. electric power sector: Impacts of full portfolios and technological change on the costs of meeting decarbonization goals. Energy Economics, 86, 104694. https://doi.org/10.1016/j.eneco.2020.104694

3. Krey, V., Luderer, G., Clark, L., \& Kriegler, E. (2014). Getting from here to there-Energy technology transformation pathways in the EMF27 scenarios. Climatic Change, 123, 369382. https://doi.org/10.1007/s10584-013-0947-5

4. Kriegler, E., Weyant, J.P., Blanford, G.J., Krey, V., Clark, L., Edmonds, J., Fawcett, A., Luderer, G., Riahi, K., Richels, R., Rose, S.K., Tavoni, M., \& vanVuuren, D.P. (2014). The role of technology for achieving climate policy objectives: Overview of the EMF 27 study on global technology and climate policy strategies. Climatic Change, 123, 353-367. https://doi.org/10.1007/s10584-013-0953-7

5. Audoly, R., Vogt-Schilb, A., Guivarch, C., \& Pfeiffer, A. (2018). Pathways toward zero-carbon electricity required for climate stabilization. Applied Energy, 225, 884-901. https://doi.org/10.1016/j.apenergy.2018.05.026

6. Thomsen, P. (2018). Geothermal selection in California resource planning: Preliminary results from the CPUC's IRP tools and recommendations for future development and analysis. Geothermal Resources Council Transactions, 42. http://pubs.geothermallibrary.org/lib/grc/1033947.pdf

7. U.S. Department of Energy (USDOE). (2019). GeoVision: Harnessing the heat beneath our feet. https://www.energy.gov/sites/prod/files/2019/06/f63/GeoVision-full-report-opt.pdf

8. U.S. Energy Information Agency (USEIA). (2020). Electricity explained: Electricity generation, capacity, and sales in the United States. https://www.eia.gov/energyexplained/electricity/electricity-in-the-us-generation-capacityand-sales.php

9. Augustine, C., Ho, J. \& Blair, N. (2019). GeoVision analysis supporting task force report: Electric sector potential to penetration. https://www.nrel.gov/docs/fy19osti/71833.pdf

10. U.S. Department of Energy (USDOE). (2006). The future of geothermal energy: Impact of enhanced geothermal systems (EGS) on the United States in the $21^{\text {st }}$ century. Report INL/EXT-06-11746. https://energy.mit.edu/wp-content/uploads/2006/11/MITEI-TheFuture-of-Geothermal-Energy.pdf

11. Brown, D. (2000) A hot dry rock geothermal energy concept utilizing supercritical $\mathrm{CO}_{2}$ instead of water. Proceedings, Twenty-Fifth Stanford Workshop on Geothermal Resevoir Engineering, Stanford University, Stanford, California, January 24-26, 2000.

12. Wang, C.L., Cheng, W.L., Nian, Y.L., Yang., L., Hang, B.B., \& Liu, M.H. (2018). Simulation of heat extraction from $\mathrm{CO}_{2}$-based enhanced geothermal systems considering $\mathrm{CO}_{2}$ sequestration. Energy, 142, 157-167. https://doi.org/10.1016/j.energy.2017.09.139

13. Gischig, V.S., Giardini, D., Amann, F., Hertrich, M., Krietsch, H., Loew, S., Maurer, H., Villiger, L., Wiemer, S., Bethmann, F., Brixel, B., Doetsch, J., Doonechaly, N.G., Driesner, T., Dutler, N., Evans, K.F., Jalali, M., Jordan, D., et al., \& Valley, B. (2020). Hydraulic stimulation and fluid circulation experiments in underground laboratories: Stepping up the 
scale towards engineered geothermal systems. Geomechanics for Energy and the Environment, 24, 100175. https://doi.org/10.1016/i.gete.2019.100175

14. Amann, F., Gischig, V., Evans, K., Doetsch, J., Jalali, R., Valley, B., Krietsch, H., Dutler, N., Villiger, L., Brixel, B., Klepikova, M., Kittilä, A., Madonna, C., Wiemer, S., Saar, M.O., Loew, S., Driesner, T., Maurer, H., \& Giardini, D. (2018). The seismo-hydromechanical behavior during deep geothermal reservoir stimulations: open questions tackled in a decameterscale in situ stimulation experiment. Solid Earth, 9, 115-137. https://doi.org/10.5194/se-9$115-2018$

15. Ellsworth, W.L., Giardini, D., Townend, J., Ge, S., \& Shimamoto, T. (2019). Triggering of the Pohang, Korea, earthquake (Mw 5.5) by enhanced geothermal system stimulation. Seismological Research Letters, 90, 1844-1858. https://doi.org/10.1785/0220190102

16. Beckers, K.F., Lukawski, M.Z., Anderson, B.J., Moore, M.C., \& Tester, J.W. (2014). Levelized costs of electricity and direct-use heat from enhanced geothermal systems. Journal of Renewable and Sustainable Energy, 6, 059902. https://doi.org/10.1063/1.4865575

17. Aghahosseini, A. \& Breyer, C. (2020). From hot rock to useful energy: A global estimate of enhanced geothermal systems potential. Applied Energy, 279, 115769. https://doi.org/10.1016/j.apenergy.2020.115769

18. CGG Robertson. (2020). Robertson basins and plays: Sedimentary basins of the world. https://www.arcgis.com/home/item.html?id=a15e179c3b6a45ef94107353c2f64fc1

19. Adams, B.M., Kuehn, T.H., Bielicki, J.M., Randolph, J.B., \& Saar, M.O. (2015). A comparison of electric power output of $\mathrm{CO}_{2}$ Plume Geothermal (CPG) and brine geothermal systems for varying reservoir conditions. Applied Energy, 140, 365-377. https://doi.org/10.1016/j.apenergy.2014.11.043

20. Banks, J. \& Harris, N.B. (2018). Geothermal potential of foreland basins: A case study from the western Canadian sedimentary basin. Geothermics, 76, 74-92. https://doi.org/10.1016/j.geothermics.2018.06.004

21. Intergovernmental Panel on Climate Change (IPCC). (2005). IPCC special report on carbon dioxide capture and storage. https://doi.org/10.1557/mrs2008.63

22. Randolph, J.B. \& Saar, M.O. (2011). Combining geothermal energy capture with geologic carbon dioxide sequestration. Geophysical Research Letters, 38, L10401. https://doi.org/10.1029/2011GL047265

23. Adams, B.M., Kuehn, T.H., Bielicki, J.M., Randolph, J.B., \& Saar, M.O. (2014). On the importance of the thermosiphon effect in $\mathrm{CPG}\left(\mathrm{CO}_{2}\right.$ plume geothermal) power systems. Energy, 69, 409-418. https://doi.org/10.1016/j.energy.2014.03.032

24. Adams, B.M., Vogler, D., Kuehn, T.H., Bielicki, J.M., Garapati, N., \& Saar, M.O. (2020). Heat depletion and its effect on the design and electric power output of $\mathrm{CO}_{2}$ Plume Geothermal (CPG) systems. Renewable Energy. https://doi.org/10.1016/j.renene.2020.11.145

25. Mines, G.L. (2016). GETEM User Manual. https://workingincaes.inl.gov/SiteAssets ICAES\%20Files/FORGE/inl ext-16-38751\%20GETEM\%20User\%20Manual\%20Final.pdf

26. Beckers, K.F. \& McCabe, K. (2019). GEOPHIRES v2.0: updated geothermal techno-economic simulation tool. Geothermal Energy, 7. https://doi.org/10.1186/s40517-019-0119-6 
27. Pacific Northwest National Laboratory (PNNL). (2009). Global deployment of geothermal energy using a new characterization in GCAM 1.0. https://www.pnnl.gov/main/publications/external/technical reports/PNNL-19231.pdf

28. U.S. National Renewable Energy Laboratory (NREL). (2011). Updated U.S. geothermal supply characterization and representation for market penetration model input. Report NREL/TP-6A20-47459. https://www.nrel.gov/docs/fy12osti/47459.pdf

29. Bell, I.H., Wronski, J., Quoilin, S., \& Lemort, V. (2014). Pure and pseudo-pure fluid thermophysical property evaluation and the open-source thermophysical property library CoolProp. Industrial and Engineering Chemistry Research, 53, 2498-2508. https://doi.org/10.1021/ie4033999

30. Garapati, N., Randolph, J.B., \& Saar, M.O. (2015). Brine displacement by $\mathrm{CO}_{2}$, energy extraction rates, and lifespan of a $\mathrm{CO}_{2}$-limited $\mathrm{CO}_{2}$-plume geothermal (CPG) system with a horizontal production well. Geothermics, 55, 182-194. https://doi.org/10.1016/i.geothermics.2015.02.005

31. Randolph, J.B., \& Saar, M.O. (2010). Coupling geothermal energy capture with carbon dioxide sequestration in naturally permeable, porous geologic formations: A comparison with enhanced geothermal systems. Geothermal Resources Council Transactions, 34, 433-437.

32. Randolph, J.B. \& Saar, M.O. (2011). Impact of reservoir permeability on the choice of subsurface geothermal heat exchange fluid: $\mathrm{CO}_{2}$ versus water and native brine. Geothermal Resources Council Transactions, 35, 521-526.

33. Adams, B.M., Saar, M.O., Bielicki, J.M., Ogland-Hand, J.D., \& Fleming, M.R. (2020). Using geologically sequestered $\mathrm{CO}_{2}$ to generate and store geothermal electricity: $\mathrm{CO}_{2}$ Plume Geothermal (CPG). Proceedings, MIT A+B Applied Energy Symposium, 12-14 Aug, 2020. https://doi.org/10.3929/ethz-b-000444911

34. Lazard. (2019). Levelized cost of energy analysis - Version 13.0. https://www.lazard.com/media/451086/lazards-levelized-cost-of-energy-version-130vf.pdf.

35. Ormat. (2020). Ormat annual report, securities and exchange commission form 10-K. https://www.sec.gov/cgi-bin/browse-edgar?CIK=1296445

36. United States Geologic Survey (USGS). (2013). National assessment of geologic carbon dioxide storage resources-Data. Data series 774 , version 1.1 . http://pubs.usgs.gov/ds/774/

37. Ezekiel, J., Adams, B.M., Saar, M.O., \& Ebigbo, A. (in review). Numerical analysis and optimization of the performance of $\mathrm{CO}_{2}$-Plume Geothermal (CPG) production wells and implications for electric power generation. Geothermics.

38. Ezekiel, J., Ebigbo, A., Adams, B.M., \& Saar, M.O. (2020). Combining natural gas recovery and $\mathrm{CO}_{2}$-based geothermal energy extraction for electric power generation. Applied Energy, 269, 115012. https://doi.org/10.1016/j.apenenergy.2020.115012

39. Sanyal, S.K., Morrow, J.W., Butler, S.J., \& Robertson-Tait, A. (2007). Cost of electricity from enhanced geothermal systems. Proceedings, Thirty-second workshop on geothermal reservoir engineering, Stanford University, Stanford, California, January 22-24, 2007.

40. Ormat. (2020). Ormat Tungsten geothermal and solar power plant. YouTube video: https://www.youtube.com/watch?v=9a2g222Dk c 
41. Ormat. (2020). Ormat Tungsten mountain field trip. A virtual field trip at the 2020 Geothermal Rising (formerly Geothermal Resources Council) annual meeting. 16 to 23 Oct, 2020.

42. Ormat. (2020). Ormat Steamboat field trip. A virtual field trip at the 2020 Geothermal Rising (formerly Geothermal Resources Council) annual meeting. 16 to 23 Oct, 2020.

43. United States Energy Information Administration (USEIA). (2020). Electric power annual 2019: October 2020. https://www.eia.gov/electricity/annual/

44. Global CCS Institute. (2020). Global status of CCS report. https://www.globalccsinstitute.com/resources/global-status-report/

45. United States Environmental Protection Agency (USEPA). (2020). Inventory of U.S. greenhouse gas emissions and sinks: 1990-2018. EPA report 430-R-20-002. https://www.epa.gov/ghgemissions/inventory-us-greenhouse-gas-emissions-and-sinks1990-2018

46. Intergovernmental Panel on Climate Change (IPCC). (2018). Special report for warming of $1.5^{\circ} \mathrm{C}$. https://www.ipcc.ch/sr15/

47. International Energy Agency (IEA). (2020). Electricity Information 2020. https://www.iea.org/subscribe-to-data-services/electricity-statistics 


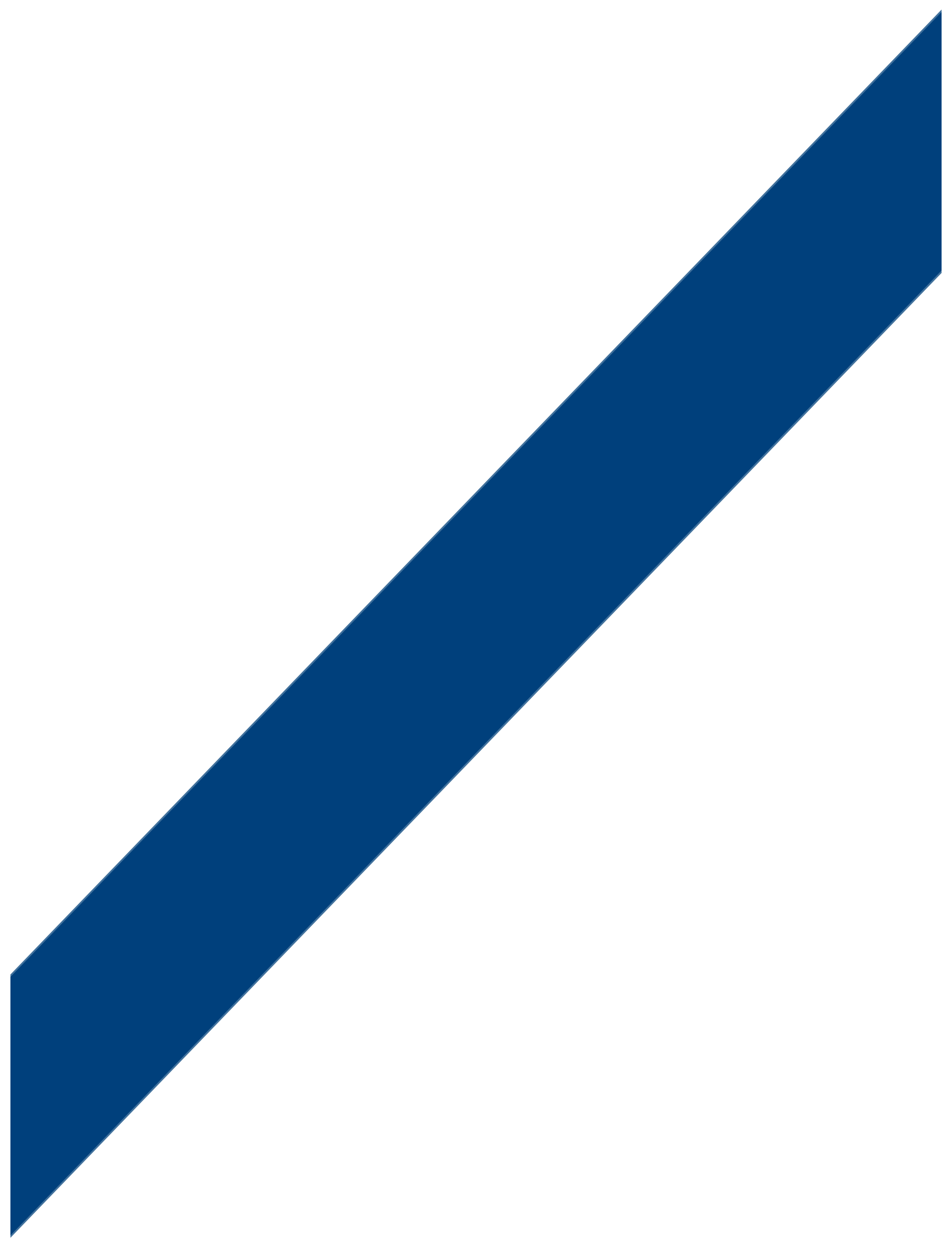




\section{Estimating The Geothermal Electricity Generation Potential of Sedimentary Basins using genGEO (the generalizable GEOthermal techno-economic simulator)}

\section{SUPPLEMENTAL INFORMATION: A detailed description of genGEO models}

Benjamin M. Adams ${ }^{1 *}$, Jonathan D. Ogland-Hand ${ }^{1}$, Jeffrey M. Bielicki ${ }^{2,3}$, Philipp Schädle ${ }^{1}$, and Martin O. Saar ${ }^{1,4 *}$

${ }^{1}$ Geothermal Energy and Geofluids Group, Department of Earth Sciences, ETH-Zürich, Sonneggstrasse 5, 8092 Zürich, Switzerland ${ }^{2}$ Department of Civil, Environmental, and Geodetic Engineering, 2070 Neil Avenue, Columbus, OH 43210, USA

3John Glenn College of Public Affairs, 1810 College Road, Columbus, OH 43210, USA

${ }^{4}$ Department of Earth and Environmental Sciences, University of Minnesota, Minneapolis, MN, USA

*Corresponding Authors: badams@ethz.ch (adam0068@umn.edu) and saarm@ethz.ch

\section{Table of Contents}

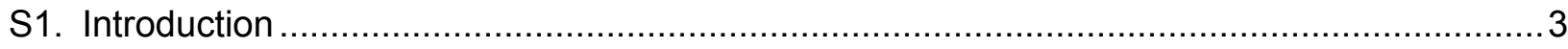

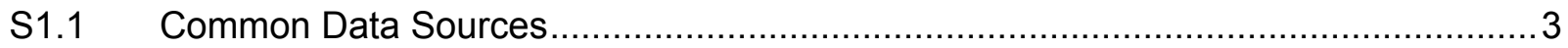

S1.2 Adjusting to Same Year Dollars ..........................................................................

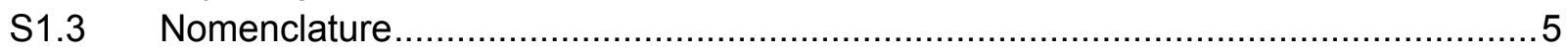

S2. LCOE Calculation Methodology ……………

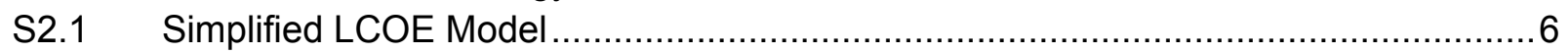

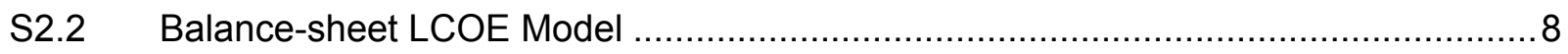

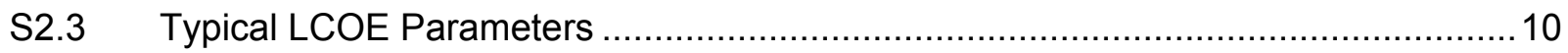

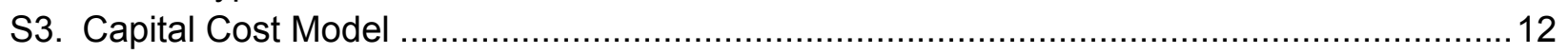

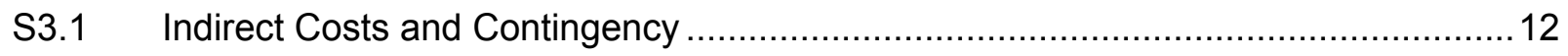

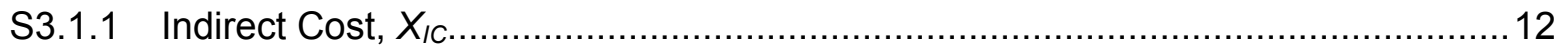

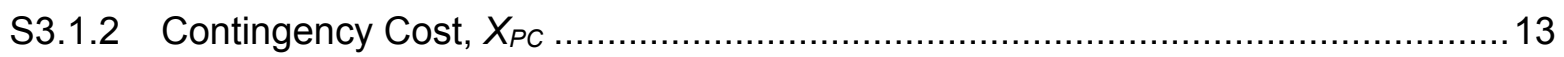

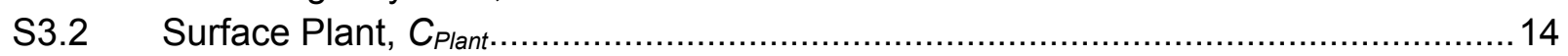

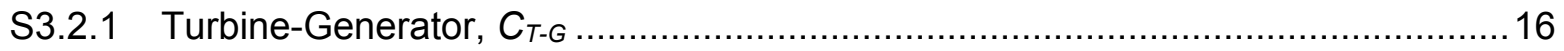

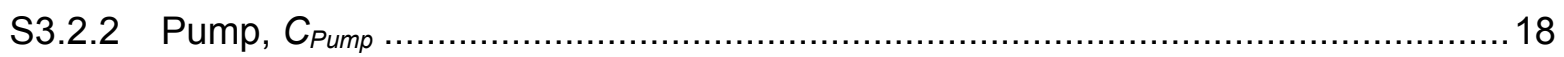

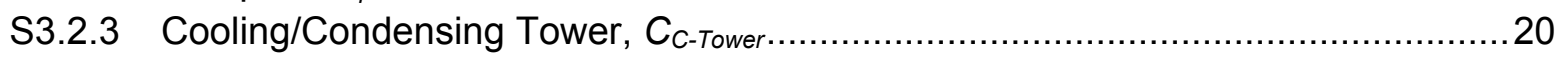

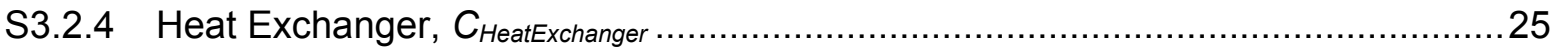

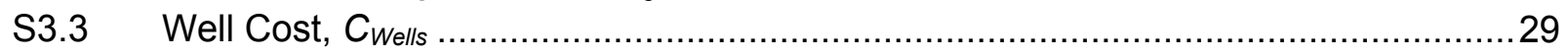

S3.3.1 Geothermal Drilling Success Rate, Swell ...................................................... 30

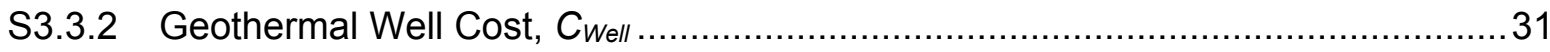

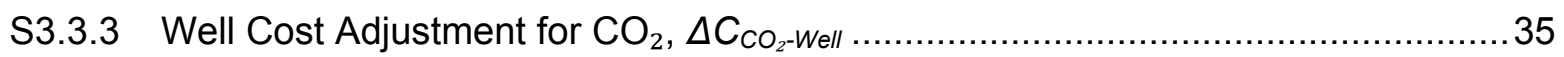

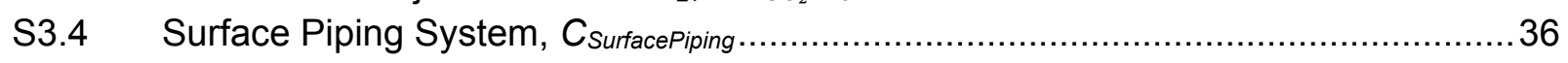

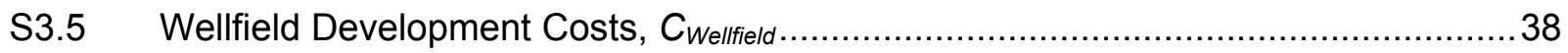




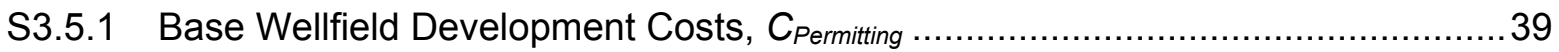

S3.5.2 Wellfield Cost Adjustment for $\mathrm{CO}_{2}, \Delta C_{P e r m i t t i n g-\mathrm{CO}_{2}}$ and $\Delta \mathrm{C}_{\text {Monitoring- } \mathrm{CO}_{2}} \ldots \ldots \ldots \ldots \ldots . \ldots . \ldots . \ldots . . .39$

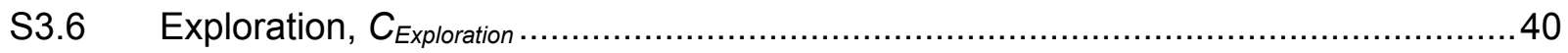

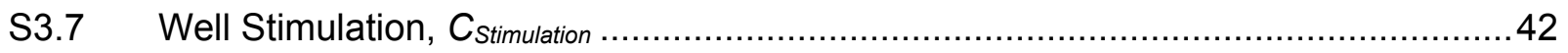

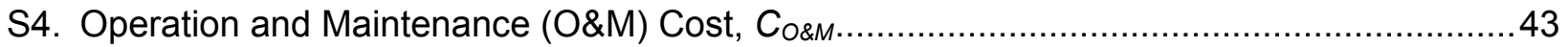

S5. Surface Power Plant ............................................................................................... 47

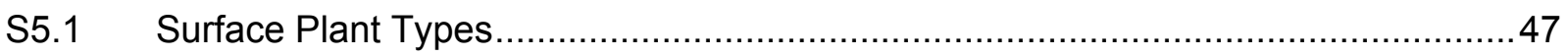

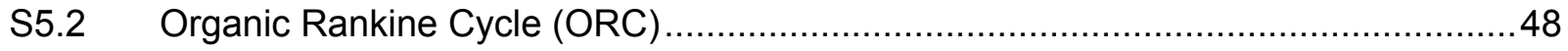

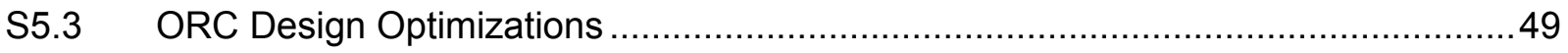

S5.3.1 Maximize Specific Electric Power ............................................................ 49

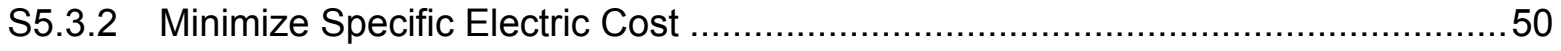

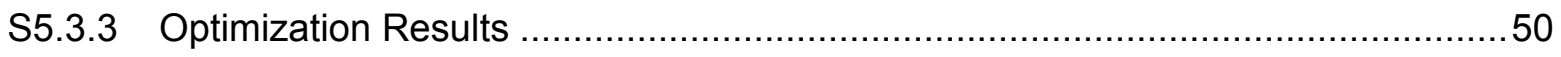

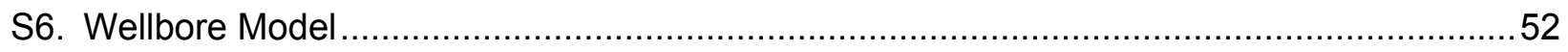

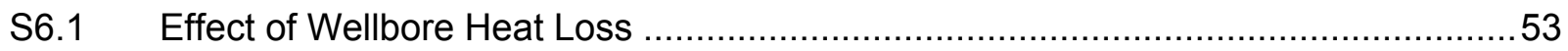

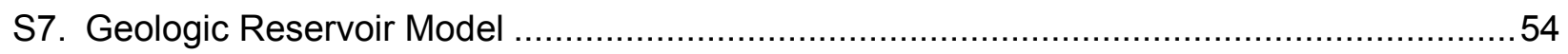

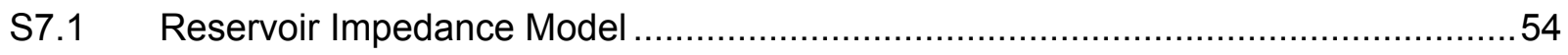

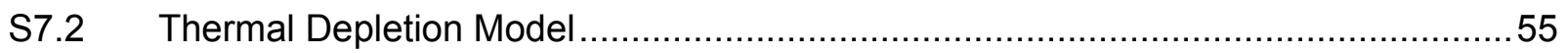

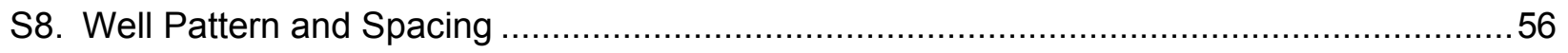

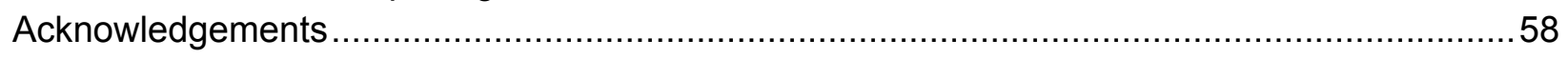

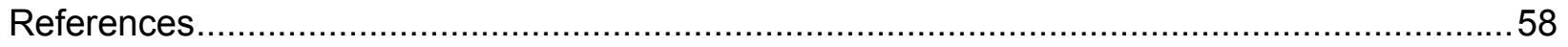




\section{S1. Introduction}

This supplemental information describes the genGEO simulator, which is a geothermal combinedreservoir, well, power plant, cost, and financing simulator. This tool was developed specifically for the analysis of the main manuscript to which this supplemental information is attached. An opensource genGEO python library is freely available which implements the various models described herein.

The primary objective of the genGEO simulator is to provide geothermal electricity power generation values, cost, and levelized cost of electricity (LCOE) for porous media geothermal reservoirs. As the python code is open-source, object-oriented, and generalizable, the provided relations and physics may be extended to virtually any geothermal power application, including: fracture-based geothermal (i.e. EGS), conduction-based geothermal (i.e. AGS), geothermal heat pumps, or district-heating.

In this supplemental information, we provide several models which are all coupled and interconnected within genGEO. The models are: Section S2) the levelized cost of electricity (LCOE) model, Section S3) the capital cost model, Section S4) the operating cost model, Section S5) the surface power plant model, Section S6) the well flow model, Section S7) the geologic model, and Section S8) the wellfield layout model. In the main text, we combine the LCOE and operating cost models into a single section, but we separate them here for clarity.

\section{S1.1 Common Data Sources}

There are several heavily referenced bodies of work in this document. We often use abbreviations to those references for simplicity. They are:

- "GETEM" (Geothermal Energy Technology Evaluation Model). Developed at Idaho National Laboratory 2004-2013, this spreadsheet tool is often cited as the standard for geothermal power and cost analysis. The most recent version is from 2016 (Mines, 2016).

- "GEOPHIRES" (GEOthermal energy for Production of Heat and electricity 'IR' Economically Simulated). Developed originally as a PhD thesis from 2012 to 2016 by Beckers (2016), GEOPHIRES is now in its second version of development by the National Renewable Energy Laboratory (NREL) (Beckers et al., 2014; 2019; Beckers, 2016).

- "NETL" refers to the National Energy Technology Laboratory's series of reports "Cost and Performance Baseline for Fossil Energy Plants: Volume 1 Bituminous Coal and Natural Gas to Electricity" (NETL 2007; 2010; 2012; 2015; 2019b) and the underlying "Cost Estimation Methodology for NETL Assessments of Power Plant Performance" (NETL, $2011 ; 2019 a)$. These reports provide detailed accounting of natural gas and coal plant components and costs for 14 different power cycle types, both with- and without- $\mathrm{CO}_{2}$ capture. Originally, these 14 power cycle types were numbered 1 to 14 ; however, they were renamed in subsequent versions to 'B1A' through 'B31B'. For example, a coal plant using a sub-critical Rankine cycle without $\mathrm{CO}_{2}$ capture (Case 9 and later ' $\mathrm{B} 11 \mathrm{~A}$ ') is often used for comparison in this manuscript.

- "GeoVision" is an extensive, multi-year DOE project to overcome geothermal development barriers. However, we specifically refer to the GeoVision "reservoir maintenance and 
development" subtask (Lowry et. al., 2017). Lowry et al. (2017) is the primary source for drilling cost data used by genGEO. It is also used by GETEM and GEOPHIRES.

- "Kemper Site" is the proposed large-scale CCS complex at the Mississippi Kemper Energy facility described in Esposito et al. (2019). Esposito et al. (2019) provides actual detailed, itemized costs for drilling both monitoring and $\mathrm{CO}_{2}$ wells and developing a $\mathrm{CO}_{2}$ site, which are not typically available within most published literature.

\section{S1.2 Adjusting to Same Year Dollars}

All costs within this document are adjusted by year using producer price index (PPI) multipliers by the U.S. Bureau of Labor Statistics (BLS). The use of BLS PPI indices is adopted from GETEM; however only a subset of the indices used in GETEM are required within genGEO. All fundamental relations in genGEO and this supplemental information are given in US 2002 dollars, unless specifically mentioned otherwise. The main manuscript provides results in 2019 dollars.

Table S1: Producer Price Indices (PPI) from the U.S. Bureau of Labor Statistics (BLS) used in genGEO.

\begin{tabular}{|c|c|c|c|c|c|c|c|c|c|}
\hline Year & Pipe $^{1}$ & $\begin{array}{l}\text { Turbine- } \\
\text { Generator } \\
2\end{array}$ & $\begin{array}{l}\text { Heat } \\
\text { Exchange } \\
\mathrm{r}(\mathrm{HX})^{3}\end{array}$ & Pumps $^{4}$ & $\begin{array}{l}\text { Process } \\
\text { Equipment } \\
5\end{array}$ & $\begin{array}{l}\text { Oil \& } \\
\text { Gas } \\
\text { Well }^{6}\end{array}$ & $\begin{array}{l}\text { Drilling } \\
\text { Services }^{7}\end{array}$ & $\begin{array}{l}\text { Permittin } \\
\text { g (legal } \\
\text { services) }\end{array}$ & $\begin{array}{l}\text { O\&G } \\
\text { Support }\end{array}$ \\
\hline Variable & PPI $\left.\right|_{\text {Pipe }}$ & $\mathrm{PPI}_{\mathrm{T}-\mathrm{G}}$ & $\mathrm{PPI}_{\mathrm{HX}}$ & $\mathrm{PPI}_{\text {Pump }}$ & $\mathrm{PPI}_{\mathrm{PE}}$ & PPlo\&G & $\mathrm{PPI}_{\mathrm{DS}}$ & $\mathrm{PPI}_{\text {Permit }}$ & PPlo\&G-s \\
\hline 2002 & 1.000 & 1.000 & 1.000 & 1.000 & 1.000 & 1.000 & 1.000 & 1.000 & 1.000 \\
\hline 2003 & 1.014 & 1.013 & 0.999 & 1.011 & 1.015 & 1.000 & 0.999 & 1.032 & 0.987 \\
\hline 2004 & 1.219 & 1.019 & 1.066 & 1.040 & 1.078 & 1.094 & 1.098 & 1.083 & 1.032 \\
\hline 2005 & 1.341 & 1.018 & 1.227 & 1.103 & 1.155 & 1.686 & 1.714 & 1.138 & 1.174 \\
\hline 2006 & 1.414 & 1.050 & 1.333 & 1.146 & 1.223 & 2.461 & 2.503 & 1.193 & 1.365 \\
\hline 2007 & 1.394 & 1.107 & 1.378 & 1.200 & 1.305 & 2.349 & 2.379 & 1.262 & 1.414 \\
\hline 2008 & 1.500 & 1.245 & 1.438 & 1.258 & 1.383 & 2.390 & 2.423 & 1.328 & 1.433 \\
\hline 2009 & 1.578 & 1.350 & 1.415 & 1.297 & 1.403 & 2.138 & 2.153 & 1.366 & 1.321 \\
\hline 2010 & 1.748 & 1.341 & 1.424 & 1.313 & 1.411 & 2.123 & 2.122 & 1.412 & 1.298 \\
\hline 2011 & 1.861 & 1.360 & 1.464 & 1.357 & 1.494 & 2.363 & 2.362 & 1.462 & 1.385 \\
\hline 2012 & 1.934 & 1.350 & 1.513 & 1.396 & 1.562 & 2.551 & 2.562 & 1.502 & 1.430 \\
\hline 2013 & 1.955 & 1.377 & 1.535 & 1.427 & 1.591 & 2.825 & 2.851 & 1.544 & 1.451 \\
\hline 2014 & 1.986 & 1.412 & 1.555 & 1.460 & 1.639 & 2.945 & 2.977 & 1.594 & 1.450 \\
\hline 2015 & 1.988 & 1.399 & 1.604 & 1.486 & 1.656 & 2.438 & 2.445 & 1.639 & 1.432 \\
\hline 2016 & 1.969 & 1.403 & 1.644 & 1.501 & 1.653 & 2.048 & 2.037 & 1.672 & 1.403 \\
\hline 2017 & 1.985 & 1.347 & 1.658 & 1.527 & 1.680 & 2.108 & 2.099 & 1.734 & 1.413 \\
\hline 2018 & 2.064 & 1.332 & 1.743 & 1.579 & 1.741 & 2.165 & 2.157 & 1.776 & 1.432 \\
\hline 2019* & 2.092 & 1.406 & 1.797 & 1.617 & 1.794 & 2.195 & 2.185 & 1.840 & 1.437 \\
\hline \multicolumn{10}{|c|}{ 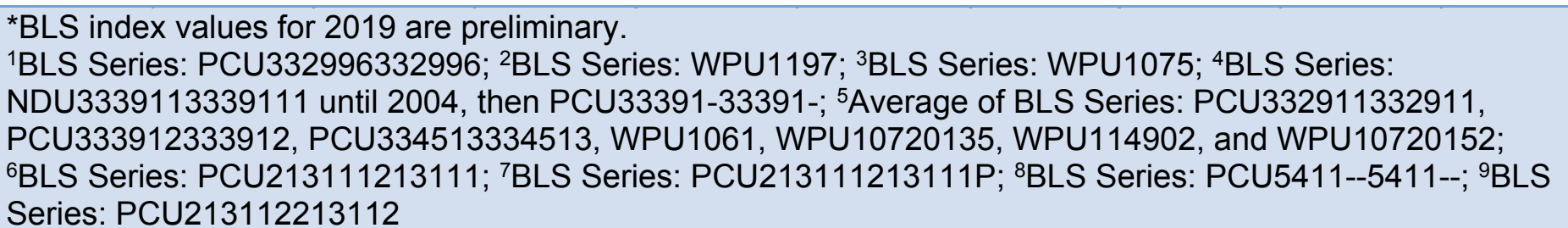 } \\
\hline
\end{tabular}


To convert from 2002 dollars to the desired year, multiply the 2002 dollar amount by the most relevant price index. Table S1 shows the price indices used in genGEO and have a 2002 reference year (i.e. in 2002, PPI $=1.000$ ) for various types of equipment. This is the same method used by GETEM, except GETEM uses several different reference years.

\section{S1.3 Nomenclature}

Nomenclature for this supplemental information are provided in Table S2.

Table S2: Nomenclature.

\begin{tabular}{|c|c|c|}
\hline Variable & Name & $\begin{array}{l}\text { Typical } \\
\text { Units }\end{array}$ \\
\hline$A_{C O 2, A M A}$ & $\begin{array}{l}\mathrm{CO}_{2} \text { Active Monitoring } \\
\text { Area }\end{array}$ & $\mathrm{m}^{2}$ \\
\hline$A_{H X}$ & Heat Exchanger Area & $\mathrm{m}^{2}$ \\
\hline ATNEC & $\begin{array}{l}\text { After-tax Net Equity } \\
\text { Cashflow }\end{array}$ & $\$$ /year \\
\hline$b$ & Reservoir Thickness & $\mathrm{m}$ \\
\hline $\boldsymbol{c}$ & Specific Cost & $\$ / \mathrm{kW}$ \\
\hline$c^{\prime}$ & Specific Heat Capacity & $\mathrm{kJ} / \mathrm{kg}-\mathrm{K}$ \\
\hline$C$ & Cost & $\$$ \\
\hline$C F$ & Capacity Factor & -- \\
\hline CRF & Capital Recovery Factor & 1/year \\
\hline$d_{D}$ & Discount Rate (Debt) & 1/year \\
\hline$d_{E}$ & Discount Rate (Equity) & 1/year \\
\hline$D$ & Diameter & $\mathrm{m}$ \\
\hline$D I$ & Debt Interest Paid & \$/year \\
\hline$D P$ & Debt Principal Paid & \$/year \\
\hline$D S$ & Levelized Debt Service & 1/year \\
\hline$D T D$ & $\begin{array}{l}\text { Depreciation Tax } \\
\text { Deduction }\end{array}$ & \$/year \\
\hline $\boldsymbol{E}$ & Energy & $M W_{e}-h$ \\
\hline EBITDA & $\begin{array}{l}\text { Earnings before Interest, } \\
\text { Tax, Depreciation, and } \\
\text { Amortization }\end{array}$ & \$/year \\
\hline$E R$ & Escalation Rate & 1/year \\
\hline $\boldsymbol{F}$ & Fraction & -- \\
\hline$F_{D}$ & Debt Fraction & $\$ / \$$ \\
\hline$F_{E}$ & Equity Fraction & $\$ / \$$ \\
\hline$F_{O \& M}$ & O\&M Cost Fraction & 1/year \\
\hline $\boldsymbol{F P}$ & Financing Period & year \\
\hline$g$ & Gravitational Constant & $\mathrm{m} / \mathrm{s}^{2}$ \\
\hline$G$ & Number of items & -- \\
\hline $\boldsymbol{h}$ & Specific Enthalpy & $\mathrm{kJ} / \mathrm{kg}$ \\
\hline$I T$ & Income Tax & \$/year \\
\hline $\boldsymbol{k}$ & Thermal Conductivity & $\mathrm{W} / \mathrm{m}-\mathrm{K}$ \\
\hline$L$ & Length & $\mathrm{m}$ \\
\hline
\end{tabular}

\begin{tabular}{|c|c|c|}
\hline$L C O E$ & $\begin{array}{l}\text { Levelized Cost of } \\
\text { Electricity }\end{array}$ & $\$ / \mathrm{MW}_{\mathrm{e}}-\mathrm{h}$ \\
\hline$\dot{m}$ & Mass Flow Rate & $\mathrm{kg} / \mathrm{s}$ \\
\hline MACRS & MACRS Coefficient & 1/year \\
\hline$N P V$ & Net Present Value & $\$$ \\
\hline$P$ & Pressure & $\mathrm{kPa}$ \\
\hline$P P I$ & Producer Price Index & $\$ / 2002 \$$ \\
\hline$\dot{Q}$ & Heat & $\mathrm{kW}_{\text {th }}$ \\
\hline$R F$ & Rate Factor & $1 / \mathrm{hr}$ \\
\hline$s$ & Specific Entropy & $\mathrm{kJ} / \mathrm{kg}-\mathrm{K}$ \\
\hline$S$ & Equipment Cost Modifier & -- \\
\hline$S_{\text {Well }}$ & Well Success Rate & -- \\
\hline SpCC & Specific Capital Cost & $\mathrm{M} \$ / \mathrm{MW}_{\mathrm{e}}$ \\
\hline$t_{d}$ & Dimensionless Time & -- \\
\hline$T$ & Temperature & K \\
\hline$T D C$ & Tower Design Coefficient & -- \\
\hline$T I$ & Taxable Income & \$/year \\
\hline$T R$ & Income Tax Rate & -- \\
\hline $\boldsymbol{U}$ & $\begin{array}{l}\text { Overall Heat Transfer } \\
\text { Coefficient }\end{array}$ & $\mathrm{W} / \mathrm{m}^{2}-\mathrm{K}$ \\
\hline$\dot{W}$ & Power & $\mathrm{MW}_{\mathrm{e}}$ \\
\hline $\bar{W}$ & Average Plant Capacity & $\mathrm{MW}_{\mathrm{e}}$ \\
\hline$W A C C$ & $\begin{array}{l}\text { Weighted Average Cost } \\
\text { of Capital }\end{array}$ & 1/year \\
\hline$X_{I C}$ & Indirect Cost Multiplier & -- \\
\hline$X_{P C}$ & $\begin{array}{l}\text { Contingency Cost } \\
\text { Multiplier }\end{array}$ & -- \\
\hline $\boldsymbol{Z}$ & Elevation & $\mathrm{m}$ \\
\hline$\beta$ & Dimensionless Factor & -- \\
\hline$\Gamma$ & $\begin{array}{l}\text { Dimensionless } \\
\text { Temperature }\end{array}$ & -- \\
\hline$\Delta$ & Difference & -- \\
\hline $\boldsymbol{\kappa}$ & Reservoir Permeability & $\mathrm{m}^{2}$ \\
\hline$\lambda$ & Parasitic Power Fraction & $\mathrm{kW}_{\mathrm{e}} / \mathrm{kW}_{\text {th }}$ \\
\hline$\mu$ & Viscosity & Pa-s \\
\hline$\pi$ & Geometric Constant & -- \\
\hline$\rho$ & Density & $\mathrm{kg} / \mathrm{m}^{3}$ \\
\hline
\end{tabular}




\section{S2. LCOE Calculation Methodology}

In simplest terms, the Levelized Cost of Electricity (LCOE) is the total cost of a power plant, $C_{\text {Total }}$, divided by the total electricity it generates, $E_{\text {Total }}$, during the financing period (Equation $\left.S 1\right)$. Thus, the LCOE is often referred to as the "break-even" price of electricity because revenue from sales will equal cost to generate the electricity if the sales price is the LCOE. In genGEO, the LCOE is reported in units of $\$ / \mathrm{MW}_{\mathrm{e}}-\mathrm{h}$.

$$
L C O E=\frac{C_{\text {Total }}}{E_{\text {Total }}}
$$

The calculation of LCOE can be complicated because some costs are incurred immediately (i.e. so-called 'overnight costs', such as the capital cost to build the plant) and other costs are recurring costs (i.e. future annualized costs, such as the O\&M cost) over the plant financing period. So to calculate the LCOE, either the capital cost must be converted to annualized costs, or the annualized recurring costs must be converted to present costs.

Several methodologies exist to calculate the Levelized Cost of Electricity (LCOE). We adopt two methods in genGEO: the simplified LCOE model (Section S2.1) and the balance-sheet LCOE Model (Section S2.2). The simplified model calculates the LCOE as the ratio of annualized costs to annual power generation, while the balance-sheet model calculates the LCOE by calculating yearly cashflows and power generation and solving for an electricity price which yields a net present value of zero. The simplified model is used by GETEM, GEOPHIRES, and NREL models in various forms. The balance-sheet model is more realistic in terms of actual cashflows and is used by Lazard (2019).

The Levelized Cost of Heat $(\mathrm{LCOH})$ can be solved in an identical manner to LCOE by replacing electricity power values $\left(\mathrm{MW}_{\mathrm{e}}\right)$ with thermal power values $\left(\mathrm{MW}_{\mathrm{th}}\right)$. Geothermal heat extraction and sales are not implemented in genGEO; however, the code could be extended to this application. Despite having a similar calculation methodology, $\mathrm{LCOH}$ is not a priority of the current genGEO implementation and is not discussed further.

\section{S2.1 Simplified LCOE Model}

The simplified model assumes that operating and maintenance (O\&M) costs and yearly power generation are constant and does not consider income tax incentives or escalating O\&M. The simplified LCOE is given in Equation S2, where $C_{\text {geothermal }}$ is the geothermal plant capital cost, $C R F$ is the capital recovery factor, $C_{O \& M}$ is the annual recurring O\&M cost, $C_{F u e l}$ is the annual fuel cost, $\bar{W}$ is the capacity of the plant (in $\mathrm{MW}_{\mathrm{e}}$ ), and $C F$ is the capacity factor.

$$
L C O E=\frac{C_{\text {geothermal }} \cdot C R F+C_{O \& M}+C_{F u e l}}{\bar{W} \cdot C F \cdot 8760 \frac{h r}{\text { year }}}
$$

In this simplified model, the O\&M costs are constant, thus the O\&M cost fraction (Equation S3) is also constant.

$$
F_{O \& M}=\frac{C_{O \& M}}{C_{\text {geothermal }}}
$$


As the fuel costs for a geothermal facility are zero, Equations S2 and S3 can be combined into Equation S4.

$$
L C O E=\frac{C_{\text {geothermal }}}{\bar{W}} \cdot \frac{C R F+F_{O \& M}}{C F \cdot 8760}
$$

The first term in Equation S4 is the specific capital cost, $S p C C$, given in Equation S5. The second term in Equation $\mathrm{S} 4$ is the rate factor, $R F$, which is also constant (Equation $\mathrm{S6}$ ).

$$
\begin{aligned}
& \text { SpCC }=\frac{C_{\text {geothermal }}}{\bar{W}} \\
& R F=\frac{L C O E}{S p C C}=\frac{C R F+F_{O \& M}}{C F \cdot 8760}
\end{aligned}
$$

The rate factor is used to easily adjust from specific capital cost to LCOE. As the specific capital cost does not depend on financing assumptions, reporting electric cost in terms of the specific capital cost is a more direct way to compare results than LCOE. Thus, we encourage the reporting of electric cost in terms of specific capital cost. For the Lazard financing assumptions of $9.6 \%$ WACC, $4.5 \%$ O\&M cost fraction, 25 year financial lifetime, and $85 \%$ capacity factor, the rate factor is $20 \times 10^{-6} \mathrm{hr}^{-1}$. So a geothermal power plant with a specific capital cost of $4 \mathrm{M} \$ / \mathrm{MW}_{\mathrm{e}}$ will have an LCOE of $80 \$ / \mathrm{MW}_{\mathrm{e}}-\mathrm{h}$, using Lazard financing assumptions.

The Capital Recovery Factor, given in Equation S7, converts a single present value $(P)$ into FP number of constant annualized values $(A)$ in the future at discount rate, $d$. For instance, assume a 25 year loan $(F P=25)$ for $\$ 100$ is secured at a $9.6 \%$ interest rate $(d=0.096)$. In this case, the CRF is 0.107 , meaning the debt service will be $\$ 10.70$ a year for 25 years. The capital recovery factor is sometimes called the fixed charge rate $(F C R)$, but they are identical (Blumsack, 2020).

$$
C R F=\frac{A}{P}=\frac{d \cdot(1+d)^{F P}}{(1+d)^{F P}-1}
$$

In genGEO, we estimate the O\&M cost fraction to be $5.5 \%\left(F_{O \& M}=0.055\right.$, Section S4). It can then be seen from Equation S4 that if the CRF is 0.11 , the O\&M costs incurred annually can be as substantial a contribution to LCOE as the debt and equity payments.

Financing of a project is often done through a combination of debt and equity. Debt is preferred as it has the advantage of retaining control of the company and having a finite payback period, but it can be very difficult to secure debt for $100 \%$ of the project cost without some equity to use as debt collateral. Conversely, equity can be easier to secure, but might have a higher cost because either: a) the equity cost (discount rate) is higher, b) unlike debt interest, equity interest is not tax deductible in the U.S., and c) equity cost usually has indefinite repayment terms. A $60 \% / 40 \%$ debt/equity financing scheme is commonly assumed.

The weighted average cost of capital, $W A C C$, is a weighted discount rate combining both the cost of debt (discount rate of debt), $d_{D}$, and the cost of equity (discount rate of equity), $d_{E}$ (Equation S8). The values $F_{D}$ and $F_{E}$ are the fractions of debt and equity, respectively, which must sum to one (Equation S9). Note that if the project is financed $100 \%$ by debt $\left(F_{D}=1\right)$, the weighted average cost of capital is equivalent to the debt cost. 


$$
\begin{aligned}
& W A C C=d=F_{D} \cdot d_{D}+F_{E} \cdot d_{E} \\
& F_{D}+F_{E}=1
\end{aligned}
$$

After the financing period is complete, the debt payments stop, but equity and O\&M payments continue. To calculate the new, post-financing rate factor, recalculate the LCOE using a WACC reduced by a factor of $F_{D}$ in place of the $C R F$, shown in Equation $S 10$. For instance, assuming a debt fraction of $60 \%\left(F_{D}=0.6\right)$, the Lazard WACC reduces by $60 \%$ from $9.6 \%$ to $3.8 \%$. In this case, the Lazard rate factor reduces from 20 to $12 \times 10^{-6} \mathrm{hr}^{-1}$ after debt financing is complete.

$$
R F_{\text {post }- \text { financing }}=\frac{L C O E}{S p C C}=\frac{\left(1-F_{D}\right) \cdot W A C C+F_{O \& M}}{C F \cdot 8760}
$$

It is important to recognize that LCOE does not decrease to zero after all debt is paid. O\&M costs and equity payments are substantial and will continue after debt is paid. Additionally, this analysis does not take into account capital improvements which must occur at on aging equipment. Thus, any post-financing LCOE calculations must be made with care. genGEO only calculates LCOE during the financing period.

Although the simplified model described in this section does not consider income tax incentives, it also neglects income taxes on electricity revenue. In reality, electricity revenue will be taxed at the corporate tax rate, increasing the break-even price of electricity. Tax incentives are in the form of avoided income taxes, and can at maximum be equal to the income taxes which would have been paid on revenue. Thus, by neglecting both income taxes and income tax incentives, this method essentially assumes that all income taxes are recovered through incentives.

\section{S2.2 Balance-sheet LCOE Model}

The balance-sheet Levelized Cost of Electricity (LCOE) model calculates the cashflows each year for a geothermal business. It very flexibly incorporates changing costs and power generation values for each year in a plant lifetime while making fewer assumptions. For instance, the balancesheet model can easily account for non-levelized MACRS depreciation tax incentives which often only occur within the first six years of a geothermal plant's operation.

In the balance-sheet model, the cashflow is calculated for every year of the financing period, $F P$. The Levelized Cost of Electricity (LCOE) is the electricity sales rate during the financing period which provides a Net Present Value (NPV) of zero. An iterative approach is needed to solve for LCOE, adjusting the LCOE until the NPV is zero. This methodology is adopted from Lazard (2019).

For any year, $y$, the "Earnings before Interest, Tax, Depreciation, and Amortization", EBITDAy, is the product of the integral of power generated for every hour, $h$, of that year and the LCOE, less

the O\&M cost, $C_{O \& M, y}$ of that year. This relation is given by Equation $\mathrm{S} 11$ when the power sold ever hour of the year, $\dot{W}_{h, y}$, is known. Alternately, Equation $\mathrm{S} 12$ is used if only the plant capacity, $\bar{W}$, and capacity factor, $C F$, are known.

$$
\operatorname{EBITD} A_{y}=\operatorname{LCOE} \cdot\left[\int_{h=1}^{8760} \dot{W}_{h, y} \cdot d h\right]-C_{O \& M, y}
$$




$$
E B I T D A_{y}=L C O E \cdot[\bar{W} \cdot C F \cdot 8760]-C_{O \& M, y}
$$

The O\&M cost, $C_{O \& M, y}$, may be escalated each year, given in Equation $\mathrm{S} 13$, where $E R$ is the escalation rate. The escalation rate often is assumed to be the inflation rate.

$$
C_{O \& M, y}=(1+E R)^{y-1} \cdot C_{O \& M}
$$

The levelized debt service, $D S$, for all years is the product of the debt fraction, $F_{D}$, geothermal plant capital cost, $C_{\text {geothermal }}$, and the Capital Recovery Factor (Equation S14). The CRF (Equation $\mathrm{S} 7$ ) is evaluated using the financing period, $F P$, and the debt cost, $d_{D}$.

$$
D S=F_{D} \cdot C_{\text {geothermal }} \cdot C R F
$$

The debt interest paid in any year, $D I_{y}$, is the product of the remaining debt principal and the debt cost, given in Equation S15. The remaining debt principal is the starting debt total less the sum of debt principal paid, $D P_{y}$, in the previous years.

$$
D I_{y}=d_{D} \cdot\left[F_{D} \cdot C_{g e o t h e r m a l}-\sum_{t=1}^{y-1} D P_{t}\right]
$$

For any year, the debt principal paid, $D P_{y}$, is the debt service less the debt interest, $D I_{y}$, given in Equation S16.

$$
D P_{y}=D S-D I_{y}
$$

The taxable income of any year, $T I_{y}$, is the ETITDA less the depreciation tax deduction, $D T D_{y}$, and less the debt interest deduction in that year, $D I_{y}$, given in Equation $\mathrm{S} 17$.

$$
T I_{y}=E B I T D A_{y}-D T D_{y}-D I_{y}
$$

The depreciation tax deduction is calculated according to the standard Modified Accelerated Cost Recovery System (MACRS) tables. A geothermal power plant is commonly assumed to be deductible using a '5-year' recovery period. The depreciation tax deduction, $D T D_{y}$, is the product of the MACRS coefficient, $M A C R S_{y}$, given in Table $S 3$ and the total capital cost of the geothermal plant (Equation S18).

$$
D T D_{y}=\operatorname{MACRS}_{y} \cdot C_{\text {geothermal }}
$$

Table S3: MACRS coefficients.

\begin{tabular}{|ll|}
\hline Year, $y$ & MACRS $_{\mathbf{y}}$ \\
\hline $\mathbf{1}$ & 0.20 \\
\hline $\mathbf{2}$ & 0.32 \\
\hline $\mathbf{3}$ & 0.192 \\
\hline $\mathbf{4}$ & 0.1152 \\
\hline $\mathbf{5}$ & 0.1152 \\
\hline $\mathbf{6}$ & 0.576 \\
\hline $\mathbf{7 +}$ & 0 \\
\hline
\end{tabular}


The Income Tax for any year, $I T_{y}$, is the product of taxable income, $T I_{y}$, and the tax rate, $T R$, given in Equation S19.

$$
I T_{y}=T I_{y} \cdot T R
$$

The depreciation tax deduction and interest deduction often reduce the taxable income to negative values. Tax incentives may not be realized from negative taxable income. Thus, we assume the company has other positive taxable income which may be combined with this negative taxable income to still benefit from this deduction.

The "After-tax Net Equity Cashflow" $\left(A T N E C_{y}\right)$ is the surplus (if positive) of cashflow which may be distributed to the equity holders, if positive. It is the EBITDA less the debt service and less the taxes, given in Equation S20.

$$
A T N E C_{y}=E B I T D A_{y}-D S_{y}-I T_{y}
$$

The Net Present Value (NPV) is the sum of the After-tax Net Equity Cashflows for every year, brought to present values using the equity cost, $d_{E}$, less the initial equity amount $\left(F_{E} \cdot C_{\text {geothermal }}\right)$, given in Equation S21.

$$
N P V=\left[\sum_{y=1}^{F P} \frac{A T N E C_{y}}{\left(1+d_{E}\right)^{y}}\right]-F_{E} \cdot C_{g e o t h e r m a l}
$$

By definition, the Net Present Value is zero when calculating the LCOE. Thus, this method requires an iterative solution to converge on the LCOE where the NPV is zero (Equation S22).

$$
N P V=0
$$

\section{S2.3 Typical LCOE Parameters}

When comparing any LCOE against another (i.e., geothermal vs geothermal, geothermal vs natural gas), identical financing assumptions and LCOE equations must be made within each LCOE calculation to ensure honest comparability. For instance, for two estimates with identical capital costs, the LCOE increases by $60 \%$ when increasing the discount rate from $5 \%$ to $10 \%$. The LCOE assumptions for common geothermal electricity models and the proposed "LIKELY" values for genGEO are given in Table S4. Lazard (2019) financing assumptions need to be used to directly compare to other LCOEs calculated with Lazard financing assumptions.

The Ormat 2019 annual report provides sufficient information to estimate their WACC, which we assume is representative of the geothermal industry (Ormat, 2020a). Ormat reports $1536 \mathrm{M} \$$ debt at an average interest rate of $5.1 \%$ and $1524 \mathrm{M} \$$ equity at an average rate of $2.1 \%$, resulting in a WACC of $3.6 \%$. Thus, a "LIKELY" WACC of $4 \%$ is expected for the geothermal industry. These "LIKELY" LCOE values may only be compared against LCOEs calculated with the same financing assumptions.

In addition to the assumed financing parameters, the geothermal capital cost, $C_{\text {geothermal }}$, and the yearly geothermal O\&M cost, $C_{O \& M}$ are needed to calculate LCOE. In the following sections of 
this supplemental information, we describe the genGEO model calculation of capital cost (Section 3) and O\&M cost (Section 4).

Table S4: LCOE Assumptions from Lazard (2019), LIKELY, GETEM, and GEOPHIRES.

\begin{tabular}{|c|c|c|c|c|c|}
\hline Parameter & Symbol & $\begin{array}{l}\text { Lazard } \\
(2019)\end{array}$ & LIKELY & GETEM & GEOPHIRES \\
\hline O\&M Escalation Rate* & $E R$ & $2.25 \%$ & $--^{a}, 2 \%$ b & $0 \%$ & $--^{c}, 2 \%{ }^{d}$ \\
\hline Financing Period & $F P$ & 25 years & 25 years & 30 years & 30 years \\
\hline Capacity Factor & $C F$ & 0.85 & 0.95 & 0.95 & 0.90 \\
\hline Debt & $F_{D}$ & $60 \%$ & $60 \%$ & $100 \%$ & $100 \%^{c}, 50 \%{ }^{d}$ \\
\hline Cost of Debt* & $d_{D}$ & $8 \%$ & $5 \%$ & $7 \%$ & $7 \%{ }^{c}, 5 \% d$ \\
\hline Equity & $F_{E}$ & $40 \%$ & $40 \%$ & $0 \%$ & $0 \%^{c}, 50 \%{ }^{d}$ \\
\hline Cost of Equity* & $d_{E}$ & $12 \%$ & $2.5 \%$ & -- & $10 \% d$ \\
\hline WACC* & $d$ & $9.6 \%$ & $4 \%$ & $7 \%$ & $7 \%{ }^{c}, 7.5 \%$ d \\
\hline O\&M Cost Fraction* & $F_{O \& M}$ & $4.5 \%$ & $5.5 \%$ & $3.0^{* *}$ & $5.6^{* *}$ \\
\hline Combined Tax Rate & $T R$ & $40 \%$ & $--^{a}, 40 \%$ b & $39.2 \%$ & $30 \%$ \\
\hline Depreciation Schedule & - & $\begin{array}{l}\text { 5-year } \\
\text { MACRS }\end{array}$ & $\begin{array}{l}\text { none }^{a}, \\
\text { 5-year } \\
\text { MACRS }^{b}\end{array}$ & $\begin{array}{l}\text { 5-year } \\
\text { MACRS }\end{array}$ & $\begin{array}{l}\text { none }^{c} \\
\text { 30-year } \\
\text { straight-line }^{d}\end{array}$ \\
\hline \multicolumn{6}{|c|}{$\begin{array}{l}\text { *per year } \\
{ }^{* *} \text { Calculated, variable in model (see Section S4) } \\
\text { asimple LCOE Model (Section S2.1) } \\
\text { bBalance Sheet LCOE Model (Section S2.2) } \\
\text { "Standard Levelized Cost Model (Beckers and McCabe, 2019) } \\
\text { dBICYCLE Levelized Cost Model (Beckers and McCabe, 2019) }\end{array}$} \\
\hline
\end{tabular}




\section{S3. Capital Cost Model}

In genGEO, the capital cost of a geothermal power plant has six cost components (Equation S23). These are: surface plant cost, $C_{\text {Plant }}$ (Section S3.2), well cost, $C_{W e l l s}$ (Section S3.3), surface piping system cost, $C_{\text {SurfacePiping }}$ (Section S3.4), wellfield cost, $C_{\text {Wellfield }}$ (Section S3.5), exploration cost, $C_{\text {Exploration }}$ (Section S3.6), and stimulation cost, $C_{\text {Stimulation }}$ (Section S3.7).

$C_{\text {Geothermal }}=C_{\text {Plant }}+C_{\text {Wells }}+C_{\text {SurfacePiping }}+C_{\text {Wellfield }}+C_{\text {Exploration }}+C_{\text {Stimulation }}$

Often, when developing a geothermal project, some of the exploration and wellfield development has already occurred, and thus those costs are not incurred a second time. As a result, in these so-called "brownfield" projects, these costs can be removed from the geothermal project cost. Conversely, if a geothermal project is planned in an undeveloped field, these are called "greenfield" projects.

Reservoir stimulation costs are included in genGEO for completeness, though they are only used in so-called Enhanced Geothermal Systems (EGS). In EGS, the low-permeability basement rock is artificially fractured and thus an additional cost is incurred. However, stimulation is not needed in power plants that use fracture-based or sedimentary geothermal resources and thus $C_{\text {Stimulation }}$ in these systems is zero.

The genGEO surface plant capital cost model is a bottom-up cost model, meaning the cost of the essential equipment is estimated and upscaled to determine the total cost. In this way, the capital costs have a fundamental cost basis and modifications to the cost of fundamental equipment can be propagated through the model. For instance, the CPG surface power plant cost is substantively the cost of three components (i.e. turbine, cooling towers, and injection pump) and the cost of each component is determined from the thermodynamic data of the power cycle. Then a multiplier is applied to the primary equipment to account for construction, labor, etc. So when the power generation of the turbine increases, or the approach temperature of the cooling tower increases, the cost of the surface plant reflects those changes.

In general, the NETL reports provide excellent equipment cost and estimation values and concepts which are applied throughout the surface plant capital cost methodology. Despite the NETL reports being for different electricity generation technologies (i.e. coal and natural gas), the NETL reports provide a level of detail and transparency which is not available in GETEM. For instance, the NETL values for turbine cost are easily extended to an ORC, whereas the GETEM second-law regression of turbine cost is not useful to estimate the cost of a turbine. Thus, the cost estimation strategy of the NETL reports reflects much of the strategy adopted within genGEO.

\section{S3.1 Indirect Costs and Contingency}

\section{S3.1.1 Indirect Cost, $X_{I C}$}

All capital cost values provided in genGEO have some accounting for indirect costs and contingency. Indirect costs, which NETL (2011, 2019a) calls Engineering, Procurement, and Construction Management (EPCM) costs, are necessary costs for administration, planning, and design that are separate from the plant material and labor costs. GETEM and GEOPHIRES generally assume indirect costs are $12 \%$ of the installed cost (i.e. bare erected cost). For example, 
if surface piping has a $1 \mathrm{M} \$$ installed cost (i.e. labor and materials), it will likely cost an additional $0.12 \mathrm{M} \$$ to draw engineering plans, procure the materials, and supervise the construction. Similarly, NETL (2012) assumes indirect cost is $9 \%$ of installed cost. We assume the GETEM indirect cost multiplier of $12 \%$ in genGEO $\left(X_{I C}=1.12\right)$, unless explicitly stated otherwise.

Indirect cost multipliers for all components of the capital cost are given in Table S5.

\section{S3.1.2 Contingency Cost, $X_{P C}$}

Separate from indirect costs are contingency costs. NETL (2011) best describes contingency costs:

"Process and project contingencies are included in estimates to account for unknown costs that are omitted or unforeseen due to a lack of complete project definition and engineering. Contingencies are added because experience has shown that such costs are likely, and expected, to be incurred even though they cannot be explicitly determined at the time the estimate is prepared."

Project contingency accounts for additional costs during construction. For example, an unforeseen postal error may delay project permit issuance or a bit may twist-off during well drilling, both incurring additional expense that would have otherwise been unbudgeted. As a result, all capital costs must have a non-zero project contingency attached to them. GETEM, GEOPHIRES, and NETL (2012) assume 15\% project contingency $(P C)$, thus we assume the same in genGEO (i.e. $X_{P C}=1.15$ ).

Process contingency accounts for additional costs for un-proven technology which does not operate as expected. NETL includes non-zero process contingency in some cases for novel, unproven fossil power generation technology. GETEM and GEOPHIRES exclude process contingency. In genGEO, we have no basis for estimation of the process contingency and therefore neglect it.

Table S5 shows multipliers for all indirect costs and contingency costs used in genGEO.

Table S5: All indirect cost (IC) and contingency cost (PC) multipliers in genGEO.

\begin{tabular}{|llll|} 
Component & Subscript & $\begin{array}{l}\text { Indirect Cost } \\
\text { Multiplier, } X_{I C}\end{array}$ & $\begin{array}{l}\text { Contingency Cost } \\
\text { Multiplier, } X_{P C}\end{array}$ \\
\hline $\begin{array}{l}\text { Surface } \\
\text { Plant }\end{array}$ & $\mathrm{p}$ & $X_{I C-p}=1.12$ & $X_{P C-p}=1.15$ \\
\hline Wells & well & $X_{I C-\text { well }}=1.05$ & $X_{P C-\text { well }}=1.15$ \\
\hline $\begin{array}{l}\text { Surface } \\
\text { Piping }\end{array}$ & pipe & $X_{I C-\text { pipe }}=1.12$ & $X_{P C-\text { pipe }}=1.15$ \\
\hline Wellfield & wf & $X_{I C-w f}=1.05$ & $X_{P C-w f}=1.15$ \\
\hline Exploration & expl & $X_{I C-\text { expl }}=1.05$ & $X_{P C-\text { expl }}=1.15$ \\
\hline Stimulation & stim & $X_{I C-\text { stim }}=1.05$ & $X_{P C-\text { stim }}=1.15$ \\
\hline
\end{tabular}




\section{S3.2 Surface Plant, $C_{\text {Plant }}$}

There are four essential components to any Rankine cycle: a turbine, a pump, a heat exchanger, and a cooling tower. Costs for all four components are included in the surface plant cost.

The surface plant cost calculation in genGEO is adopted from National Energy Technology Laboratory "Power Plant Cost Estimation Methodology" (NETL, 2011; 2019a). This methodology is a bottom-up estimation approach that estimates the cost of equipment and then applies scaling factors to account for construction, indirect costs, and contingency. A similar approach is applied in GETEM. However, GETEM has some inconsistencies and less supporting documentation.

There are four steps to calculate the total cost of a surface plant:

1. The cost of the primary equipment (PEC), $C_{\text {Plant-PEC }}$, is found. The primary equipment consists of the main equipment in the power cycle. (Equation S24)

2. The primary equipment cost is multiplied by the secondary equipment factor to add on the additional cost of secondary equipment (e.g. separators, valves, etc.). The result is the surface plant total equipment cost (TEC), $C_{\text {Plant-TEC }}$ (Equation S25)

3. The total equipment cost is multiplied by construction factors for labor, materials, sales tax, and equipment freight. The result is the surface plant bare erected cost (BEC), $C_{\text {Plant-BEC }}$ (Equation S26)

4. The bare erected cost is multiplied by factors to account for indirect cost, process contingency, and project contingency. The result is the total plant cost (TPC) of the surface plant, $C_{\text {Plant }}$. (Equation S27)

Similar to GETEM, the primary equipment cost (PEC), $C_{\text {Plant-PEC }}$, in genGEO is the sum of the major equipment, given in Equation S24. In the case of an ORC, these are: turbine, pump, geofluid heat exchanger, and cooling tower. Note: The major equipment parts will vary by cycle design. For example, a binary system might have two pumps: an ORC circulation pump and a lineshaft production pump. Similarly, a CPG system may only have a turbine generator and cooling tower. Equation S24 should be adapted as needed for the specific power cycle for which costs are being estimated.

$$
C_{\text {Plant }-P E C}=C_{T-G}+C_{\text {Pump }}+C_{C-\text { Tower }}+C_{\text {HeatExchanger }}+\ldots
$$

The total equipment cost (TEC), $C_{\text {Plant-TEC }}$, is the primary equipment cost (PEC) scaled by a factor, $X_{S E}$, to account for secondary equipment such as: separators, pumps, valves, control systems, building, etc. The secondary equipment is different from the construction materials such as: raw steel, piping, concrete, aggregate, wiring, which are considered separately. The total equipment cost in genGEO is given by Equation $\mathrm{S} 25$.

$$
C_{\text {Plant-TEC }}=X_{S E} \cdot C_{P l a n t-P E C}
$$

The secondary equipment cost fraction, $X_{S E}$, in genGEO is taken from NETL (2012) cost estimates for new coal plants. In each of the 14 subsystems identified in the pulverized coal with a subcritical Rankine cycle and without $\mathrm{CO}_{2}$ capture system (Case 9) by NETL (2012), the single largest piece of equipment was compared against the total equipment cost for the subsystem. On 
average, the total equipment cost was $39 \%$ greater than the single largest piece of equipment, and thus we set $X_{S E}=1.39$.

The bare erected cost (BEC), $C_{\text {Plant-BEC }}$, is the total construction cost of the surface plant itself, including equipment, materials, and labor, given in Equation S26, where $X_{C L}$ is the construction labor and fringe cost, $X_{C M}$ is the construction material cost, $X_{S T}$ is the sales tax, and $X_{F}$ is the freight cost. Sales tax and freight cost are not considered in NETL, but are considered in GETEM, thus these costs are included in genGEO.

$$
C_{\text {Plant-BEC }}=C_{\text {Plant-TEC }} \cdot\left(1+X_{C L}+X_{C M}+X_{S T}+X_{F}\right)
$$

In genGEO, labor is $58 \%$ of the total equipment cost $\left(X_{C L}=0.58\right)$ and construction materials are $11 \%$ of the total equipment cost $\left(X_{C M}=0.11\right)$, determined from the same NETL (2012) subcritical coal (Case 9) cost estimates. GETEM assumes $5 \%$ sales tax on equipment; however, NETL (2011) assumes sales tax is recuperated (i.e. 0\%). Additionally, GETEM assumes $5 \%$ freight on primary equipment cost (4\% when applied to total equipment cost), which NETL also neglects (freight can arguably be included as a procurement cost). In genGEO, we compromise and neglect sales tax but include freight $\left(X_{S T}=0.00 ; X_{F}=0.04\right)$. The cost multipliers are summarized in Table S6. The total surface plant cost (TPC), $C_{\text {Plant }}$, is given in Equation S27.

$$
C_{\text {Plant }}=X_{P C-p} \cdot X_{I C-p} \cdot C_{P l a n t-B E C}
$$

In genGEO, we adopt the GETEM values of a $12 \%$ indirect cost multiplier $\left(X_{I C-p}=1.12\right)$ and $15 \%$ project contingency multiplier $\left(X_{P C-p}=1.15\right)$ (see Table S5).

\begin{tabular}{|c|c|c|}
\hline $\begin{array}{l}\text { Cost } \\
\text { Multiplier }\end{array}$ & Value & Description \\
\hline$X_{S E}$ & 1.39 & $\begin{array}{l}\text { Secondary Equipment Cost (control } \\
\text { system, pumps, valves, building, etc.) }\end{array}$ \\
\hline$X_{C L}$ & 0.58 & $\begin{array}{l}\text { Construction Labor Cost (building and } \\
\text { assembling, including fringe) }\end{array}$ \\
\hline$X_{C M}$ & 0.11 & $\begin{array}{l}\text { Construction Material Cost (concrete, } \\
\text { pipe, wire, rentals, etc.) }\end{array}$ \\
\hline$X_{S T}$ & 0.00 & Sales Tax \\
\hline$X_{F}$ & 0.04 & Equipment Freight \\
\hline
\end{tabular}

Table S6: Equipment and construction cost fractions.

\section{Comparison with GETEM Cost Fractions}

As part of our literature review, the NETL-derived cost fractions of Table S6 are compared against GETEM values. GETEM provides five multipliers which grow the primary equipment cost: material cost multiplier (0.70), Labor cost multiplier (0.39), construction materials multiplier $(0.25)$, sales tax (0.05), and freight (0.05). The source of these numbers is not well documented as they originate from ASPEN simulations. Additionally, the difference between "material cost," "other construction," and "construction materials" is not clear. Thus, these GETEM values are only used in this review for validation of the NETL-derived cost fractions that are used within genGEO. 
In GETEM, the bare erected cost divided by the primary equipment cost is the sum of all the multiplier values, i.e. $(1+0.70+0.39+0.25+0.05+0.05)=2.44$, or $244 \%$. In the genGEO methodology described here, the bare erected cost divided by the primary equipment cost is $(1.39 \cdot(1+0.58+0.11+0.00+0.04))=2.40$, or $240 \%$. Thus, the two models agree to less than $2 \%$ of each other. GEOPHIRES does not estimate surface plant costs based on an up-scaling of sub-component costs and therefore cannot be compared.

\section{Comparison with "Chemical Process Design and Integration" (Smith, 2016)}

Smith (2016) is a chemical and process engineering standard that provides a similar system of scaling factors to determine overall project cost from individual equipment cost. Smith (2016) estimates that the bare erected cost divided by primary equipment cost for a fluid processing system is 3.4 (see Smith's Table 2.7). In genGEO, this fraction is 2.40 , which is $29 \%$ lower than Smith (2016). Smith (2016) has large multipliers for piping and utilities, perhaps due to having chemical processing as its target audience. If the piping and utility costs are halved, the ratio of bare erected cost to primary equipment cost reduces from 3.4 to 2.8. Nonetheless, this alternate methodology provides a different, higher estimate, and this value could justifiably be used as a conservative upper bound, depending on the needs of the user.

\section{S3.2.1 Turbine-Generator, $\boldsymbol{C}_{T-G}$}

A turbine $(T)$ is an expansion device which converts the energy in an expanding fluid into shaft power. Typically, a generator $(G)$ is attached to the shaft to convert the shaft power to electrical power. This combined turbine-generator ( $T-G)$ set is an essential component of a power generation cycle as it provides the electricity to sell.

We found three primary sources of turbine-generator costs in our review: GETEM, NETL cost reports for 'Bituminous Coal Power Plants' (NETL, 2007; 2010; 2012; 2015; 2019b), and NETL process equipment costs (NETL, 2002). GETEM and NETL (2002) are based on ASPEN simulations while NETL (2007-2019b) uses an undisclosed combination of ASPEN simulations and vendor quotes. There is not enough information in these models to make any cost distinction between turbine working fluids or pressures. Thus, both supercritical and subcritical steam turbine costs from all years are included (i.e. NETL cases 9, 10, 11, 12, B11A, B11B, B12A, and B12B).

Table S7: Comparison of different turbine-generator cost relations.

\begin{tabular}{|c|c|c|c|}
\hline Component & Source & Cost & Notes \\
\hline Turbine, Binary & GETEM & $C=7400 \cdot\left(\dot{W}_{\text {Turbine }}\right)^{0.6}$ & $\begin{array}{l}\text { Up to } 11 \mathrm{MW}_{\mathrm{e}} \\
\text { Cost in } 2002 \$\end{array}$ \\
\hline Generator, Binary & GETEM & $C=1800 \cdot\left(\dot{W}_{\text {Turbine }}\right)^{0.67}$ & Cost in $2002 \$$ \\
\hline Turbine, Flash & GETEM & $C=2830 \cdot\left(\dot{W}_{\text {Turbine }}\right)^{0.745}$ & Cost in $2002 \$$ \\
\hline Generator, Flash & GETEM & $C=3680 \cdot\left(\dot{W}_{\text {Turbine }}\right)^{0.617}$ & Cost in $2002 \$$ \\
\hline Turbine, Steam & $\begin{array}{l}\text { NETL } \\
(2007-2019 b)\end{array}$ & $\begin{array}{l}20 \mathrm{~T}-\mathrm{G} \text { units with an } \\
\text { average cost of } 49.6 \mathrm{M} \$ \\
\text { and power of } 643 \mathrm{MW}_{\mathrm{e}}\end{array}$ & $\begin{array}{l}\text { Cost in } 2007 \$ \text {, } \\
2007 \$, 2011 \$ \text {, } \\
2011 \$, 2018 \$\end{array}$ \\
\hline Turbine, Steam & NETL (2002) & $\begin{array}{l}\text { Costs of } 13 \mathrm{~T}-\mathrm{G} \text { units } \\
\text { from } 10 \text { to } 30,000 \mathrm{HP}\end{array}$ & Cost in $1998 \$$ \\
\hline
\end{tabular}


Table S7 shows the relations from GETEM and NETL. Turbine-generator gross power, $\dot{W}_{\text {Turbine }}$, is given in $\mathrm{kW}_{\mathrm{e}}$.

Figure S1 shows the comparison of turbine-generator cost between GETEM and NETL (2002). Cost is reported as specific cost, which is the ratio of total cost to gross turbine power. The GETEM binary (i.e. ORC) turbine-generator specific cost has a minimum, constant cost above $11 \mathrm{MW}_{\mathrm{e}}$, after which the specific cost remains constant. Conversely, the GETEM flash turbine-generator specific cost continuously decreases with turbine size, as is expected with economy of scale. NETL (2002) turbine cost doesn't include a generator cost. Thus NETL (2002) turbine costs are plotted with both GETEM binary and flash generator costs added.

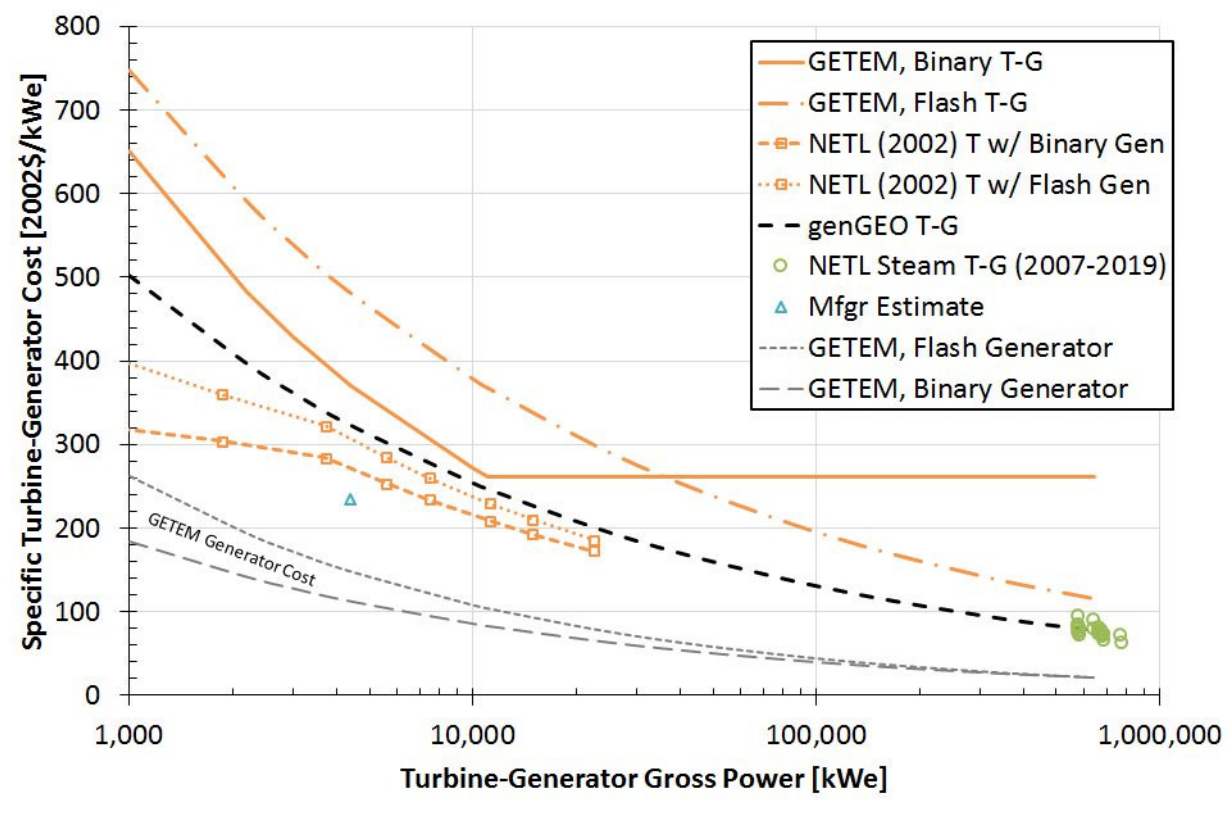

Figure S1: Specific turbine-generator (T-G) cost as a function of gross power output.

In genGEO, the specific turbine-generator cost is the GETEM flash turbine-generator cost, with an added coefficient (i.e. 0.67 ) so the genGEO curve passes through the average NETL coal plant steam turbine cost. It is unclear why GETEM reports two different cost relations for electricity generators: one for the ORC and another for the flash plant. One would expect these generator costs to be independent of working fluid and thus the same for both. We infer that the inconsistency is a result of performing a regression on dissimilar ASPEN-derived datasets. Thus, we adapt the GETEM flash turbine and generator together for use within genGEO. The genGEO turbine-generator cost is given in Equation $\mathrm{S} 28$ and is adjusted using the turbine-generator cost index, $P P I_{T-G}$.

$$
C_{T-G}=0.67 \cdot P P I_{T-G} \cdot\left[S_{T-\{\text { fluid }\}} \cdot 2830 \cdot\left(\dot{W}_{\text {Turbine }}\right)^{0.745}+3680 \cdot\left(\dot{W}_{\text {Turbine }}\right)^{0.617}\right]
$$

The GETEM and NETL turbine costs are for mature turbomachinery with known working fluids. As a result, $20 \%$ is added to the turbine cost in genGEO if geologic $\mathrm{CO}_{2}$ is the working fluid $\left(S_{T-\mathrm{CO} 2}=1.20\right)$. For all others, the un-augmented cost is used $\left(S_{T-\text { others }}=1.00\right)$. 


\section{S3.2.2 Pump, C Cump}

Pumps are used throughout geothermal energy applications. Pumps induce a pressure gradient, causing movement. For example, this can be used to circulate the working fluid within a Rankine cycle (called feed-water or circulation pumps), to produce geofluid up a production well (production pumps), or to pressurize geofluid before reinjection (injection pumps). Circulation and injection pumps tend to be very similar; however, water production pumps are unique because the pump must be located several hundred meters below the surface in the production well to prevent flashing of water.

Two types of production well pumps are used in geothermal power plants: lineshaft and submersible. A lineshaft pump has a motor at the surface connected to a downhole mechanical pump with several hundred meters of shaft. A submersible pump is a combined electric motor and mechanical pump submerged in a well with electric wires running to the surface. Each pump has tradeoffs when compared to the other, for instance: lineshaft pumps are cheaper and last longer, while submersible pumps have higher efficiency (DiPippo, 2015). GETEM only provides costs for lineshaft pumps, so we only consider lineshaft pump cost in genGEO.

In genGEO, the total pump cost, $C_{\text {Pump }}$, is given in Equation $\mathrm{S} 29$ and is a function of the type of pump (surface or lineshaft) and the pump material.

$$
C_{\text {Pump }}=P P I_{\text {Pump }} \cdot S_{\text {Pump }} \cdot C_{\text {Pump-\{Surface,Lineshaft }\}}
$$

Table S8: Pump cost relations.

\begin{tabular}{|c|c|c|}
\hline Component & Source & Cost, $C_{\text {pump }}[2002 \$]$ \\
\hline $\begin{array}{l}\text { Iron Circulation } \\
\text { Pump }\end{array}$ & GETEM & $C=1185 \cdot\left(1.34 \cdot \dot{W}_{\text {Pump }}\right)^{0.767}$ \\
\hline $\begin{array}{l}\text { Iron Injection Pump+ } \\
\left.\text { (C } C_{\text {Pump-Surface }}\right)\end{array}$ & GETEM & $C=1750 \cdot\left(1.34 \cdot \dot{W}_{\text {Pump }}\right)^{0.7}$ \\
\hline $\begin{array}{l}\text { Iron Lineshaft Pump+ } \\
\left.\text { ( } C_{\text {Pump-Lineshaft }}\right)\end{array}$ & GETEM & $\begin{array}{c}C=1750 \cdot\left(1.34 \cdot \dot{W}_{\text {Pump }}\right)^{0.7}+5750 \\
\cdot\left(1.34 \cdot \dot{W}_{\text {Pump }}\right)^{0.2}\end{array}$ \\
\hline $\begin{array}{l}\text { Iron Cooling Loop } \\
\text { Circulation Pumps }\end{array}$ & $\begin{array}{l}\text { NETL } \\
(2007-2019 b)\end{array}$ & $\begin{array}{l}\text { Twenty costs of } 0.8 \mathrm{M} \$ \text { to } 1.5 \mathrm{M} \$ \text { for } 2.2 \text { to } 6.1 \\
\mathrm{MW}_{\mathrm{e}} \text { pumps. }\end{array}$ \\
\hline $\begin{array}{l}\text { Flowserve } \mathrm{CO}_{2} \text { Pump } \\
\text { Cost }\end{array}$ & Vendor Quote & $\begin{array}{l}\text { One } 0.93 \mathrm{M} \$ \text { quote for a } 3 \text {-stage, stainless steel, } \\
50 \text { bar pressure differential, } 84 \% \text { efficiency, } 2.1 \\
\mathrm{MW}_{\mathrm{e}} \mathrm{CO}_{2} \text { pump. }\end{array}$ \\
\hline $\begin{array}{l}\mathrm{CO}_{2} \text { Compressor } \\
\text { Cost }\end{array}$ & $\begin{array}{l}\text { Duc et al. } \\
(2007)\end{array}$ & $C=6950 \cdot\left(1.34 \cdot \dot{W}_{\text {Compressor }}\right)^{0.82}$ \\
\hline $\mathrm{CO}_{2}$ Compressors & $\begin{array}{l}\text { NETL } \\
(2007-2019 b)\end{array}$ & $\begin{array}{l}\text { Ten } \mathrm{CO}_{2} \text { compressor costs of } 8.7 \mathrm{M} \$ \text { to } 13.5 \mathrm{M} \$ \text { for } \\
17.8 \mathrm{MW}_{\mathrm{e}} \text { to } 25.8 \mathrm{MW}_{\mathrm{e}} \text { units. }\end{array}$ \\
\hline
\end{tabular}

All pump cost estimates found in our review are shown in Table S8, two of which, $C_{P u m p \text {,Surface }}$, (i.e. circulation and injection) and $C_{P u m p, \text { Lineshaft }}$, are adopted in genGEO. The pump material 
multiplier, $S_{\text {Pump }}$, adjusts the pump cost when materials other than iron are used. All pump costs are adjusted by the price index for pumps, $P P I_{\text {Pump }}$.

Among all sources compared, the pump costs in genGEO are taken primarily from GETEM. GETEM provides pump relationships for circulation pumps, injection pumps, and lineshaft pumps. Costs for circulation pumps for cooling water are obtained from NETL $(2007 ; 2010 ; 2012 ; 2015$; $2019 b)$. Additionally, to estimate the cost of a $\mathrm{CO}_{2}$ pump, both $\mathrm{CO}_{2}$ compressor and pump costs are analyzed. $\mathrm{CO}_{2}$ compressor costs are obtained from NETL and Duc et al. (2007). $\mathrm{CO}_{2}$ liquid pump cost is obtained from a Flowserve vendor quote. Ultimately, compressor costs were substantially higher than pump costs and thus did not inform the genGEO $\mathrm{CO}_{2}$ pump cost estimate. $\mathrm{CO}_{2}$ compressor cost is only shown for reference.

Table S8 shows the genGEO lineshaft pump cost, $C_{P u m p-L i n e s h a f t}$, is the sum of the GETEM

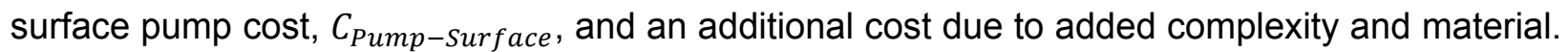
GETEM sets a maximum depth for lineshaft pumps in the production well of $610 \mathrm{~m}$ (2000 ft), which is adopted in genGEO. We assume the lineshaft pump cost is irrespective of pump depth.

Figure S2 compares the cost relationships of Table S8 in terms of specific pump cost. The specific pump cost is the ratio of pump cost to pump power. GETEM provides two different costs for iron circulation and injection pumps which are very similar. Thus, we neglect the GETEM circulation pump relationship and use the injection pump relationship for all surface pumps in genGEO. Additionally, GETEM sets an upper limit of $1.5 \mathrm{MW}_{\mathrm{e}}$ for its injection pump cost relationship; however, when extrapolated, this curve extends nicely through the NETL pump cost data points. Thus, in genGEO, the GETEM surface pump costs are used for all pump sizes.

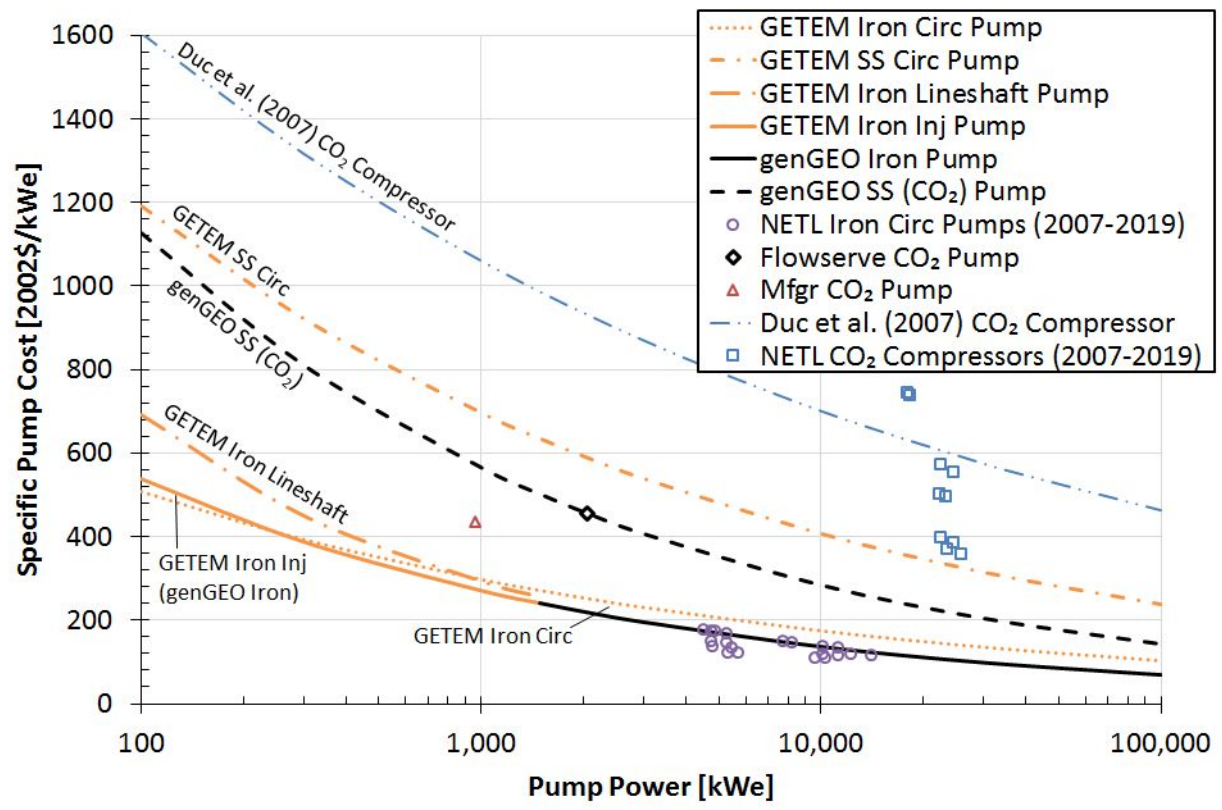

Figure S2: Specific pump cost as a function of pump power. The genGEO iron pump cost is the same as the GETEM iron injection pump cost and passes through the NETL cooling water pump costs. The genGEO stainless pump cost for $\mathrm{CO}_{2}$ is the GETEM iron pump cost multiplied by a factor of 2.09 to fit the Flowserve $\mathrm{CO}_{2}$ pump quote. 


\section{Pump Material Multiplier, $\boldsymbol{S}_{\text {Pump }}$}

Iron pumps are ideally suited to pump non-corrosive liquids, like water or glycol. When pumping other liquids, more expensive materials such as stainless steel are used to limit corrosion. GETEM accounts for this increased cost by applying a material multiplier of $2.35\left(S_{\text {Pump }}=2.35\right)$ to the surface pump cost relationship. Similarly, NETL (2002) recommends material multipliers from 1.43 to 2.00 , depending on the stainless alloy used.

In genGEO, we find a material multiplier of $\left(S_{\text {Pump }}=2.09\right)$ for all non-water applications (e.g. R245fa, $\mathrm{CO}_{2}$ ) by fitting the GETEM surface pump cost to the $\mathrm{CO}_{2}$ Flowserve pump quote, shown in Figure S2. All pump multipliers compared for this review are given in Table S9.

Table S9: Pump material multiplier, S Pump, from different sources and genGEO.

\begin{tabular}{|llll|}
\hline Pump Material & Source & Suitability & Spump \\
\hline Iron & GETEM & e.g. Water, Glycol & 1.00 \\
\hline Stainless Steel & GETEM & e.g. R245fa, $\mathrm{CO}_{2}$ & 2.35 \\
\hline Stainless Steel & NETL $(2002)$ & e.g. R245fa, $\mathrm{CO}_{2}$ & 1.43 to 2.00 \\
\hline Iron & genGEO & e.g. Water, Glycol & 1.00 \\
\hline Stainless Steel & genGEO & e.g. R245fa, $\mathrm{CO}_{2}$ & 2.09 \\
\hline
\end{tabular}

\section{S3.2.3 Cooling/Condensing Tower, $C_{c \text {-Tower }}$}

Cooling and condensing towers are necessary for any power cycle. They are special liquid-to-air heat exchangers that reject the low temperature waste heat from the power cycle to the atmosphere. In a cooling tower, a process liquid is decreasing in temperature as it is cooled, while in a condensing tower, a process liquid is changing phase from gas to liquid.

Cooling and condensing towers can be either wet or dry. A wet cooling tower uses the evaporation of liquid water to remove heat. A dry cooling tower relies only on cooling from atmospheric air forced across the heat exchanger surface. Wet cooling towers tend to be more efficient, but consume water. Thus, dry towers tend to be used in arid regions.

Cooling towers can be either open or closed-loop, while condensing towers can only be closedloop. Open cooling towers are also necessarily wet towers. An open cooling tower directly sprays the process water into atmospheric air where some of it evaporates, cooling the remaining water, which is collected in a basin at the bottom of the tower. In a closed tower, the process liquid and air are always separated by a heat exchange barrier. Open cooling towers have fewer parts and are therefore less expensive; however, they may only be used to cool liquid water.

Lastly, most cooling towers use fans to force air through the tower to maximize heat transfer. Natural convection towers are uncommon as they require very large volumes to allow the air to buoyantly circulate and are thus expensive. We only analyze forced-convection towers in this analysis and quantify the electricity cost (i.e. "parasitic power") they incur to cool the process fluid. The parasitic power is quantified in genGEO using the parasitic power fraction, $\lambda$, shown in Equation S30, which is the ratio of tower parasitic electric power, $\dot{W}_{\text {Tower }}$, to the tower thermal 
heat rejection, $\dot{Q}_{\text {Tower }}$. This parasitic power fraction concept is adopted from Adams et al. (2015) and we use slightly different regression coefficients in this study.

$$
\lambda_{i}=\frac{\dot{W}_{\text {Tower }, i}}{\dot{Q}_{\text {Tower }, i}}
$$

In genGEO, the cost of a cooling or condensing tower is determined by a two-step process: 1) finding the cost of a Baltimore Aircoil Company (BAC) cooling tower with a nominal cooling capacity of $1 \mathrm{MW}_{\text {th }}$, and 2) up-scaling the cost to the cooling capacity required. This allows highfidelity data obtained from BAC to be used to estimate the cost and performance of much larger units. The physics of cooling and condensing towers is the same for any capacity.

Equation S31 illustrates the two-step process used in genGEO to determine the total tower cost, $C_{C-\text {-Tower }}$. The first term in Equation S31 is the cost of a reference BAC cooling tower, $C_{R e f-B A C}$, with a $1 \mathrm{MW}_{\text {th }}$ nominal heat load, $\left(\dot{Q}_{R e f-B A C}=1 M W_{t h}\right)$. Then, the reference unit cost is scaled by the total cooling and condensing heat rejected, $\left(\dot{Q}_{\text {Cooling }}+\dot{Q}_{\text {Condensing }}\right)$. The up-scaling exponent of 0.8 is adopted from the GETEM flash cooling tower cost relation.

$$
C_{C-T o w e r}=C_{R e f-B A C} \cdot\left(\frac{\dot{Q}_{\text {Cooling }}+\dot{Q}_{\text {Condensing }}}{\dot{Q}_{R e f-B A C}}\right)^{0.8}
$$

The cost of the reference BAC tower used in genGEO is given in Equation S32, where $c_{\text {Cooling }}$ and $c_{\text {Condensing }}$ are the specific costs of the reference BAC cooling and condensing towers, respectively. The specific cost is the ratio of tower cost to the heat rejected. Similarly, the cooling tower load fraction, $F_{\text {Cooling }}$, is the ratio of cooling tower heat load to total tower heat load, given in Equation S33. All tower costs are adjusted using process engineering cost index, $P P I_{P E}$, which our review discovered was not consistently applied to cooling tower cost in GETEM. The process engineering index represents cooling tower construction most appropriately, thus we adopt that index in genGEO.

$$
\begin{aligned}
& C_{\text {Ref-BAC }}=P P I_{P E} \cdot \dot{Q}_{\text {Ref-BAC }} \cdot T D C \cdot\left(F_{\text {Cooling }} \cdot c_{\text {Cooling }}+\left(1-F_{\text {Cooling }}\right) \cdot c_{\text {Condensing }}\right) \\
& F_{\text {Cooling }}=\frac{\dot{Q}_{\text {Cooling }}}{\dot{Q}_{\text {cooling }}+\dot{Q}_{\text {Condensing }}}
\end{aligned}
$$

The 'Tower Design Coefficient', $T D C$, is a multiplier which adjusts the cooling tower cost due to an open or closed tower design. The tower design coefficients are shown in Table S10.

Table S10: Tower Design Coefficients (TDC) for cooling tower designs.

\begin{tabular}{|ll|}
\hline Design & $\begin{array}{l}\text { Tower Design Coefficient, } \\
\text { TDC }\end{array}$ \\
\hline Open Water & 0.252 \\
\hline $\begin{array}{l}\text { Closed-circuit Glycol or R22 } \\
\text { (base quote) }\end{array}$ & 1.00 \\
\hline Closed-circuit $\mathbf{C O}_{2}$ & 1.2 \\
\hline
\end{tabular}


The cost and thermodynamic performance data for BAC towers we obtained is only for closedcircuit glycol and R22 towers. Therefore the closed-circuit design coefficient is one. The genGEO open water tower design coefficient, $T D C$, of 0.252 is found so the genGEO cost line in Figure S3 passes through the average NETL specific tower cost from coal plants.

We approximate a Tower Design Coefficient of 1.2 when $\mathrm{CO}_{2}$ is used in a closed-circuit cooling tower instead of glycol or R22. This $20 \%$ increase in cost is estimated due to the higher pressures of $\mathrm{CO}_{2}$ condensation. The BAC PC2 condensers are rated for $2.8 \mathrm{MPa}$ maximum working pressure, while we expect typical $\mathrm{CO}_{2}$ condensing pressures to be about $6 \mathrm{MPa}$, and possibly as high as $10 \mathrm{MPa}$. Building equipment for higher pressures involves thicker tubing walls, which both increase the cost of material and decrease the heat exchanger effectiveness, increasing the cooling tower size required.

Figure S3 shows the cooling tower specific costs compared in this analysis. All costs are shown for tower standard design conditions of a $15^{\circ} \mathrm{C}$ ambient temperature, a $7^{\circ} \mathrm{C}$ approach temperature, and a $4^{\circ} \mathrm{C}$ temperature range. The single 'BAC' data point is the specific cost of the $1 \mathrm{MW}_{\text {th }}$ reference unit. The forty-five cooling towers for natural gas and coal plants from NETL (2007-2019b) are also shown. Pidaparti et al. (2015) reports several vendor quotes for an open wet cooling tower from Delta Cooling Towers. Additionally, the four binary cooling tower cost data points shown result from complete GETEM simulations with geofluid (GF) production temperatures between $125^{\circ} \mathrm{C}$ and $200^{\circ} \mathrm{C}$.

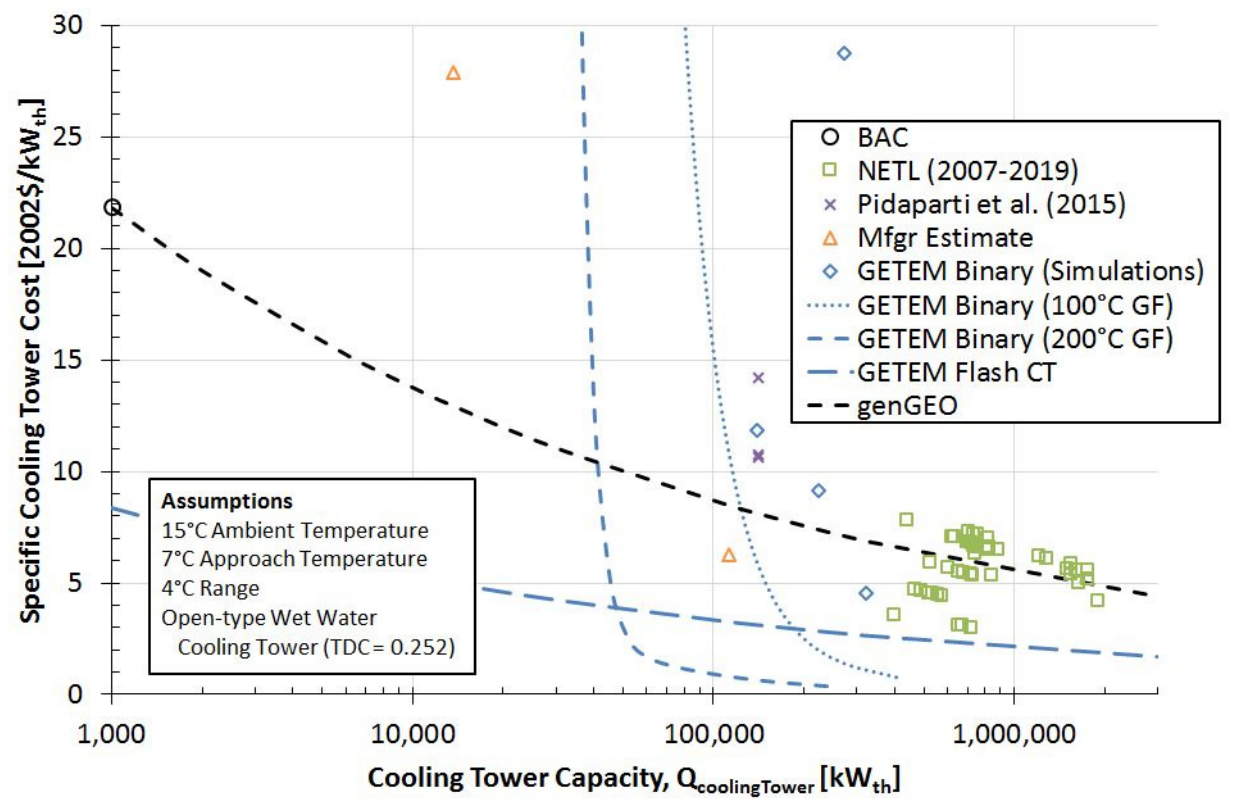

Figure S3: The specific cooling tower cost of an open-type wet water cooling tower as a function of capacity. All towers were compared using a $15^{\circ} \mathrm{C}$ approach temperature difference, a $7^{\circ} \mathrm{C}$ temperature range, and a $15^{\circ} \mathrm{C}$ ambient wet bulb temperature.

The GETEM binary costs relationships are derived from ASPEN simulations with a dependence on second law efficiency which had to be assumed for this comparison, so they are likely extrapolated beyond their useful range. Conversely, the GETEM flash cooling tower estimate is 
lower than most costs, but scales appropriately with capacity. The bulk of the NETL cooling towers are between $400 \mathrm{MW}_{\text {th }}$ and $2000 \mathrm{MW}_{\text {th }}$.

More information on the BAC cooling tower cost estimates and methodology for comparing cooling tower cost estimates with different design conditions is described below.

\section{Baltimore Aircoil Specific Cost, C $_{\text {cooling }}$ and Condensing $_{\text {Con }}$}

Baltimore Aircoil Company (BAC) is a manufacturer of cooling and condensing towers which provides extensive online documentation on the performance of small- and medium- size cooling towers (BAC, 2020). The BAC estimator provides parasitic load and heat rejection for each model as a function of cooling tower parameters, such as ambient air temperature. Additionally, budgetary numbers for BAC units were obtained from a vendor.

Baltimore Aircoil values are obtained by screen-scraping BAC's online performance estimation tool for three models: 1) PC2-509-1218-30, 509 nominal ton, R22, condensing tower, and models 2) FXV-0812B-12D-J and 3) FXV-1212C-16Q-K, which are 98 ton and 123 ton, respectively, glycol, closed-circuit cooling towers. Only the FXV-1212C_16Q-K tower is used in the dry cooling tower regressions as irregularities were found with the FXV-0812B results. Vendor-supplied budgetary numbers were obtained of: $106,000,68,000$, and 110,000 2013\$ for the PC2, FXV0812, and FXV-1212 units, respectfully. This same data was used in Adams et al. (2015) only to report parasitic load fraction; however, it is shown in this study for both parasitic load fraction and cost. The parasitic load fraction data is also re-regressed here using a different model for a better fit. Both wet and dry closed-circuit towers are examined.

The specific cost and parasitic load fraction are regressed of the form of Equation S34, where a, $b, c$, and $d$ are the regression coefficients. The cost and load fraction is a function of ambient temperature $\left(T_{\text {WetBulb }[\mathrm{K}]}\right)$ (given in $\mathrm{K}$ ), approach temperature difference $\left(\Delta T_{\text {Approach }}\right)$, and temperature range $\left(\Delta T_{\text {Range }}\right)$. The approach temperature difference is the difference between the fluid temperature leaving the tower and the ambient temperature. The temperature range is the difference between inlet and exit fluid temperature. For a condensing tower, the range is zero.

$x=a \cdot\left(\frac{1}{\Delta T_{\text {Approach }}}\right)+b \cdot T_{\text {WetBulb }[K]}+c \cdot T_{\text {WetBulb }[K]} \cdot\left(\frac{1}{\Delta T_{\text {Approach }}}\right)+d \cdot\left(\frac{1}{\Delta T_{\text {Approach }}+\Delta T_{\text {Range }}}\right)$

The parasitic power fractions and specific costs are shown in Table S11. Only statistically significant $(p<0.05)$ regression coefficients are reported.

Table S11: Regression coefficients for cooling and condensing tower parasitic load fraction and specific cost

\begin{tabular}{|c|c|c|c|c|c|c|c|c|}
\hline Type & & Result, $\mathrm{x}$ & a & b & C & d & $\mathbf{N}$ & $r^{2}$ \\
\hline \multirow[t]{2}{*}{ Cooling } & \multirow[t]{2}{*}{ Wet } & $\lambda$ Cooling,wet & $1.20 \times 10^{0}$ & & $-3.79 \times 10^{-3}$ & $1.95 \times 10^{-2}$ & 1407 & $98.4 \%$ \\
\hline & & CCooling,wet & $5.58 \times 10^{3}$ & & $-1.77 \times 10^{1}$ & $1.96 \times 10^{2}$ & 1407 & $97.7 \%$ \\
\hline \multirow[t]{2}{*}{ Cooling } & \multirow[t]{2}{*}{ Dry } & $\lambda_{\text {Cooling,dry }}$ & $7.65 \times 10^{-1}$ & & & $1.28 \times 10^{-1}$ & 63 & $98.3 \%$ \\
\hline & & CCooling,dry & $7.31 \times 10^{3}$ & & & $1.23 \times 10^{3}$ & 63 & $98.3 \%$ \\
\hline \multirow[t]{2}{*}{ Condensing } & \multirow[t]{2}{*}{ Wet } & $\lambda_{\text {Condensing,wet }}$ & $1.65 \times 10^{0}$ & $-6.24 \times 10^{-6}$ & $-5.03 \times 10^{-3}$ & & 55 & $98.0 \%$ \\
\hline & & CCondensing,wet & $4.08 \times 10^{3}$ & $-1.54 \times 10^{-2}$ & $-1.24 \times 10^{1}$ & & 55 & $98.0 \%$ \\
\hline \multirow[t]{2}{*}{ Condensing } & \multirow[t]{2}{*}{ Dry } & $\lambda$ Condensing, dry & $6.19 \times 10^{-1}$ & & & & 84 & $98.7 \%$ \\
\hline & & CCondensing,dry & $1.91 \times 10^{3}$ & & & & 84 & $98.7 \%$ \\
\hline
\end{tabular}


The parasitic power fraction, $\lambda_{\text {cooling }}$, (Figure S4A) and specific cost, $c_{\text {Cooling }}$, (Figure S4C) are shown for glycol-water closed circuit cooling towers. The condensing tower parasitic power fraction, $\lambda_{\text {Condensing }}$, (Figure S4B) and specific condensing tower cost, $c_{\text {Condensing }}$, (Figure S4D) are shown for an R22 condensing tower. The data are found to vary most substantially with the approach temperature difference. The wet towers have a dependence on the ambient wet bulb temperature (shown in each legend), while the dry towers do not. Only data for a temperature range of $4^{\circ} \mathrm{C}$ is plotted for cooling towers; however, temperature range data between $2^{\circ} \mathrm{C}$ and $32^{\circ} \mathrm{C}$ is used in the regression.

(A)
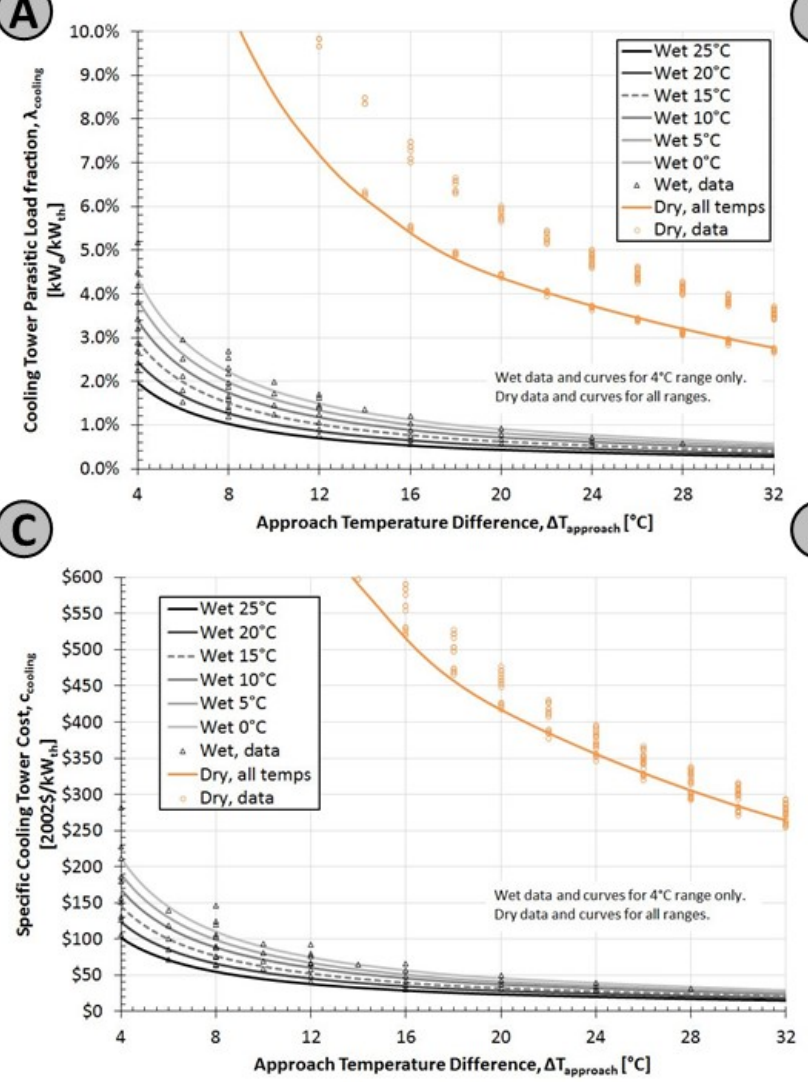
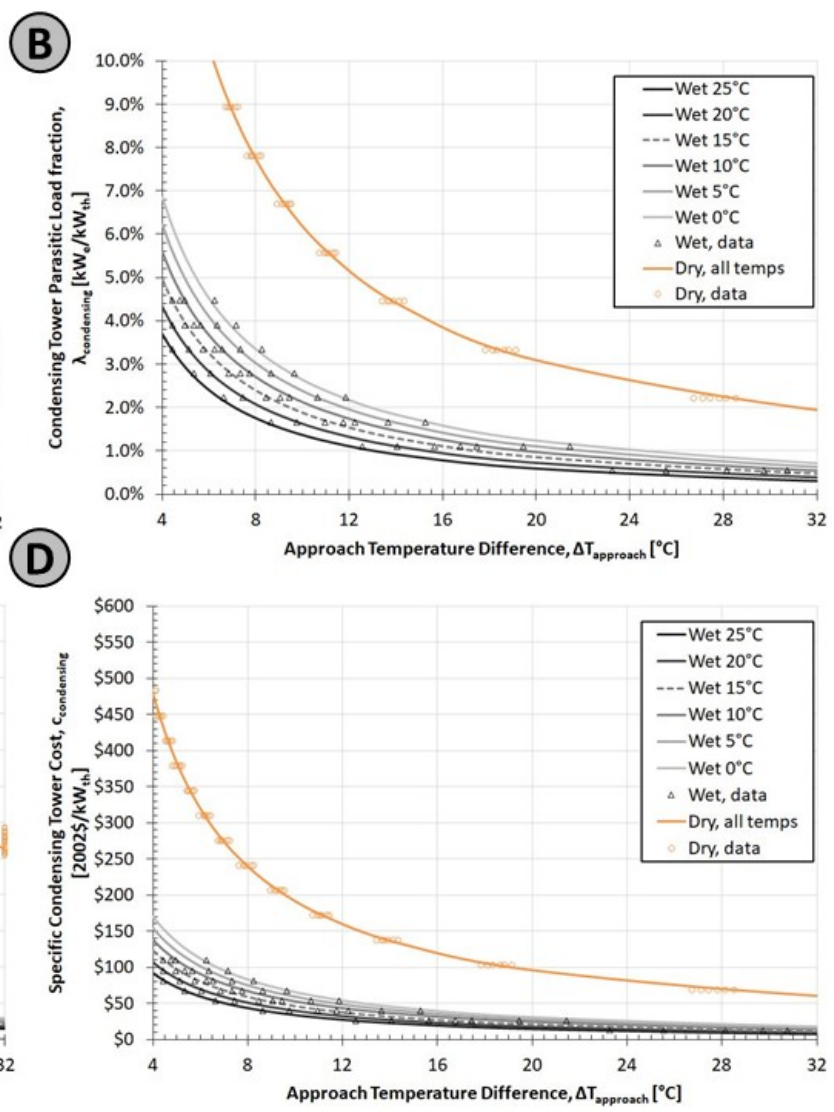

Figure S4. The fraction of parasitic fan power to heat rejected, $\lambda$, for Baltimore Aircoil Company (BAC) cooling $(A)$ and condensing $(B)$ towers. Also, the tower cost as a function of heat rejected for cooling (C) and condensing $(D)$ towers. The approach temperature difference on the $x$-axis is the difference between the fluid temperature exiting the tower and the ambient temperature.

\section{Correcting to Standard Design Conditions}

It is difficult to compare cooling tower costs when they all have different design conditions, which affect their cost. For instance, the GETEM cooling tower costs assume a $15^{\circ} \mathrm{C}$ ambient temperature, a $7^{\circ} \mathrm{C}$ approach temperature, and a $4^{\circ} \mathrm{C}$ range, while the NETL (2007-2019b) costs assume an $11^{\circ} \mathrm{C}$ ambient temperature, $5^{\circ} \mathrm{C}$ approach temperature, and $11^{\circ} \mathrm{C}$ range. It is not possible to directly compare these units without first correcting each to the same design conditions. Thus, we created the 'Design Correction Factor', DCF, in Equation S35. 


$$
D C F=\frac{\left.c_{\{\text {cooling } \mid \text { condensing }}\right\}^{\left(T_{\text {ambient }}, \Delta T_{\text {approach }}, \Delta T_{\text {range }}\right)}}{c_{\{\text {cooling } \mid \text { condensing }\}}\left(15^{\circ} \mathrm{C}, 7^{\circ} \mathrm{C}, 4^{\circ} \mathrm{C}\right)}
$$

The design correction factor, $D C F$, is the ratio of the specific cost of a cooling or condensing tower at arbitrary conditions over the specific cost of a cooling or condensing tower at the standard conditions of a $15^{\circ} \mathrm{C}$ ambient temperature, a $7^{\circ} \mathrm{C}$ approach temperature difference, and a $4^{\circ} \mathrm{C}$ range. The specific costs are evaluated using the relationships described in Table S11 and Equation S34. For instance, the NETL design conditions of $11^{\circ} \mathrm{C}$ ambient temperature, $5^{\circ} \mathrm{C}$ approach temperature, and $11^{\circ} \mathrm{C}$ range yield a design correction factor of $0.71(D C F=0.71)$. Thus, the costs of all NETL reported towers are multiplied by 0.71 to obtain the cost if standard design conditions had been used.

\section{Tower Makeup Water Consumption}

Wet cooling towers evaporate water to cool the process fluid. A wet tower has a lower parasitic power fraction and a lower capital cost than a dry tower, but at the expense of water consumption. If desired, the water consumption of a wet cooling tower can be roughly approximated by assuming all heat rejected from the towers is used to evaporate water. Thus, divide the total heat rejected by the heat of vaporization of water $\left(h_{f g, \text { Water }}\right)$ at atmospheric pressure to get the mass flowrate of water ( $\left.\dot{m}_{C-\text { Towers,Water }}\right)$ required by the wet cooling towers (Equation S36).

$$
\dot{m}_{C-\text { Towers }, \text { Water }} \approx \frac{\dot{Q}_{\text {Cooling }}+\dot{Q}_{\text {Condensing }}}{h_{f g, \text { Water }}}
$$

\section{S3.2.4 Heat Exchanger, $\boldsymbol{C}_{\text {HeatExchanger }}$}

Heat exchangers are used within a geothermal power cycle to transfer heat from one fluid to another, for instance, within evaporators or condensers. In an ORC, heat must be transferred from the hot geofluid to boil the organic working fluid. If an open cooling tower is used, heat is again transferred in a heat exchanger after the turbine to a third cooling circuit.

The cost of the heat exchanger is the product of the heat exchanger type cost and the heat exchanger cost index, $P P I_{H X}$.

$$
C_{\text {HeatExchanger }}=P P I_{H X} \cdot C_{\{S \& T, G a s k e t e d P l a t e, \text { WeldedPlate,BondedPlate }\}}
$$

There are four types of heat exchanger costs in genGEO: shell \& tube $\left(C_{S \& T}\right)$, gasketed plate $\left(C_{\text {GasketedPlate }}\right)$, welded plate $\left(C_{\text {WeldedPlate }}\right)$, and bonded plate $\left(C_{\text {BondedPlate }}\right)$. Shell and tube heat exchangers are large and expensive, but are easily cleaned. Plate heat exchangers are more compact and less expensive, but are susceptible to fouling and are not recommended for phase change processes. Gasketed plate heat exchangers are the least expensive type of plate heat exchanger, but have only a rubber gasket between plates, so they are not be suitable for high pressures $(<2 \mathrm{MPa})$ or corrosives. Welded plate heat exchangers replace the gasket with weld and can tolerate higher pressures. Bonded plate heat exchangers are the most expensive type of plate heat exchanger and are diffusion bonded to have very small channels which accommodate very high pressures in both fluids, as is required in $\mathrm{CO}_{2}$ Rankine cycle recuperation. Many 
excellent heat exchanger design references exist for further design information (Smith, 2016; Peters, 2003; Douglas, 1988).

The cost of a heat exchanger is typically defined by its heat transfer area, $A_{H X}$. Table $\mathrm{S} 12$ shows the heat exchanger cost relations found in our review as a function of heat transfer area. Four of these are adopted in genGEO: the heat exchanger costs for (1) shell and tube $\left(C_{S \& T}\right)$, (2) gasketed plate $\left(C_{\text {GasketedPlate }}\right)$, and (3) welded plate $\left(C_{\text {WeldedPlate }}\right)$ are adopted from Peters (2003) as shown while (4) the bonded plate heat exchanger cost $\left(C_{\text {Bondedplate }}\right)$ is the welded plate cost relation, scaled to pass through a vendor cost quote. Cost relations showing an $\mathrm{r}^{2}$ value are derived from printed plots. All relations are cost adjusted for stainless steel tubing or plates. The shell and tube heat exchanger costs allow for at least $5 \mathrm{MPa}$ fluid pressure.

Table S12: Heat exchanger cost relations as a function of heat exchange area, $A_{H X .}$

\begin{tabular}{|c|c|c|c|c|}
\hline Type & Sub-type & Source & Cost [2002\$] & $r^{2}$ \\
\hline Shell \& Tube & Condenser & $\begin{array}{l}\text { GETEM } \\
\text { (Flash system) }\end{array}$ & $C=768 \cdot\left(A_{H X}\right)^{0.85}$ & -- \\
\hline Shell \& Tube & NCG Condenser & $\begin{array}{l}\text { GETEM } \\
\text { (Flash system) }\end{array}$ & $C=1780 \cdot\left(A_{H X}\right)^{0.72}$ & -- \\
\hline Shell \& Tube & $\begin{array}{l}\text { Fixed/Floating } \\
\text { Head }\end{array}$ & NETL (2002) & $C=235 \cdot A_{H X}+17900$ & $0.999^{*}$ \\
\hline Shell \& Tube & Fixed Head & Peters (2003) & $C=181 \cdot A_{H X}+3320$ & $0.999^{*}$ \\
\hline $\begin{array}{l}\text { Shell \& Tube+ } \\
\left(C_{\text {S\&T }}\right)\end{array}$ & Floating Head & Peters (2003) & $C=239 \cdot A_{H X}+13400$ & $0.999^{*}$ \\
\hline Shell \& Tube & $\begin{array}{l}\text { Fixed/Floating } \\
\text { Head }\end{array}$ & Smith (2016) & $C=3120 \cdot\left(A_{H X}\right)^{0.68}$ & -- \\
\hline Plate & Spiral & NETL (2002) & $C=468 \cdot A_{H X}+8190$ & $0.965^{*}$ \\
\hline Plate & Spiral & Peters (2003) & $C=11700 \cdot\left(A_{H X}\right)^{0.44}$ & $1.000^{*}$ \\
\hline $\begin{array}{l}\text { Plate+ } \\
\text { (C GasketedPlate) }\end{array}$ & Gasketed & Peters (2003) & $C=29 \cdot A_{H X}+1560$ & $0.999^{*}$ \\
\hline $\begin{array}{l}\text { Plate+ } \\
\text { (C } \text { WeldedPlate })\end{array}$ & Welded & Peters (2003) & $C=69 \cdot A_{H X}+4670$ & $1.000^{*}$ \\
\hline Plate & $\begin{array}{l}\text { Diffusion Bonded } \\
\left.\text { (For } \mathrm{CO}_{2}\right)\end{array}$ & $\begin{array}{l}\text { Vendor Quote } \\
\text { (Heatric) }\end{array}$ & $\begin{array}{l}C=39100 \\
A_{H X}=149\end{array}$ & -- \\
\hline $\begin{array}{l}\text { Plate } \\
\left(C_{\text {BondedPlate }}\right)\end{array}$ & Diffusion Bonded & genGEO & $C=2.6 \cdot\left(69 \cdot A_{H X}+4670\right)$ & -- \\
\hline \multicolumn{5}{|c|}{$\begin{array}{l}\text { + Directly adopted in genGEO. Cost variable shown in parenthesis. } \\
{ }^{*} \text { Relation plotted in reference and fit in this study. } \\
\text { Note: Heat exchange area }\left(\boldsymbol{A}_{H X}\right) \text { is given in } \mathrm{m}^{2} \text {. }\end{array}$} \\
\hline
\end{tabular}

Figure S5 shows that the heat exchanger relationships provided by Peters (2003) and NETL (2002) are linear relationships with heat exchange area. Conversely, the relations provided by GETEM and Smith (2016) have non-linear relationships with heat exchange area. It is a common first-approximation to size equipment using a scaling exponent less than one (i.e. non-linearly), as is the case of GETEM and Smith (2016). However, Peters (2003) and NETL (2002) both provide cost estimate data points from underlying data that scale linearly, while GETEM provides 
no supporting data. Thus, the data support a linear scaling of heat exchanger cost with heat exchange area and we adopt the linear relationships of Peters (2003) in genGEO.

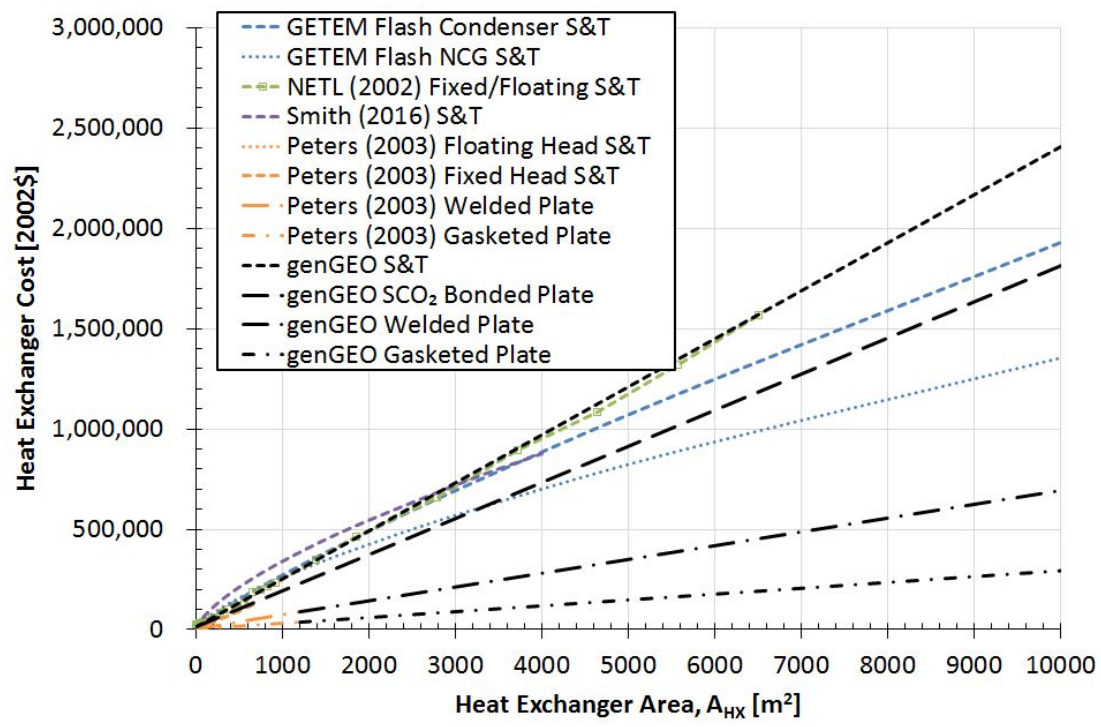

Figure S5: Heat exchanger cost as a function of heat exchange area. GETEM and Smith (2016) provide cost relations that increase with an exponent less than one. Conversely, Peters (2003) and NETL (2002) provide data-backed relations that scale linearly with heat exchange area.

Figure S6 shows the specific heat exchanger cost as a function of logarithmically-scaled heat exchange area for the same data as Figure S5. Spiral plate heat exchangers are not commonly used in geothermal applications, but shown for comparison.

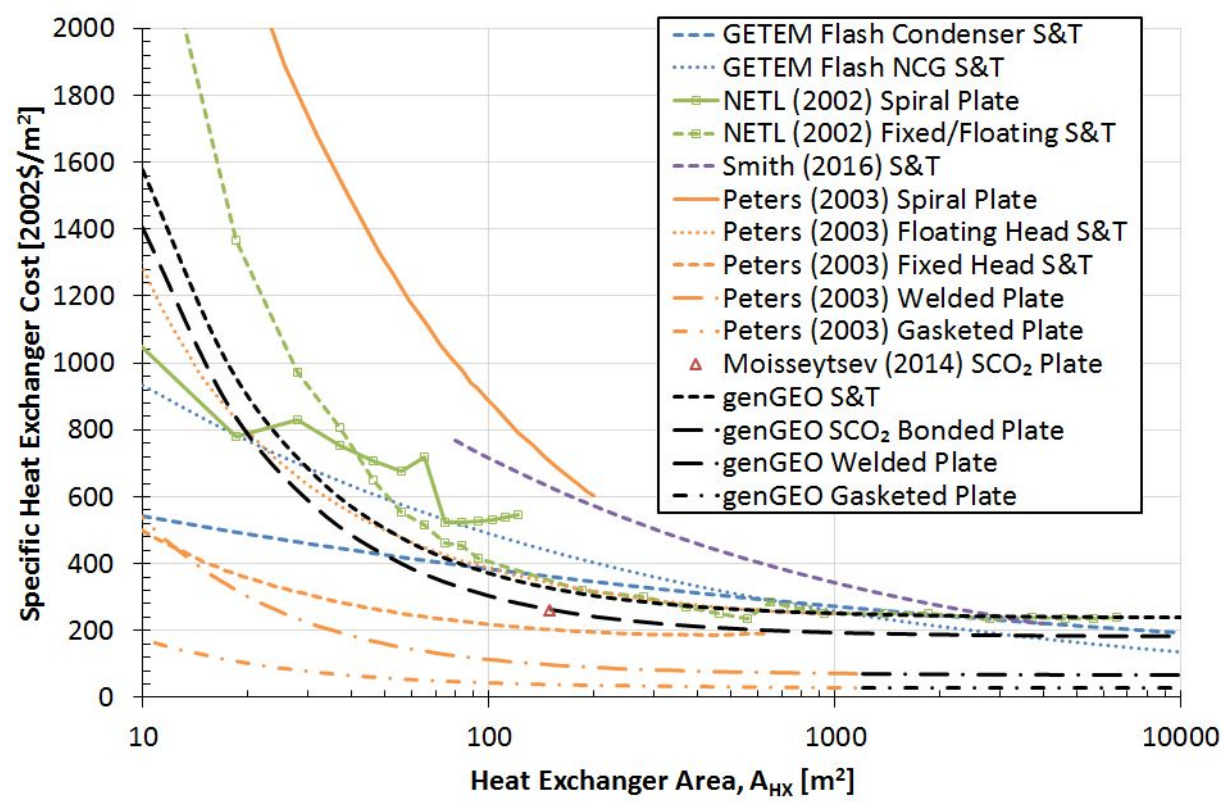

Figure S6: Specific heat exchanger cost as a function of heat exchange area. The genGEO shell-and-tube (S\&T) relation is a regression of Peters (2003) reported data. Thus, the two curves differ at small heat exchange areas. 
Figure S6 shows two key findings for shell and tube heat exchangers: 1) the fairly good agreement between NETL (2002) Fixed/Floating S\&T and Peters (2003) floating head shell and tube costs, especially at large heat exchange areas, and 2) the poor fit of cost data by GETEM and Smith (2016) across the heat exchange areas investigated. A regression of the Peters (2003) floatinghead data is used for all shell and tube heat exchangers in genGEO (see table S12).

It is unclear why GETEM provides cost estimates for two different types of shell \& tube condensers: one for Non Condensable Gas (NCG) stage condensers and another for primary steam condensing. Without any further description of the design of these devices, they should be the same. The typical heat exchange area of an NCG condenser in GETEM is much smaller than a steam condenser, thus it is possible these exponential fits are the result of fitting different ranges of heat exchanger area data to an exponential regression model.

The cost estimate for the diffusion bonded $\mathrm{SCO}_{2}$ plate heat exchanger manufactured by Heatric is extracted from Moisseytsev \& Sienicki (2014) and Pidaparti et al. (2015). These are designed for use as recuperators in high-temperature and high-pressure $\mathrm{SCO}_{2}$ Rankine cycles. If $\mathrm{CO}_{2}$ is used with typical tube-side pressure (i.e. $<10 \mathrm{MPa}$ ) with low shell-side pressure, shell \& tube heat exchangers should be equally suitable to remove heat from $\mathrm{CO}_{2}$ with process water.

More information on how to implement the heat exchanger cost equations with using power cycle simulation results is described below.

\section{Calculating the Heat Transfer Area, $A_{H X}$}

Equation S38 can be used to solve for the heat transfer area, $A_{H X}$, where the heat, $\dot{Q}$, is the product of the overall heat transfer coefficient, $U$, the heat exchange area, $A_{H X}$, and the log mean temperature difference, $\Delta T_{L M T D}$. Thus, assuming that the heat transferred through the exchanger is known, only the overall heat transfer coefficient and log mean temperature difference are needed to find the heat exchange area.

$$
\dot{Q}=U \cdot A_{H X} \cdot \Delta T_{L M T D}
$$

\section{Log Mean Temperature Difference, $\Delta T_{L M T D}$}

The log mean temperature difference, $\Delta T_{L M T D}$, given in Equation $\mathrm{S} 39$, is an average effective temperature difference between the two fluids within the heat exchanger. It is a function of the temperature differences at arbitrarily assigned ends " $A$ ", $\Delta T_{A}$, and " $\mathrm{B}$ ", $\Delta T_{B}$. The log mean temperature difference makes the assumption of constant heat capacity in the fluids; thus it can't be used across heat exchangers which transition between phase changing and non-phase changing processes. It must be applied separately to each process.

$$
\Delta T_{L M T D}=\frac{\Delta T_{A}-\Delta T_{B}}{\ln \left(\frac{\Delta T_{A}}{\Delta T_{B}}\right)}
$$

\section{Overall Heat Transfer Coefficient, $\boldsymbol{U}$}

The overall heat transfer coefficient, $U$, is a composite measure of the heat transfer coefficients of both fluids. As such, the overall heat transfer coefficient is dependent on the fluid properties of each fluid, fluid velocities, heat exchanger geometry, etc., and is not easily estimated. 
Nonetheless, a comparison of overall heat transfer coefficients is given in Table S13. The values collected for this table from Peters (2003) and Douglas (1988) are selected to represent ORC evaporators or condensers, which is heat exchanged between a phase-changing organic fluid and water. Additionally, a typical water-water heat exchange value is shown.

Table S13: Overall Heat Transfer Coefficients, $U$.

\begin{tabular}{|c|c|c|}
\hline Source & Туре & $\begin{array}{l}\text { Overall Heat Transfer } \\
\text { Coefficient, U } \\
{\left[\mathrm{W} / \mathrm{m}^{2}-\mathrm{K}\right]}\end{array}$ \\
\hline GETEM, Flash & $\begin{array}{l}\text { Shell \& Tube Steam } \\
\text { Condenser }\end{array}$ & 1990 \\
\hline $\begin{array}{l}\text { Moisseytsev \& Sienicki } \\
\text { (2014) }\end{array}$ & $\mathrm{SCO}_{2}$ Plate & 810 \\
\hline DiPippo (2015) & Not Specified, Assume S\&T & $170-1140$ \\
\hline Thulukkanam (2013) & Plate & $3000-7000$ \\
\hline Peters (2003) & Light Organic-Water, Cooler & $\begin{array}{l}375-750 \\
\text { *Use upper for Condensers }\end{array}$ \\
\hline Peters (2003) & Light Organic-Water, Heater & $\begin{array}{l}500-1000 \\
* \text { Use upper for Evaporators }\end{array}$ \\
\hline Peters (2003) & Water-Water & $1400-2850$ \\
\hline Douglas (1988) & Condensing Vapor-Liquid & 850 \\
\hline Douglas (1988) & Liquid_LLiquid & 280 \\
\hline Atrens (2011) & Condensing Vapor - Liquid & 300 \\
\hline genGEO & Light Organic-Water & 500 \\
\hline genGEO & Water-Water & 2000 \\
\hline
\end{tabular}

Peters (2003) describes their overall heat transfer coefficients as being based on results from "ordinary engineering practice." Additionally, they appear conservatively smaller than most shell and tube values. The GETEM value is larger than most phase change process values and a smaller value should be used for ORC condensers/evaporators. Thus, Peters (2003) overall heat transfer coefficient ranges are adopted in genGEO. We additionally propose two average values in Table S13 for water-organic and water-water heat transfer, although these should be used carefully.

It is important to take note that the GETEM assumed overall heat transfer coefficient of Table S13 is approximately 2 to 6 times larger than other coefficients for similar processes. As such, it is likely that GETEM underestimates heat exchanger cost by a similar amount.

The overall heat transfer coefficients given in genGEO are useful for preliminary cost analyses, but should be replaced with more accurate values as soon as possible. Smith (2016) provides excellent simplifying relations to calculate the overall heat transfer coefficient in its appendix $\mathrm{C}$.

\section{S3.3 Well Cost, CWells}

The total cost of the wells in genGEO is the sum of the cost of each of the total number of wells drilled, $G_{W e l l s}$, given in Equation S40. Each geothermal well has a base drilling cost, $C_{W e l l, d r i l l i n g}$, 
plus an additional cost for $\mathrm{CO}_{2}$ wells, $\Delta C_{\mathrm{CO} 2-\text { Well }}$. Each well in a wellfield may vary in diameter and depth, thus the cost of each is calculated separately and then summed.

$$
C_{W e l l s}=\sum_{i=1}^{G_{W e l l s}}\left(C_{\text {Well, drilling, } i}+\Delta C_{C O 2-\text { Well }, i}\right)
$$

The geothermal well cost is augmented by the drilling success rate, explained in Section S3.3.1. The geothermal well cost, $C_{\text {Well,drilling }}$, is explained in Section S3.3.2 and the additional $\mathrm{CO}_{2}$ well cost, $\Delta C_{C O 2-W e l l}$, is explained in Section S3.3.3.

\section{S3.3.1 Geothermal Drilling Success Rate, Swell}

The total cost of a drilled well, $C_{W e l l, \text { drilling }}$, is the well cost, $C_{W e l l}$, increased by the well success rate, $S_{W e l l}$, shown in Equation $S 41$.

$$
C_{\text {Well, } \text {,rilling }}=\frac{C_{W e l l}}{S_{W e l l}}
$$

Well success rates will vary substantially based on different geologies and Table S14 shows a comparison of well success rates found from our review for each geology targeted for geothermal power generation. Traditional geothermal wells target existing fractured geology while EGS wells target basement rock with known fractures to stimulate.

Table S14: Well drilling success rates for different reservoir types.

\begin{tabular}{|lllll|}
\hline Source & Study Years & $\begin{array}{l}\text { Oil \& Gas } \\
\text { (sedimentary) }\end{array}$ & $\begin{array}{l}\text { Traditional } \\
\text { Geothermal } \\
\text { (fractured) }\end{array}$ & $\begin{array}{l}\text { EGS } \\
\text { (basement) }\end{array}$ \\
\hline Sanyal and Morrow (2012) & $1921-2011$ & -- & $68 \%$ & -- \\
\hline Borowski et al. (1984) & 1983 & $63 \%$ & -- & -- \\
\hline Levitt (2016) & $1930-1968$ & $65 \%$ & -- & -- \\
\hline Boyd (2002) & $1957-2001$ & $90 \%$ & -- & -- \\
\hline Sell et al. (2011) & $1981-2010$ & $97 \%$ & -- & -- \\
\hline GETEM & -- & -- & $75 \%$ & $90 \%$ \\
\hline GEOPHIRES & -- & -- & $100 \%$ & $100 \%$ \\
\hline genGEO & -- & $95 \%$ & $75 \%$ & $90 \%$ \\
\hline
\end{tabular}

Sanyal and Morrow (2012) is an often cited source for geothermal well success rates. It should be noted, however, that the majority of these geothermal fields are "classical" fields, such as the Geysers in California. They are steam generating, fracture-dominated reservoirs where the prediction of subsurface heterogeneities is difficult. Thus, there is a low success rate $(\sim 68 \%)$. This is the classical application of GETEM and thus the source of their $75 \%$ well success recommendation. We adopted GETEM's recommendation for fractured reservoir types in genGEO.

Successfully completions for Oil \& Gas within sedimentary reservoirs (i.e. wells drilled that produce oil or gas) have been steadily increasing, even for tight basins. This is due to the advances in drilling technology, enhanced subsurface modelling, and because the number of exploratory oil and gas wells drilled in general decreases with time (there are a finite number of 
undiscovered oil and gas reservoirs). Thus, higher success rates in sedimentary formations than in fractured formations is appropriate. We use a $95 \%$ well drilling success rate in genGEO for sedimentary formations.

Lastly, GETEM and GEOPHIRES both provide success rate recommendations for drilling of EGS wells into basement rock. The success of this technology is not well known as EGS wells have not been drilled on a wide scale. Therefore, we default to GETEM's EGS success rate of $90 \%$ in genGEO.

\section{S3.3.2 Geothermal Well Cost, $C_{\text {well }}$}

Geothermal wells are perhaps the most expensive single capital costs in a geothermal project. The genGEO well cost relationship is given in Equation S42, where $L_{W e l l}$ is the well depth, $D_{W e l l}$ is the well diameter. genGEO adopts the $15 \%$ contingency cost $\left(X_{P C \text {-well }}=1.15\right)$ and $5 \%$ indirect costs $\left(X_{I C-\text { well }}=1.05\right)$ from GETEM. All well cost data are adjusted by the Oil and Gas cost index, $P P I_{O \& G}$.

$$
C_{\text {Well }}=X_{I C-\text { well }} \cdot X_{P C-\text { well }} \cdot P P I_{O \& G} \cdot\left(0.105 \cdot L_{W e l l}^{2}+1776 \cdot L_{W e l l} \cdot D_{W e l l}+275300\right)
$$

Well cost data is considered from many sources: GETEM, Lukawski et al. (2014), Klein et al. (2004), GeoVision (Lowry et al., 2017), and GEOPHIRES. Well cost models from GETEM and GeoVision are partially bottom-up models that try to build a well by summing individual costs, while Lukawski et al. (2014) and Klein et al. (2004) are top-down models that aggregate available drilled well cost data. Klein et al. (2004) is a subset of the geothermal well data used in Lukawski et al. (2014). The bottom-up models tend to be more accessible and are more easily adapted for use in genGEO.

Table S15 shows geothermal well relationships compared to determine the genGEO relationship. The GeoVision "Baseline" and "Ideal" vertical well cost models represent the current state-of-theart well costs and the theoretical minimum cost, respectively. GeoVision also reports intermediate cost models and horizontal wells that are not compared in this study. The GeoVision curves are derived from published figures in Lowry et al. (2017). Two well diameters are commonly used by GETEM, GEOPHIRES, and GeoVision for analysis: Small Diameter (i.e. SD or $21.6 \mathrm{~cm}$ or 8.5 inch diameter) and Large Diameter (i.e. LD or $31.1 \mathrm{~cm}$ or 12.25 inch diameter).

The well diameter values given in genGEO are for an open downhole borehole (i.e. not lined downhole). If the well is lined, the cost does not change appreciably, but the wellbore inner diameter decreases by approximately 2 inches $(5 \mathrm{~cm})$. In the case of a lined well, genGEO uses the unlined diameter to determine cost.

GEOPHIRES uses polynomial fits of the GeoVision cost curves; however, analysis shows these fits differ from the GeoVision curves by $2.6 \%$ on average between 1 and $7 \mathrm{~km}$. Thus, we neglected the GEOPHIRES relationships in our comparison. 
Table S15: Existing and genGEO geothermal well cost models.

\begin{tabular}{|c|c|c|}
\hline Name & Cost Relation & Notes \\
\hline GETEM SD + & $C=0.033 \cdot L_{W e l l}^{2}+150 \cdot L_{W e l l}+290000$ & $\begin{array}{l}\text { Depth in } \mathrm{ft} \\
\text { Cost in } 2010 \$\end{array}$ \\
\hline GETEM LD + & $C=0.033 \cdot L_{W e l l}{ }^{2}+350 \cdot L_{W e l l}+290000$ & $\begin{array}{l}\text { Depth in ft, } \\
\text { Cost in } 2010 \$\end{array}$ \\
\hline $\begin{array}{l}\text { Lukawski et al. } \\
(2014) \\
\text { (all diam.) }{ }^{* *}+\end{array}$ & $C=1.72 \times 10^{-7} \cdot L_{W e l l}{ }^{2}+2.3 \times 10^{-3} \cdot L_{W e l l}-0.62$ & $\begin{array}{l}\text { Depth in } \mathrm{m}, \\
\text { Cost in } 2012 \$ M\end{array}$ \\
\hline Klein et al. (2004) + & $C=0.019069 \cdot L_{W e l l}{ }^{2}+210 \cdot L_{W e l l}+240,785$ & $\begin{array}{l}\text { Depth in } \mathrm{ft}, \\
\text { Cost in } 2003 \$ \mathrm{M}\end{array}$ \\
\hline $\begin{array}{l}\text { GeoVision SD } \\
\text { Vertical Baseline + }\end{array}$ & $C=0.127 \cdot L_{W e l l}{ }^{2}+417 \cdot L_{W e l l}+81700$ & $\begin{array}{l}\text { Depth in } \mathrm{m}, \\
\text { Cost in } 2002 \$\end{array}$ \\
\hline $\begin{array}{l}\text { GeoVision LD } \\
\text { Vertical Baseline + }\end{array}$ & $C=0.110 \cdot L_{W e l l}^{2}+810 \cdot L_{W e l l}-96980$ & $\begin{array}{l}\text { Depth in } \mathrm{m}, \\
\text { Cost in } 2002 \$\end{array}$ \\
\hline $\begin{array}{l}\text { GeoVision SD } \\
\text { Vertical Ideal }\end{array}$ & $C=216 \cdot L_{W e l l}+284000$ & $\begin{array}{l}\text { Depth in } \mathrm{m}, \\
\text { Cost in } 2002 \$\end{array}$ \\
\hline $\begin{array}{l}\text { GeoVision LD } \\
\text { Vertical Ideal }\end{array}$ & $C=346 \cdot L_{W e l l}+267000$ & $\begin{array}{l}\text { Depth in } \mathrm{m}, \\
\text { Cost in } 2002 \$\end{array}$ \\
\hline $\begin{array}{l}\text { GEOPHIRES SD } \\
\text { Vertical + }\end{array}$ & $C=0.302 \cdot L_{W e l l}{ }^{2}+585 \cdot L_{W e l l}+751400$ & $\begin{array}{l}\text { Depth in } \mathrm{m}, \\
\text { Cost in } 2017 \$\end{array}$ \\
\hline $\begin{array}{l}\text { GEOPHIRES LD } \\
\text { Vertical + }\end{array}$ & $C=0.282 \cdot L_{W e l l}{ }^{2}+1275 \cdot L_{\text {Well }}+632300$ & $\begin{array}{l}\text { Depth in } \mathrm{m}, \\
\text { Cost in } 2017 \$\end{array}$ \\
\hline $\begin{array}{l}\text { genGEO } \\
\text { (Baseline) }\end{array}$ & $C=0.105 \cdot L_{\text {Well }}^{2}+1776 \cdot L_{\text {Well }} \cdot D_{\text {Well }}+275300$ & $\begin{array}{l}\text { Depth in } \mathrm{m} \text {, } \\
\text { Diameter in } \mathrm{m} \text {, } \\
\text { Cost in } 2002 \$\end{array}$ \\
\hline $\begin{array}{l}\text { genGEO } \\
\text { (Ideal) }\end{array}$ & $C=1288 \cdot L_{W e l l} \cdot D_{W e l l}-62 \cdot L_{W e l l}+275300$ & $\begin{array}{l}\text { Depth in } \mathrm{m}, \\
\text { Diameter in } \mathrm{m} \text {, } \\
\text { Cost in } 2002 \$\end{array}$ \\
\hline \multicolumn{3}{|c|}{$\begin{array}{l}\text { *SD = Small Diameter, } 21.6 \mathrm{~cm} \text { diameter open production interval } \\
{ }^{*} \text { LD = Large Diameter, } 31.1 \mathrm{~cm} \text { diameter open production interval } \\
{ }^{* *} \text { Lukawski }(2014) \text { does not account for well diameter in cost relationship } \\
\text { + Includes contingency cost in cost relation. No relation includes indirect cost. }\end{array}$} \\
\hline
\end{tabular}

Figure S7 shows the genGEO well cost relation for vertical small diameter $(21.6 \mathrm{~cm})$ and large diameter $(31.1 \mathrm{~cm})$ wells as solid lines. The genGEO well cost relation is a least squares regression of the GeoVision 'baseline' data points, with a constrained y-intercept determined by the GeoVision 'ideal' well model. Only statistically significant $(p<0.05)$ terms are included in the genGEO relationship. The cost regressions given by GeoVision are dashed and dotted lines. 


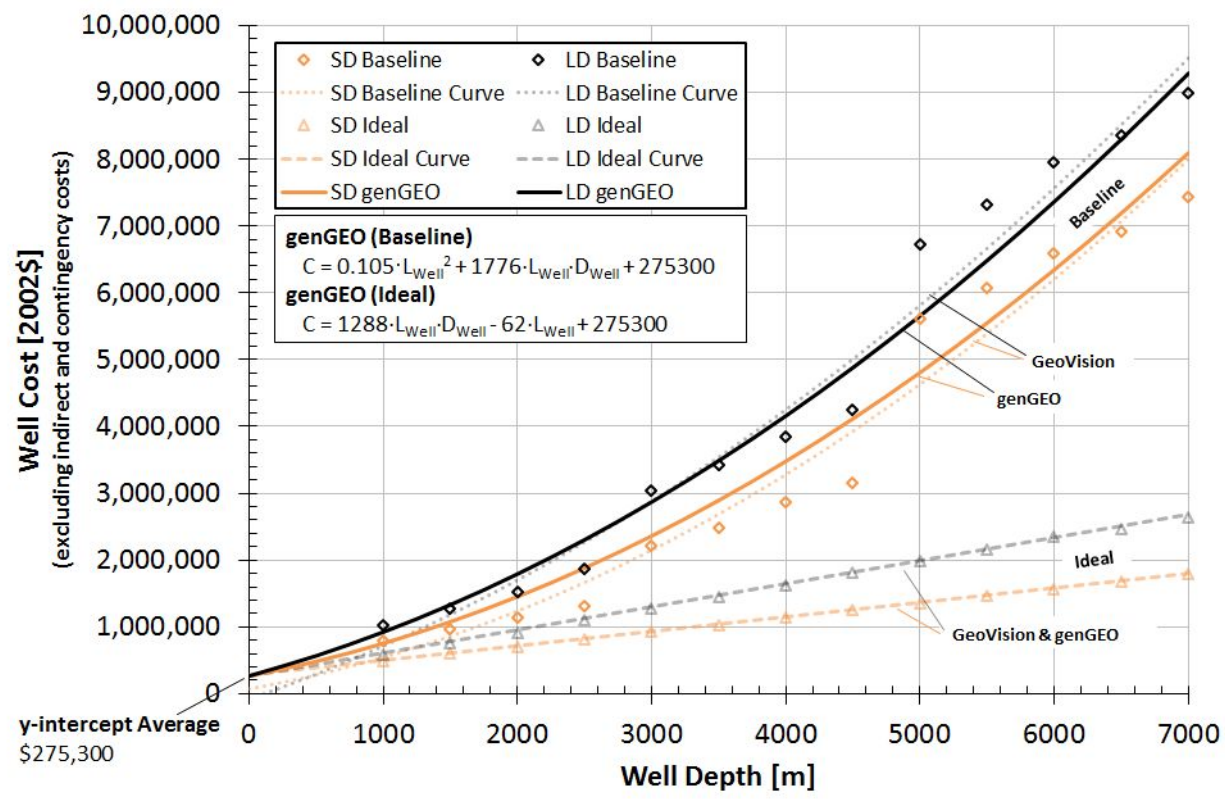

Figure S7: genGEO well cost (solid lines) for small diameter (SD, $22 \mathrm{~cm}$ ) and large diameter (LD, $31 \mathrm{~cm})$ wells. The genGEO relationship is a least-squares regression of GeoVision baseline data points (shown) with a fixed $y$-intercept as a function of well depth and diameter.

Figure S7 shows the genGEO cost relationship fits the GeoVision data points well $\left(r^{2}=0.947\right)$. The genGEO well cost is given in Equation S42 and Table S15.

At depths of and below $3 \mathrm{~km}$ and $5 \mathrm{~km}$, GETEM adds an additional casing interval. GeoVision well models follow the same rule. This causes apparent discontinuities in the cost data near $3 \mathrm{~km}$ and $5 \mathrm{~km}$. The genGEO cost curves average out these step changes into a continuous curve.

It should be noted that while both GETEM and GeoVision appear to have worked separately to develop cost models, the degree of circular referencing between each leads one to the conclusion that there is only one underlying data model. GETEM, prior to 2012 , developed its own bottomup well cost model. Later, GETEM adopted the polynomial cost models shown in this supplemental information, which are each a regression of six unpublished GeoVision data points. Then GeoVision published well cost models, also shown, which are developed from an improved version of the original pre-2012 GETEM bottom-up well cost model. Thus, while substantial work, validation, and improvement has been performed to develop these cost relations, the GETEM, GeoVision, GEOPHIRES, and genGEO relations should not be mistaken for a meta-analysis of more than one independent well cost model.

\section{Comparing Old GETEM and New GETEM Cost Models}

Figure S8 shows the genGEO well cost lines for diameters ranging from $14 \mathrm{~cm}$ to $66 \mathrm{~cm}$. Figure S8 also shows GETEM bottom-up well cost relationships that were used prior to 2012 for these same well diameters. Figure S8 shows the genGEO diameter-dependent relationship encapsulates the original GETEM values. For comparison, the current GETEM well costs for both a large-diameter $31 \mathrm{~cm}$ well and small-diameter $22 \mathrm{~cm}$ well are also shown in blue. 


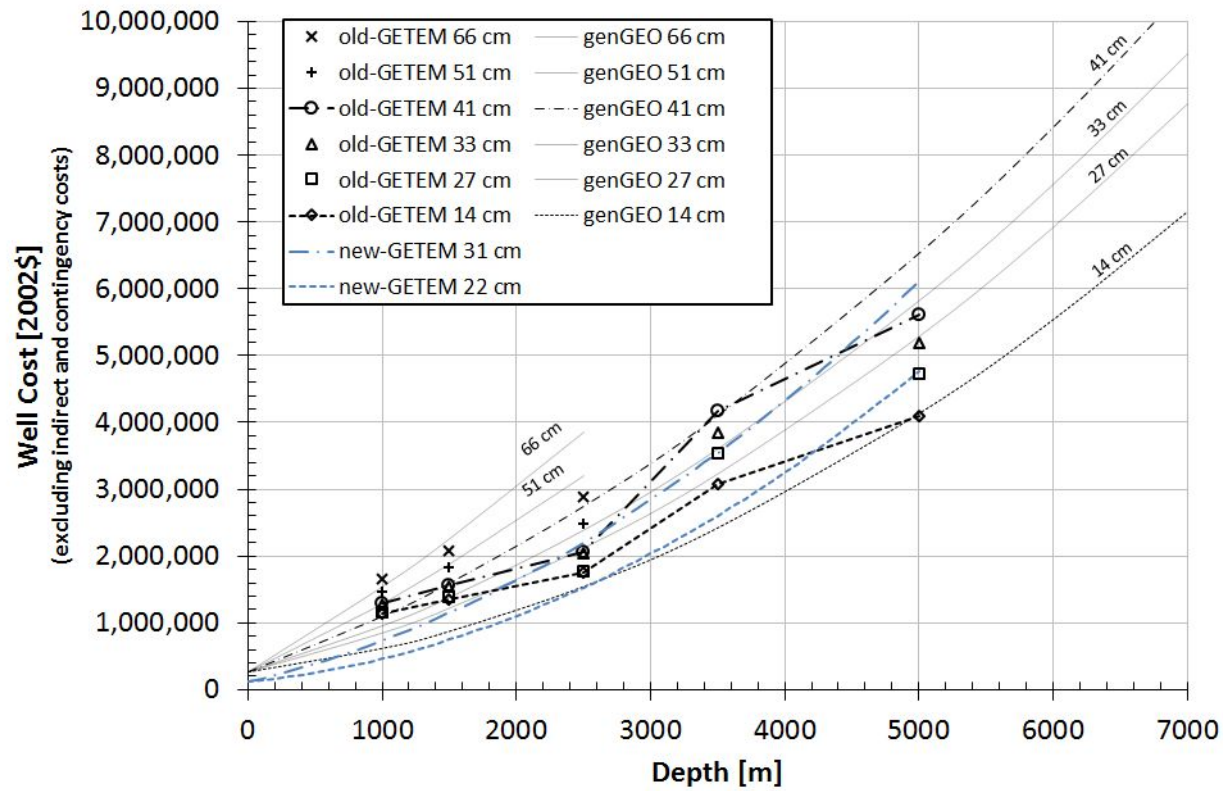

Figure S8: genGEO well cost for diameters varying from $14 \mathrm{~cm}$ to $66 \mathrm{~cm}$. Before 2012, GETEM used a different model for determining well cost, shown for the same well diameters, labelled "old-GETEM". Current GETEM costs "new-GETEM" for both a large diameter $(31 \mathrm{~cm})$ and small diameter $(22 \mathrm{~cm})$ well are also shown.

\section{Difference between Well Cost Models}

Because well costs have such a large impact on overall project costs, we further justify the robustness of the genGEO well cost relationship with Figure S9.

Figure S9A shows the total cost of a $31 \mathrm{~cm}$ well, including contingency and direct costs in 2019 dollars, for all well models considered in this analysis. For example, most models predict a $31 \mathrm{~cm}$, $3 \mathrm{~km}$ geothermal well costs approximately $8 \mathrm{M} \$$ in 2019.
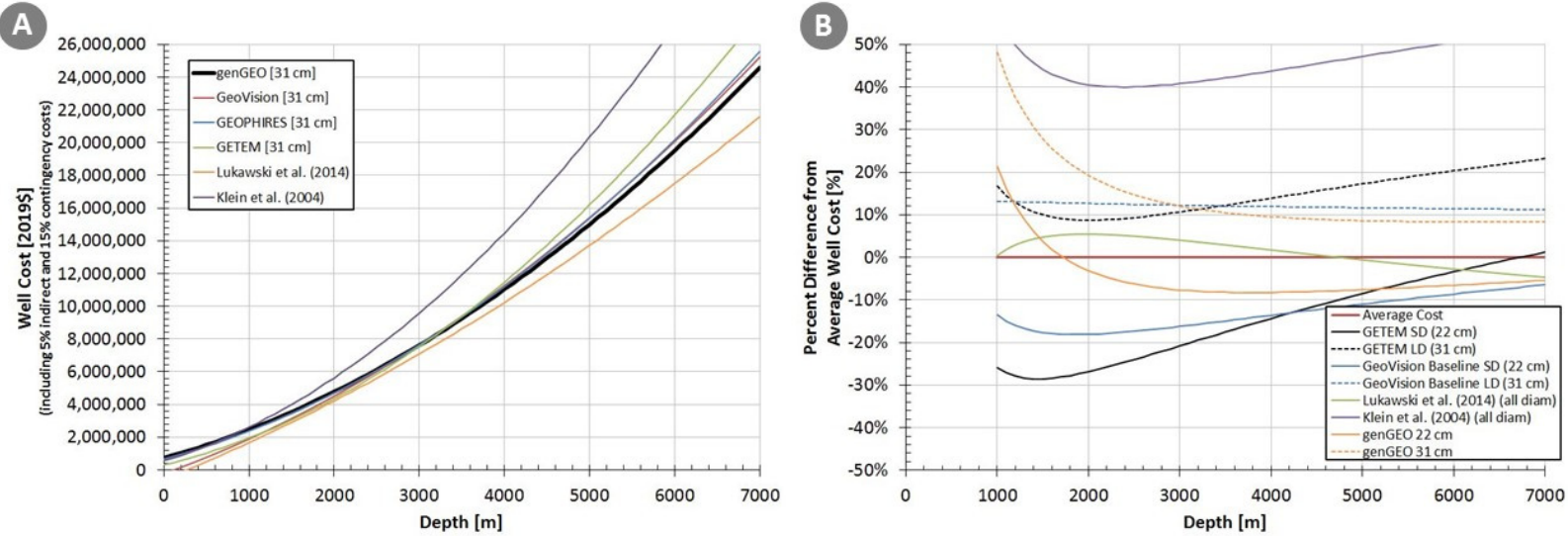

Figure S9: A) The well cost in $2019 \$$ for all well models considered, and B) the difference between well cost and the average cost for all well models considered. The 'average' cost is the average of: Lukawski et al.

(2014), GeoVision Baseline Small-diameter (SD), and GeoVision Baseline Large-diameter (LD) costs.

Figure S9B shows the percent difference between the average cost of all wells at a given depth and the cost curves of GETEM, GeoVision, Lukawski et al. (2014), Klein et al. (2004), and 
genGEO. The average cost is the average of the cost of the Lukawski et al. (2014), GeoVision 'Baseline SD', and GeoVision 'Baseline LD' models at each depth. GEOPHIRES essentially uses the GeoVision 'Baseline' cost relationships and is thus excluded from the figure.

Figure S9B shows the GETEM costs tend to be higher than the other well models, especially at great depth. Also, the Klein et al. (2004) cost relationship consistently predicts a well cost approximately $50 \%$ greater than the average. The genGEO cost curves tend to be within $10 \%$ of the average, except at shallow depths where the genGEO curves are greater than average. This exception is due to the negative y-intercepts of the Lukawski et al. (2014) and GeoVision LD curves, which provide unrealistically low well costs at shallow depths. Thus, the genGEO model is better suited for a large range of well depths and diameters.

Perhaps the most important finding of Figure S9 is the field-reported data of Lukawski et al. (2014) and the bottom-up models (GETEM/GeoVision) tend to agree within $20 \%$ on well cost. The greatest difference is the field-reported Klein et al. (2004) data; however, this dataset had low correlation $\left(r^{2}=0.558\right)$ and thus presumably it was corrected and included in Lukawski et al. (2014), where it had a higher correlation $\left(r^{2}=0.92\right)$.

\section{S3.3.3Well Cost Adjustment for $\mathrm{CO}_{2}, \Delta \mathrm{CCO}_{2}$-Well}

If a well is used to inject or produce $\mathrm{CO}_{2}$, it has additional expenses such as corrosion resistant lining and $\mathrm{CO}_{2}$-resistant cement. Figure $\mathrm{S} 10$ shows the cost of injection and monitoring wells as data points for the Kemper $\mathrm{CO}_{2}$ storage site in the Southeast USA (Esposito et al., 2019) as well as general $\mathrm{CO}_{2}$ well cost estimates from EPA (2008; 2010). The genGEO monitoring well relation in Figure $\mathrm{S} 10$ is not adjusted for $\mathrm{CO}_{2}$ use and is a $22 \mathrm{~cm}$ diameter water well calculated using Equation S43.

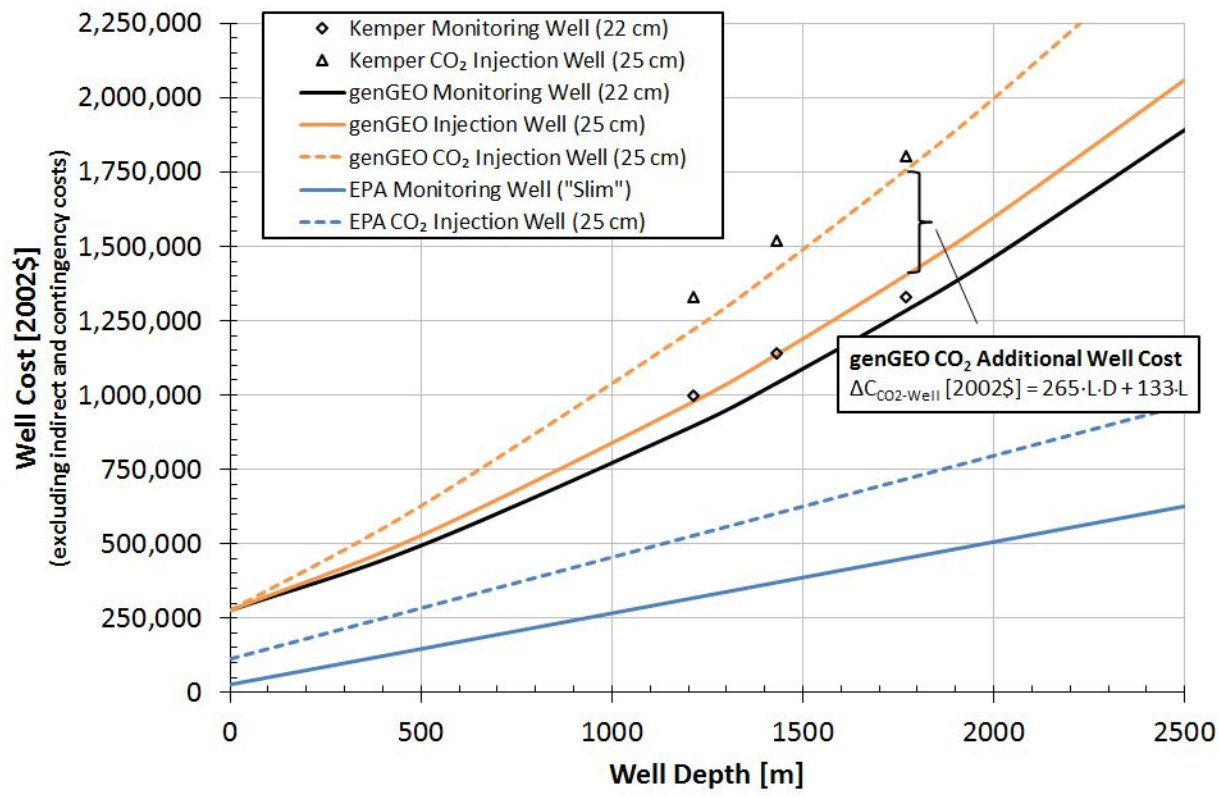

Figure S10: genGEO additional well cost when using $\mathrm{CO}_{2}$. The genGEO hydrothermal well cost model closely estimates the cost of a $\mathrm{CO}_{2}$ monitoring well at the Kemper site (black line) (Esposito et al., 2019). An additional well cost is added to the water well cost to match the Kemper $\mathrm{CO}_{2}$ well costs (orange lines). 
Figure S10 shows that the EPA $(2008 ; 2010)$ well costs scale linearly with depth, which is not consistent with our well cost analysis. This discrepancy questions the robustness of the EPA well costs because a $22 \mathrm{~cm}$ monitoring well should cost very similar to a $22 \mathrm{~cm}$ water well. The linear scaling and costs of the EPA estimates match closely with the slopes of the GeoVision "Ideal" well cost data (Section S3.3.2). The GeoVision "Ideal" well costs differ the GeoVision "Baseline" costs because the "Ideal" costs only consider a single "mono-bore" casing in the well. The monobore casing represents a new technology step that has not yet been achieved. Current well drilling practice minimizes the number of well casings to stabilize the borehole, but still requires several, depending on depth (Lowry et al., 2017). Thus, similar to the idealized GeoVision assumptions, we do not use the EPA monitoring and injection well cost estimates in genGEO.

Figure S10 shows that the genGEO $22 \mathrm{~cm}$ well cost fits the Kemper $22 \mathrm{~cm}$ monitoring well cost estimates without modification. However, a genGEO $25 \mathrm{~cm}$ well cost (solid orange line in Figure $\mathrm{X}$ ) does not fit the Kemper $25 \mathrm{~cm} \mathrm{CO}_{2}$ injection well. Thus, an additional cost is needed, $\Delta C_{C O 2-W e l l}$, to modify the $25 \mathrm{~cm}$ genGEO well for $\mathrm{CO}_{2}$ injection. This additional cost is shown in Equation S43, where $L_{W e l l}$ is the length of the well and $D_{W e l l}$ is the inner well diameter. Contingency, $X_{P C-\text { well }}$, and indirect cost coefficients, $X_{I C-w e l l}$, for wells are used. These costs are adjusted by the oil \& gas price index, $P P I_{O \& G}$.

$$
\Delta C_{C O 2-W e l l}=X_{I C-\text { well }} \cdot X_{P C-\text { well }} \cdot P P I_{O \& G} \cdot\left(265 \frac{\$}{m^{2}} \cdot L_{W e l l} \cdot D_{W e l l}+133 \frac{\$}{m} \cdot L_{W e l l}\right)
$$

EPA (2008; 2010) explicitly defines a cost of $4.902008 \$ \mathrm{ft}^{-1} \mathrm{in}^{-1}$ to build-up wells to be suitable for $\mathrm{CO}_{2}$ flow. This cost is converted to base-year dollars (i.e. $2652002 \$ \mathrm{~m}^{-2}$ ) and directly used as the first cost term within the parenthesis in Equation S43. The second term in Equation S43 is a least squares fit to account for the remaining difference in cost between the genGEO $25 \mathrm{~cm}$ monitoring water well and the three Kemper $\mathrm{CO}_{2}$ injection wells.

\section{S3.4 Surface Piping System, $C_{\text {surfacePiping }}$}

We found four sources of surface piping system costs in our review: GETEM, GEOPHIRES, EPA (EPA, 2008; 2010), and the Kemper $\mathrm{CO}_{2}$ storage site (Esposito et al., 2019). The surface piping system is sometimes called the "field gathering system" in the geothermal community but is predominantly the pipe cost to connect the wellheads to the central generating plant. In genGEO, any downhole production pumps are categorized as part of the surface plant, and not the surface piping system, despite possibly being located remotely within the piping network.

The genGEO specific surface piping cost and surface piping cost are given in Equations S43 and S44, where $L_{\text {Pipe }}$ is the total surface pipe length and $D_{\text {Pipe }}$ is the surface pipe diameter. These costs are adjusted by year using the pipe cost index, $P P I_{\text {Pipe }}$. Project contingency for surface piping system, $X_{P C-p i p e}$, and indirect cost, $X_{I C-p i p e}$, multipliers are applied using GETEM values $\left(X_{P C \text {-pipe }}=1.15\right.$ and $\left.X_{I C-\text { pipe }}=1.12\right)$.

$$
\begin{aligned}
& c_{\text {SurfacePiping }}=2205 \frac{\$}{m^{3}} \cdot D_{\text {Pipe }}^{2}+134 \frac{\$}{m} \\
& C_{\text {SurfacePiping }}=X_{P C-p i p e} \cdot X_{\text {IC-pipe }} \cdot P P I_{\text {Pipe }} \cdot\left(c_{\text {SurfacePiping }} \cdot L_{\text {Pipe }}\right)
\end{aligned}
$$


Table S16 shows the specific surface pipe costs, $c_{\text {SurfacePiping }}$, in 2002 year dollars and SI units. The cost of $\mathrm{CO}_{2}$ surface piping by EPA $(2008 ; 2010)$ is $830002008 \$ \mathrm{in}^{-1} \mathrm{mile}^{-1}$, which is for "all elements of pipeline costs," therefore we assume it includes indirect cost and contingency. At the Kemper site, Esposito et al. (2019) reports the cost of 5 miles of 8- and 12-inch $\mathrm{CO}_{2}$ pipeline as $1200002017 \$ \mathrm{in}^{-1} \mathrm{mile}^{-1}$, including indirect costs but excluding contingency. GEOPHIRES provides a cost of $5002017 \$ \mathrm{~m}^{-1}$, irrespective of diameter and excluding contingency and indirect costs. GETEM and GEOPHIRES provide piping cost for water while EPA $(2008 ; 2010)$ and Esposito et al. (2019) provide pipe cost for $\mathrm{CO}_{2}$. No appreciable dependence on fluid type is seen in this analysis.

Table S16: Specific surface pipe cost without contingency or indirect costs.

\begin{tabular}{|ll|}
\hline Source & $\begin{array}{l}\text { Specific Pipe Cost, CsurfacePiping } \\
{[2002 \$ / \mathrm{m}]}\end{array}$ \\
\hline GETEM & $c=2160 \cdot D_{\text {Pipe }}{ }^{2}-6.097 \cdot D_{\text {Pipe }}+134$ \\
\hline EPA (2008; 2010) & $c=1051 \cdot D_{\text {Pipe }}$ \\
\hline Esposito et al. (2019) & $c=1148 \cdot D_{\text {Pipe }}$ \\
\hline GEOPHIRES & $c=252$ \\
\hline genGEO & $c=2205 \cdot D_{\text {Pipe }}{ }^{2}+134$ \\
\hline
\end{tabular}

Most sources use a pipe cost that is linearly proportional with pipe diameter. However, GEOPHIRES assumes a constant value for all diameters and GETEM provides a second-order relation for "standard schedule" (i.e. steel) hydrothermal piping as a function of pipe diameter. This relationship is derived from ASPEN simulations of surface piping, valid from $10 \mathrm{~cm}$ to $90 \mathrm{~cm}$, and without indirect cost or contingency.

Out of all sources found in our review, GETEM provides the best evidence of an accurate cost relationship. First, the GETEM cost model is derived from ASPEN simulations of wellfield surface piping, including typical features such as expansion loops, check valves, and insulation. While the details of these simulations are not available or reproducible, this level of detail in-and-of itself provides certainty beyond the rule-of-thumb approximations given by EPA (2008; 2010), Esposito et al. (2019), and GEOPHIRES. Second, a linear relationship cost model with pipe diameter does not reflect the complexity of purchasing and handling large-diameter piping. Thus, a second-order relationship based on GETEM simulations is a better way to estimate surface piping costs. As a result, the genGEO cost relationship is a regression of the surface pipe cost data provided by GETEM. The genGEO relationship differs from GETEM by removing the first-order pipe diameter term, which was not statistically significant. All four of these relations considered in this analysis and the genGEO relationship are given in Table S16 and plotted in Figure S11. 


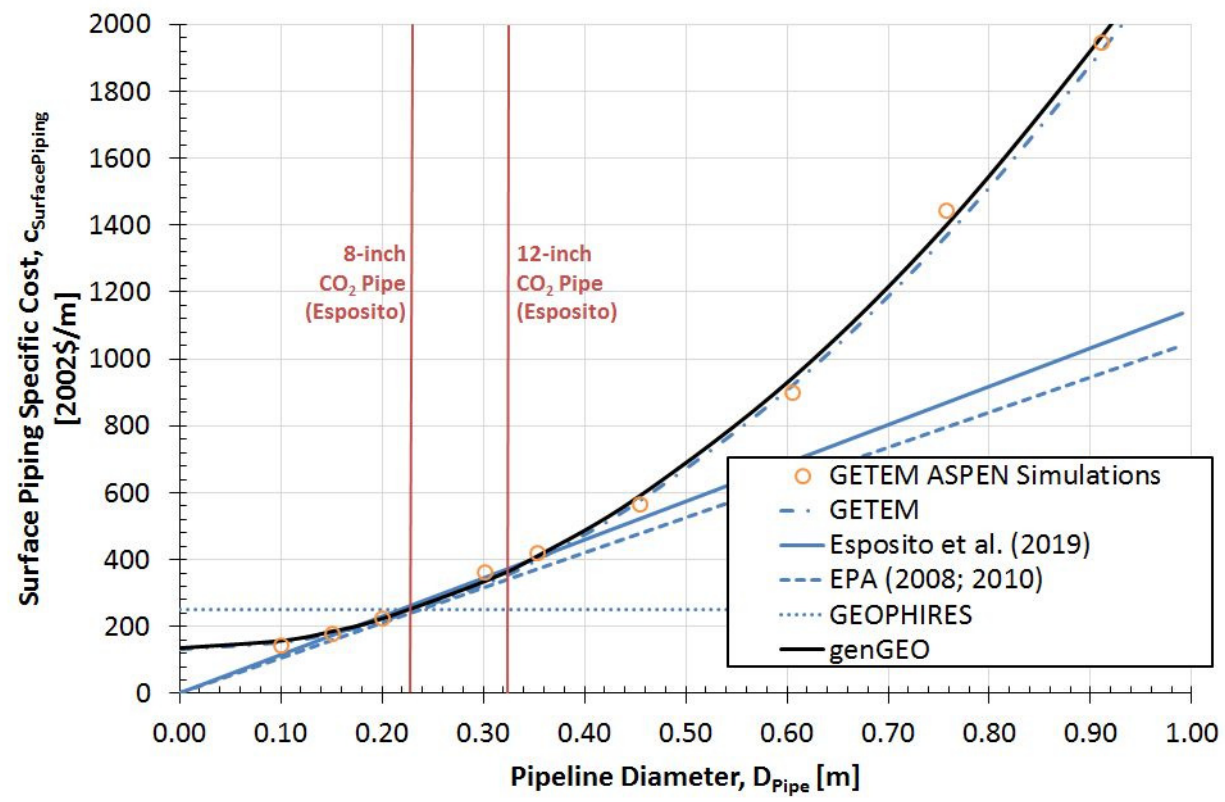

Figure S11: A comparison of the specific pipeline cost as a function of pipeline diameter for different cost models. The genGEO surface piping cost is a regression of the GETEM ASPEN cost data, neglecting insignificant terms.

Figure S11 shows that all cost models align near a pipe diameter of $0.20 \mathrm{~m}$ (8 inches), where the variation is the smallest at $+/-11 \%$. Thus, it is possible that most pipe cost models were derived by assuming a linear relationship with pipe diameter and calculated the cost from this single data point.

Interestingly, the substantial variation in surface pipeline cost models does not provide sufficient granularity to compare the effect of $\mathrm{CO}_{2}$-compatible pipeline materials on cost. One would expect a $\mathrm{CO}_{2}$ pipeline to have a higher cost than a steel pipeline of the same diameter. This increased cost would be due to the higher costs associated with procuring and working with stainless steel. Nonetheless, we assume that the pipeline cost is insensitive to material type and recommend using the genGEO relation derived in this study for both $\mathrm{CO}_{2}$ and water.

Many assumptions can be made to estimate the length and diameter of surface piping required. GETEM and GEOPHIRES both assume $750 \mathrm{~m}$ of surface piping per production and injection well. GETEM uses the pipe diameter which results in a surface pipe pressure drop of $68 \mathrm{kPa}(10 \mathrm{psi})$, though this value appears to be arbitrarily chosen. Similarly, GEOPHIRES specifies a $68 \mathrm{kPa}$ pressure loss in surface equipment, but does not calculate a surface pipe diameter. In genGEO, any surface pipe length and diameter may be used, as required for the well configuration.

\section{S3.5 Wellfield Development Costs, $C_{\text {Wellfield }}$}

Wellfield development costs include the cost to permit and develop a geothermal power plant site. Wellfield costs for water in genGEO are adopted from GETEM (Section S3.5.1). A $\mathrm{CO}_{2}$ wellfield incurs additional costs for a Class VI permit, which is a special regulatory permit required for $\mathrm{CO}_{2}$ injection wells in the United States. This additional $\mathrm{CO}_{2}$ cost is for monitoring wells and equipment, 
according to Esposito (2019) (Section S3.5.2). $\mathrm{CO}_{2}$ geothermal systems located outside the United States likely have different costs.

Equation S46 shows the wellfield development costs, $C_{\text {Wellfield, }}$ included in genGEO for permitting, $C_{\text {Permitting }}, \mathrm{CO}_{2}$ wellfield permitting, $\Delta C_{\text {Permitting,CO2 }}$, and $\mathrm{CO}_{2}$ wellfield monitoring, $\Delta C_{\text {Monitoring,CO2 }}$. The additional $\mathrm{CO}_{2}$ costs are neglected for a water wellfield. We adopt GETEM indirect and contingency cost multipliers $\left(X_{I C-w f}=1.05\right.$ and $\left.X_{P C-w f}=1.15\right)$.

$$
C_{\text {Wellfield }}=C_{\text {Permitting }}+\Delta C_{\text {Permitting-CO2 }}+\Delta C_{\text {Monitoring-CO2 }}
$$

Fluid and pore rights are assumed to be already obtained and are therefore outside the scope of this work. This assumption is also made by EPA (2008; 2010), GEOPHIRES, and Esposito et al. (2019).

\section{S3.5.1 Base Wellfield Development Costs, $C_{\text {Permitting }}$}

GETEM includes a fixed cost for wellfield and power plant permitting of $1,000,0002012 \$$ or $665,7002002 \$$. This cost is included in genGEO for any working fluid as shown in Equation S47. The permitting cost index, $P P I_{P e r m i t}$, is used to adjust to the desired year.

$$
C_{\text {Permitting }}=X_{I C-w f} \cdot X_{P C-w f} \cdot P P I_{\text {Permit }} \cdot\left(665700 \frac{\$}{\text { site }}\right)
$$

GEOPHIRES does not consider wellfield development costs.

\section{S3.5.2 Wellfield Cost Adjustment for $\mathrm{CO}_{2}, \Delta C_{P e r m i t t i n g-\mathrm{CO}_{2}}$ and $\Delta \boldsymbol{C}_{\text {Monitoring-CO}}$}

The costs of developing a $\mathrm{CO}_{2}$ wellfield in genGEO are adopted from Kemper $\mathrm{CO}_{2}$ storage site cost estimates (Esposito et al., 2019; Riestenberg et al., 2018). The Kemper cost estimates plan for sufficient monitoring to meet all expected U.S. EPA CCS monitoring requirements to receive tax credits for $\mathrm{CO}_{2}$ sequestration. Thus, these costs may be increased, reduced, or eliminated in countries with different regulations. The costs reported in Esposito et al. (2019) are assumed in $2017 \$$.

The wellfield costs are normalized by the Active Monitoring Area (AMA), Aco2,AMA, of the CCS development. The AMA is the Area of Review (AOR), $A_{C O 2, A O R}$, plus a 0.5 mile $(800 \mathrm{~m})$ buffer on all sides. The $A O R$ is the area of drinking water aquifers that may be affected by $\mathrm{CO}_{2}$ injection wells. For a square area of injection and production wells with side length $L_{\text {Wellzone }}$, the Area of Review is given by Equation S48 and the Active Monitoring Area is given by Equation S49.

$$
\begin{aligned}
& A_{C O 2, A O R}=\left(L_{\text {Wellzone }}\right)^{2} \\
& A_{\text {CO2,AMA }}=\left(L_{\text {Wellzone }}+1600 \mathrm{~m}\right)^{2}
\end{aligned}
$$

For the Kemper $\mathrm{CO}_{2}$ storage site, the $\mathrm{AOR}$ is $1 \mathrm{mi}^{2}\left(\mathrm{~A}_{\mathrm{CO}, \mathrm{AOR}}=2.6 \mathrm{~km}^{2}\right)$ and the AMA is $4 \mathrm{mi}^{2}$ $\left(A_{C O 2, A M A}=10.2 \mathrm{~km}^{2}\right)$. The U.S. EPA Class VI well permitting costs are 823,000 $2017 \$$, excluding indirect and contingency costs (see Table 4, Sections A.2 through A.4 in Esposito et al. (2019)). In genGEO, this cost is adjusted to $45,000 \$ / \mathrm{km}^{2}$ in Equation $\mathrm{S} 50$. 


$$
\Delta C_{\text {Permitting-CO2 }}=X_{I C-w f} \cdot X_{P C-w f} \cdot P P I_{\text {Permit }} \cdot\left(45000 \frac{\$}{\mathrm{~km}^{2}}\right) \cdot \frac{1 \mathrm{~km}^{2}}{10^{6} \mathrm{~m}^{2}} \cdot A_{C O 2, A M A}
$$

$\mathrm{CO}_{2}$ monitoring costs for the Kemper CCS site are incurred for monitoring wells and surface monitoring equipment (Esposito et al., 2019). The size and extent of this monitoring system is designed to copy that used at the Decatur $\mathrm{CO}_{2}$ storage site to assure the issuance of an EPA Class VI permit at Kemper (Esposito et al., 2019). The actual language of the EPA Class VI permitting policy is up to interpretation and thus precedent is currently the best method to determine the monitoring equipment needed. The $\mathrm{CO}_{2}$ monitoring cost, $\Delta C_{\text {Monitoring-CO2 }}$, is given in Equation S51, where $C_{\text {MonitoringWells-CO2 }}$ is the $\mathrm{CO}_{2}$ monitoring well cost and $C_{\text {SurfaceMonitoring-CO2 }}$ is the $\mathrm{CO}_{2}$ surface monitoring cost.

$$
\Delta C_{\text {Monitoring-CO2 }}=C_{\text {MonitoringWells-CO2 }}+C_{\text {SurfaceMonitoring-CO2 }}
$$

The majority of the monitoring cost at the Kemper site is from the monitoring wells (i.e. $91 \%$ ). The Kemper site has two deep in-zone monitoring wells and one shallower drinking water (USDW) well per $\mathrm{CO}_{2}$ injection well. The deep monitoring wells at Kemper are fully cased to depth, using 5.5 inch $(14 \mathrm{~cm})$ outer diameter, 4.75 inch $(12 \mathrm{~cm})$ inner diameter casing in an 8.5 inch $(21.6 \mathrm{~cm})$ borehole, assuming a 0.375 inch $(1 \mathrm{~cm})$ wall. The cost of the deep monitoring wells matches very closely to the cost of a $21.6 \mathrm{~cm}$ well using the genGEO well cost relation (Equation S42) (See also Figure S10). Thus, the cost of $\mathrm{CO}_{2}$ monitoring wells in genGEO, $C_{\text {MonitoringWells-CO2 }}$, is given in Equation S52 as the product of the number of monitoring wells, $G_{\text {MonitoringWells-CO2 }}$, and the cost of a $21.6 \mathrm{~cm}$ diameter well drilled to the reservoir depth, $C_{W e l l, D=21.6 \mathrm{~cm}}$. The well cost already has indirect and contingency cost included, so it is not included again.

$$
C_{\text {MonitoringWells-CO2 }}=G_{\text {MonitoringWells }-\mathrm{CO} 2} \cdot C_{W e l l, D=21.6 \mathrm{~cm}}
$$

The number of monitoring wells required at a site is site-specific. In genGEO, we account for the cost of drilling one monitoring well per injection well for $\mathrm{CO}_{2}$-geothermal power plants.

For surface monitoring of the $\mathrm{CO}_{2}$ plume, the Kemper site proposes to use seismic monitoring. The cost at the Kemper site is 2,000,000 2017\$, excluding indirect and contingency costs. The $\mathrm{CO}_{2}$ surface monitoring cost, $C_{\text {SurfaceMonitoring-CO2 }}$, is adjusted using the oil \& gas support price index, $P P I_{O \& G-S}$, and normalized by the Active Monitoring Area. The cost of surface monitoring of the $\mathrm{CO}_{2}$ plume in genGEO is given in Equation S53.

$$
C_{\text {SurfaceMonitoring-CO2 }}=X_{I C-w f} \cdot X_{P C-w f} \cdot P P I_{O \& G-s} \cdot\left(138000 \frac{\$}{\mathrm{~km}^{2}}\right) \cdot \frac{1 \mathrm{~km}^{2}}{10^{6} \mathrm{~m}^{2}} \cdot A_{C O 2, A M A}
$$

\section{S3.6 Exploration, $C_{\text {Exploration }}$}

Exploration costs in genGEO are derived from GETEM and cost estimates for the Kemper $\mathrm{CO}_{2}$ storage site (Esposito et al., 2019). The exploration cost, consists of two primary tasks: drilling exploration wells and reservoir modeling. The exploration cost, $C_{\text {Exploration }}$, is given in Equation S54, where $C_{\text {Modeling }}$ is the cost to model the reservoir (e.g. groundwater flow, fracture models) and $\Delta C_{\text {Characterizationwells }}$ is the additional cost of a well to extract cores for reservoir modelling. Additionally, $\Delta C_{\text {Modeling, } \mathrm{CO} 2}$ is an additional cost for $\mathrm{CO}_{2}$ reservoir modeling, but may be excluded 
when using hydrothermal reservoirs. For exploration, we adopt the GETEM exploration indirect and contingency cost multipliers in genGEO (i.e. $X_{I C-\operatorname{expl}}=1.05$ and $X_{P C-\operatorname{expl}}=1.15$ ).

$$
C_{\text {Exploration }}=C_{\text {Modeling }}+\Delta C_{\text {CharaterizationWells }}+\Delta C_{\text {Modeling,CO2 }}
$$

GETEM has two exploration costs: modeling/permitting and drilling costs. The modeling and permitting cost are lump-sum costs of 500,000 $2010 \$$ per site for reservoir modeling plus 50,000 $2012 \$$ for non-drilling permitting and $125,0002012 \$$ for exploration drilling permitting. We adopt the GETEM modeling and permitting cost in genGEO and adjust it using the oil \& gas support price index, $P P I_{O \& G-S}$, to 508,000 2002\$, given in Equation $S 55$.

$$
C_{\text {Modeling }}=X_{I C-\operatorname{expl}} \cdot X_{P C-\operatorname{expl}} \cdot P P I_{O \& G-S} \cdot\left(508000 \frac{\$}{\text { site }}\right)
$$

The exploration drilling cost assumed by GETEM is for two successful exploration wells drilled at a $50 \%$ success rate (i.e. 4 wells drilled total). Each of these wells cost $20 \%$ more than a standard water production well of the same size. The additional well characterization cost includes coring, collecting, and analyzing reservoir rock samples. The exploration wells are used as either monitoring or water production wells after the exploration phase, so only the additional $20 \%$ characterization cost suggested by GETEM for a well is included in genGEO for characterization wells. Similar to GETEM, the Kemper site also includes two characterization wells $\left(G_{\text {CharacterizationWells }}=2\right)$ with an additional cost of $28 \%$ each. However, Kemper assumes a success rate of $100 \%$ due to the porous and homogenous nature of their wellfield. Thus, we assume the additional cost for characterization, $\Delta C_{\text {Characterizationwells }}$, is $20 \%$ the cost of two fullsize production or monitoring wells with the same well success rate, $S_{W e l l}$, used in genGEO, given in Equation S56. No indirect or contingency costs or price index adjustments are given in Equation S56 as they are already included in well cost, $C_{W e l l}$.

$$
\Delta C_{\text {CharacterizationWells }}=0.2 \cdot C_{\text {Well }} \cdot \frac{G_{\text {CharacterizationWells }}}{S_{\text {Well }}}
$$

When using $\mathrm{CO}_{2}$, additional exploration costs are incurred to model and survey the site. This additional exploration cost in genGEO is extracted from Esposito et al. (2019) for the Kemper site. The non-drilling exploration costs for Kemper are 1,380,000 2017\$, including 15\% contingency. This cost is adjusted by $P P I_{O \& G-S}$ to $977,0002002 \$$. The difference between the Kemper nondrilling cost and GETEM non-drilling cost is assumed to be the additional $\mathrm{CO}_{2}$ non-drilling exploration cost in genGEO, which is 554,000 2002\$ including contingency. This exploration cost is normalized by the Active Monitoring Area of the $\mathrm{CO}_{2}$ plume at the Kemper site, resulting in $44,8002002 \$ \mathrm{~km}^{-2}$ without indirect or contingency costs, given in Equation S57.

$$
\Delta C_{\text {Modeling,CO2 }}=X_{I C-\operatorname{expl}} \cdot X_{P C-\operatorname{expl}} \cdot P P I_{O \& G-s} \cdot\left(44800 \frac{\$}{\mathrm{~km}^{2}}\right) \cdot \frac{1 \mathrm{~km}^{2}}{10^{6} \mathrm{~m}^{2}} \cdot A_{C O 2, A M A}
$$

For comparison, GEOPHIRES assumes exploration costs are $60 \%$ the cost of one regular well and $\$ 1 \mathrm{M}$ per site for geophysical and field work, where both values have $12 \%$ indirect costs and $15 \%$ contingency added. This methodology uses the same non-drilling and drilling methodology used in genGEO; however, the values are reduced-order approximations of GETEM costs and are therefore not considered in genGEO development. 


\section{S3.7 Well Stimulation, $C_{\text {Stimulation }}$}

Well stimulation cost is the cost of pressurizing the impermeable basement rock of a so-called Enhanced Geothermal System (EGS) reservoir to create artificial fractures through which heat can be extracted. Naturally permeable geothermal systems, such as those using porous reservoirs, do not require stimulation. When these typical, naturally permeable, geothermal resources are used, the stimulation cost is zero. Table S17 shows a comparison of stimulation costs found in our literature review. The costs are inflated by the inverse of the success rate and do not include indirect costs and contingency.

Table S17: Well stimulation cost comparison including success rate, but without indirect and contingency costs.

\begin{tabular}{|llc|} 
& $\begin{array}{l}\text { Naturally Permeable } \\
{[2002 \$ / W e l l]}\end{array}$ & $\begin{array}{l}\text { EGS } \\
{[2002 \$ / W e l l]}\end{array}$ \\
\hline GETEM & 0 & $1,301,000$ \\
\hline $\begin{array}{l}\text { GEOPHIRES } \\
\text { Lowry et al. (2017) }\end{array}$ & 0 & 596,000 \\
\hline Sanyal et al. (2007) & -- & 248,000 \\
\hline genGEO (average) & 0 & 715,000 \\
\hline
\end{tabular}

GETEM assumes a well stimulation cost of 2,500,000 2012\$ per injection well for EGS reservoirs, plus a $75 \%$ success rate, $5 \%$ indirect cost, and $15 \%$ contingency. GEOPHIRES assumes an EGS stimulation cost of 1,250,000 $2017 \$$ per injection well, plus $15 \%$ contingency and $5 \%$ indirect cost (Beckers and Young, 2017). The same value of $1,250,0002017 \$$ is assumed by GeoVision (Lowry et al., 2017). Lastly, Sanyal et al. (2007) reports that well stimulation costs for EGS projects in Soultz (Europe) and the Cooper Basin (Australia) are 750,000 2006\$ per well, on average, assuming included indirect cost and contingency. In genGEO, we have assumed the average of these three sources. The stimulation cost is given in Equation S58. All costs are adjusted to $2002 \$$ using the Drilling Services cost index, $P P I_{D S}$ and a $5 \%$ indirect cost and $15 \%$ contingency cost are assumed $\left(X_{I C-\text { stim }}=1.05\right.$ and $\left.X_{P C-\text { stim }}=1.15\right)$.

$$
C_{\text {Stimulation }}= \begin{cases}0, & (\text { Hydrothermal }) \\ X_{I C-\text { stim }} \cdot X_{P C-\text { stim }} \cdot G_{\text {Wells }} \cdot 715000, & (E G S)\end{cases}
$$




\section{S4. Operation and Maintenance (O\&M) Cost, Co\&M}

Operation and maintenance (O\&M) costs are needed to calculate the Levelized Cost of Electricity (LCOE) of any electricity generator. We report O\&M cost in this analysis with respect to three commonly reported sub-costs: 1) Labor, 2) Material, and 3) Taxes and Insurance. A fourth O\&M sub-cost, fuel, is commonly reported for fossil power generation, but are neglected in this analysis because geothermal power plants typically do not have fuel cost. The three costs are summed to equal the total O\&M cost of a general geothermal power plant in Equation S59.

$$
C_{O \& M}=C_{O \& M, L a b o r}+C_{O \& M, M a t e r i a l}+C_{O \& M, T a x e s \& I n s u r a n c e}
$$

While separating the total O\&M cost into its sub-costs provides more granularity, most sources report geothermal O\&M cost in the form of the O\&M cost fraction, $F_{O \& M}$, which is the ratio of operating and maintenance cost to overall capital cost, shown in Equation S60.

$$
F_{O \& M}=\frac{C_{O \& M}}{C_{\text {Geothermal }}}
$$

Our analysis suggests the O\&M cost fraction may be approximated as 5.5\% (Equation S61).

$$
F_{O \& M} \approx 5.5 \%
$$

Thus, the total annual O\&M cost in genGEO is the product of this O\&M cost fraction and the total capital cost of the geothermal facility, given in Equation S62.

$$
C_{O \& M}=0.055 * C_{\text {Geothermal }}
$$

Figure S12 shows O\&M costs from several references for both geothermal systems and power cycle electricity generation systems in general. The average O\&M cost fraction for each source is reported by the bar height. The geothermal community does not publish its cost figures readily, thus we have also included relevant related power cycles costs such as coal and natural gas electricity generators. The O\&M cost fractions are also reported in Table S18.

References which provide sufficient detail of their O\&M cost breakdowns have their O\&M costs itemized, while references reporting only a single overall O\&M cost have 'unspecified' costs.

Figure S12 shows there is wide variability in O\&M cost fraction, between roughly $1 \%$ and $12 \%$, and when only geothermal facilities are included, this range only decreases slightly to between $3 \%$ and $12 \%$. The lowest cost fraction, Schuster et al. (2009) is a highly-cited Organic Rankine Cycle techno-economic simulation paper. The highest cost fraction, Sanyal et al. (2007) estimates the capital and operating costs of an enhanced geothermal system (EGS). Neff (2019) and Lazard (2019) aggregate existing literature values and thus have very large variability.

It is worth noting that O\&M costs reported from within the geothermal industry (i.e. Sanyal (2004; 2007), Calpine, and Ormat) have higher O\&M cost fractions than typically used sources such as Lazard and GETEM. Sanyal (2004) and Sanyal et al. (2007) are published works of GeothermEx, a Schlumberger geothermal consulting company that cooperates closely with the Geysers. The Geysers is operated by Calpine and is the largest geothermal installation in the world. Conversely, 
the O\&M fraction from Calpine (2020) is lower than Sanyal (2004). This may be attributed to the small fraction of geothermal generation within Calpine's generation portfolio. Only $\sim 3 \%$ of Calpine's generation is geothermal, the remainder are fossil facilities.

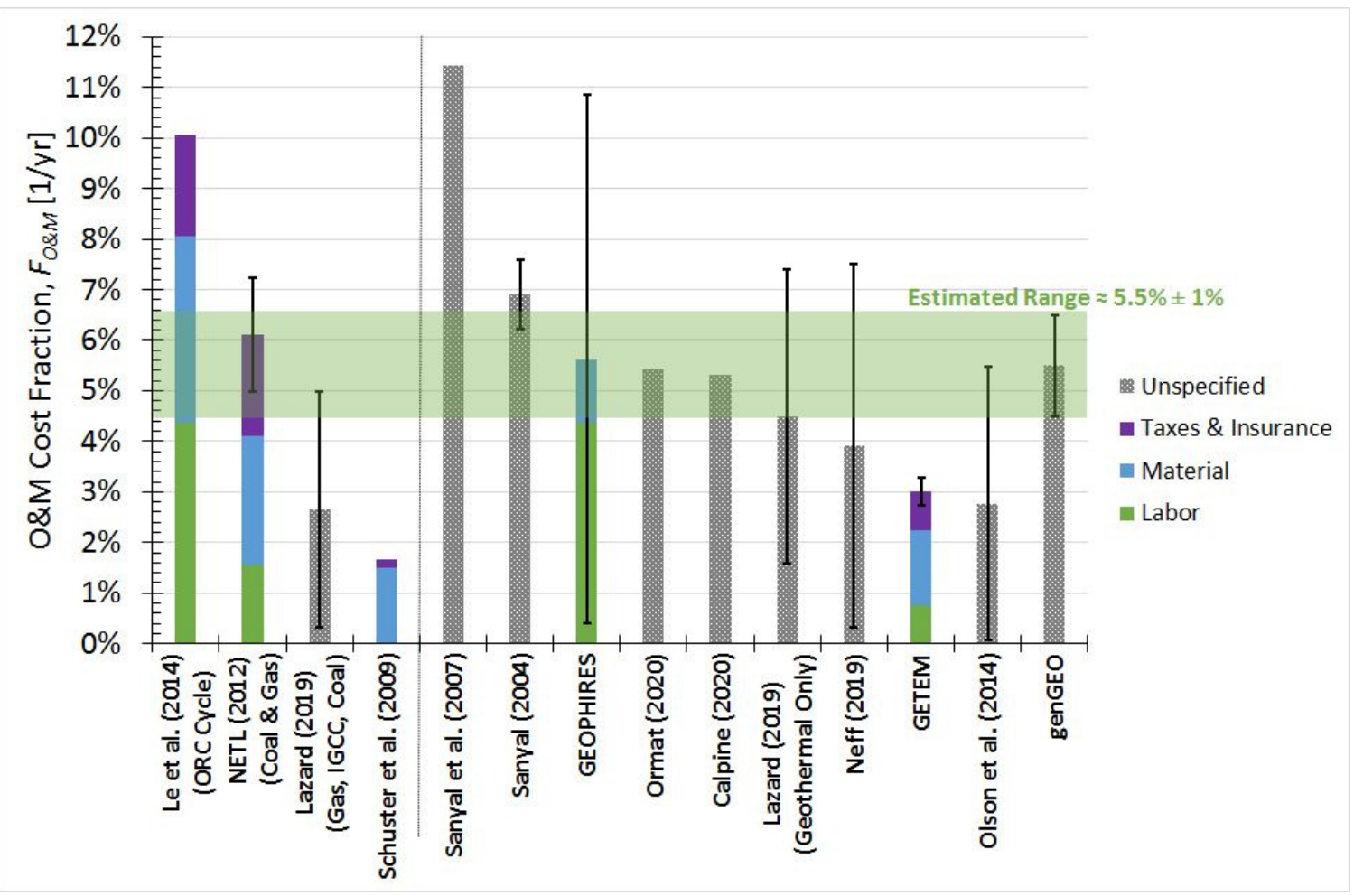

Figure S12: Operation and maintenance (O\&M) costs as a fraction of total capital cost. When provided, the sources of each O\&M cost are itemized. The bar height represents the average total O\&M cost fraction from each source while the error bars represent the range of values containing $95 \%$ of the data points. Sources to the right of the vertical line are for geothermal-specific costs, while sources to the left are for common power cycle generation, such as coal and gas.

When more than one cost fraction is provided, the error bars in Figure S12 and the variation in Table S18 show the range which contains $95 \%$ of data points. For GETEM and GEOPHIRES, this range is determined by simulating geothermal resources between $125^{\circ} \mathrm{C}$ and $200^{\circ} \mathrm{C}$ and capacities between $1 \mathrm{MW}_{\mathrm{e}}$ and $100 \mathrm{MW}_{\mathrm{e}}$ for a depth of $2.5 \mathrm{~km}$. For the Neff (2019) and Lazard (2019) sources, the variability represents the results from all combinations of capital cost, capacity factor, and O\&M costs given. The NETL (2012) dataset contains eight data points representing $550 \mathrm{MW}_{\mathrm{e}}$ coal, IGCC, and NGCC plants both with and without $\mathrm{CO}_{2}$ capture.

The Calpine (2020) and Ormat (2020a) O\&M costs are derived from their annual reports, i.e. SEC form 10-k. In 2019, Calpine reports "Operating and Maintenance Expense" of $1001 \mathrm{M} \$$ and "Property, plant and equipment" asset value, without depreciation, of $18810 \mathrm{M} \$$. Thus, the O\&M fraction is the ratio of these, or $5.3 \%$. Similarly, Ormat (2020a) reports a total cost of electricity revenue of $313 \mathrm{M} \$$ and $6240 \mathrm{GW}_{\mathrm{e}} \mathrm{h}$ generated, resulting in an electricity cost of $50 \$ / \mathrm{MW}_{\mathrm{e}}-\mathrm{h}$. Unfortunately, the O\&M cost itself can't be discerned from the form 10-k as Ormat (2020a) includes both debt service cost and O\&M costs in their electricity cost value. Instead, we use an O\&M value of $25 \$ / M_{\mathrm{e}}-\mathrm{h}$ reported by Ormat (2020b). Thus, we assume $50 \%$ of the total cost of 
electricity revenue is due to O\&M (i.e. $313 / 2=156 \mathrm{M} \$$ ). Ormat $(2020 \mathrm{a})$ reports total undepreciated generation assets of $2883 \mathrm{M} \$$. Thus, we find the Ormat O\&M fraction is the ratio of total cost of electricity revenue due to O\&M to the total undepreciated generation assets, or $5.4 \%$.

While most sources describe O\&M costs as O\&M cost fractions, a few (i.e. Sanyal (2004), GETEM, and GEOPHIRES) provide O\&M costs as a function of capacity. We discovered that despite the use of non-linear relations by these sources to estimate O\&M cost as a function of capacity, when the O\&M cost is normalized, the O\&M cost fraction is relatively constant. This is shown by the narrow error bars of Sanyal (2004) and GETEM in Figure S12. Thus, we find that reporting O\&M cost as an O\&M cost fraction still provides the same sensitivity to capacity as more complex models. Lastly, the large O\&M cost fraction variation of GEOPHIRES is due to an incomplete characterization of the GETEM model upon which it is based and we therefore do not weight it heavily.

Table S18: The O\&M cost fractions of Figure S12.

\begin{tabular}{|c|c|c|c|c|c|c|}
\hline & & & M Fraction & 1/year] & & \\
\hline Source & Labor & Material & $\begin{array}{l}\text { Taxes \& } \\
\text { Insurance }\end{array}$ & Unspecified & Total & $\begin{array}{l}\text { Variation } \\
(+/-)\end{array}$ \\
\hline $\begin{array}{l}\text { Le et al. (2014) } \\
\text { [ORC Cycle] }\end{array}$ & $4.4 \%$ & $3.7 \%$ & $2.0 \%$ & & $10.1 \%$ & \\
\hline $\begin{array}{l}\text { NETL (2012) } \\
\text { [Coal \& Gas] }\end{array}$ & $1.6 \%$ & $2.6 \%$ & $2.0 \%$ & & $6.1 \%$ & $1.1 \%$ \\
\hline $\begin{array}{l}\text { Lazard (2019) } \\
\text { [Gas, IGCC, Coal] }\end{array}$ & & & & $2.6 \%$ & $2.6 \%$ & $2.3 \%$ \\
\hline $\begin{array}{l}\text { Schuster et al. } \\
\text { (2009) } \\
\text { [ORC Cycle] }\end{array}$ & & $1.5 \%$ & $0.2 \%$ & & $1.7 \%$ & \\
\hline $\begin{array}{l}\text { Sanyal et al. (2007) } \\
\text { [Geothermal] }\end{array}$ & & & & $11.4 \%$ & $11.4 \%$ & \\
\hline $\begin{array}{l}\text { Sanyal (2004) } \\
\text { [Geothermal] }\end{array}$ & & & & $6.9 \%$ & $6.9 \%$ & $0.7 \%$ \\
\hline GEOPHIRES & $4.4 \% *$ & $1.3 \%$ ** & $0.0 \%$ & & $5.6 \%$ & $5.2 \%$ \\
\hline $\begin{array}{l}\text { Ormat (2020a) } \\
\text { [Geothermal] }\end{array}$ & & & & $5.4 \%$ & $5.4 \%$ & \\
\hline $\begin{array}{l}\text { Calpine (2020) } \\
\text { [Geothermal \& Gas] }\end{array}$ & & & & $5.3 \%$ & $5.3 \%$ & \\
\hline $\begin{array}{l}\text { Lazard (2019) } \\
\text { [Geothermal] }\end{array}$ & & & & $4.5 \%$ & $4.5 \%$ & $2.9 \%$ \\
\hline $\begin{array}{l}\text { Neff (2019) } \\
\text { [Geothermal] }\end{array}$ & & & & $3.9 \%$ & $3.9 \%$ & $3.6 \%$ \\
\hline GETEM & $0.8 \% *$ & $1.5 \%$ & $0.8 \%$ & & $3.0 \%$ & $0.3 \%$ \\
\hline $\begin{array}{l}\text { Olson et al. (2014) } \\
\text { [Geothermal] }\end{array}$ & & & & $2.8 \%$ & $2.8 \%$ & $2.7 \%$ \\
\hline genGEO & & & & $5.5 \%$ & & $1.0 \%$ \\
\hline
\end{tabular}


The variability in O\&M cost is similar across all sources and technologies in Figure S12. For instance, the non-geothermal cost estimates have a similar variability in cost fraction as the geothermal cost estimates. More detailed data from electricity operators would be needed to distinguish geothermal costs from other types of power cycles. However, but based on the data found in our review, we can't make meaningful comparisons between geothermal and nongeothermal power plants and thus assume the O\&M cost fraction is constant across all technologies.

In the studies that broke down their O\&M cost, we found that there was a large variability in "Taxes and Insurance" reported by sources, varying from $0 \%$ (i.e. omitted) to $2 \%$. GETEM assumes a value of $0.75 \%$ while NETL assumes a value of $2 \%$. While the property tax and insurance paid by any operator can certainly vary based on any number of factors, it is conservative to assume a higher number.

GETEM and NETL both calculate their O\&M labor costs using a heuristic to estimate annual manhours required for a power plant and then combine those with an hourly rate and overhead percentages to estimate O\&M labor cost. However, the NETL labor cost is $100 \%$ greater than the GETEM cost. This is due, in part, to NETL having a $20 \%$ greater base pay rate than GETEM. Both NETL and GETEM provide detailed bottom-up estimations of O\&M labor costs, however, the NETL labor costs are more in-line with other estimates. We can extract from this comparison the cautionary tale that detailed bottom-up analyses often look convincing due to their simple, straightforward display of facts, but the result must ultimately be validated with comparison to other models or data.

A primary finding of this review of O\&M cost is the large variability in O\&M cost fraction. Sources from industry (e.g. Sanyal (2004; 2007), Ormat (2020a), and Calpine (2020)) are rare and difficult to interpret due to lack of documentation and resolution. Larger, bottom-up analyses (e.g. GETEM, NETL) have increased transparency, but leave in question their validity by only promising that they are providing realistic values. Thus, in genGEO, we cautiously apply more weight to the industry-derived values and estimate from this meta-analysis that an appropriate O\&M cost fraction is within the range of $4.5 \%$ to $6.5 \%$ (Equation S61). 


\section{S5. Surface Power Plant}

In genGEO, two types of surface power plants are simulated: an indirect organic Rankine cycle (ORC) and a direct $\mathrm{CO}_{2}$-based power cycle. These surface plant types are described in Section S5.1. Then the organic Rankine cycle (Section S5.2) and ORC optimization (Section S5.3) are further described.

\section{S5.1 Surface Plant Types}

A direct $\mathrm{CO}_{2}$-based power cycle is shown in Figure S13A and indirect organic Rankine cycle (ORC) is shown in Figure S13B. Both systems are nearly identical to those described in Adams et al. (2015).

A CO 2 -based direct geothermal system (CPG) circulates $\mathrm{CO}_{2}$ through the subsurface and directly expands the $\mathrm{CO}_{2}$ in a surface turbine to generate electricity (Figure $\mathrm{S} 13 \mathrm{~A}$ ). The $\mathrm{CO}_{2}$ system is a single power cycle circuit between the reservoir and surface, which has the advantages of both utilizing the low viscosity of the $\mathrm{CO}_{2}$ within the porous media and eliminating the heat transfer irreversibilities that occur when transferring heat from geofluid to the organic fluid.

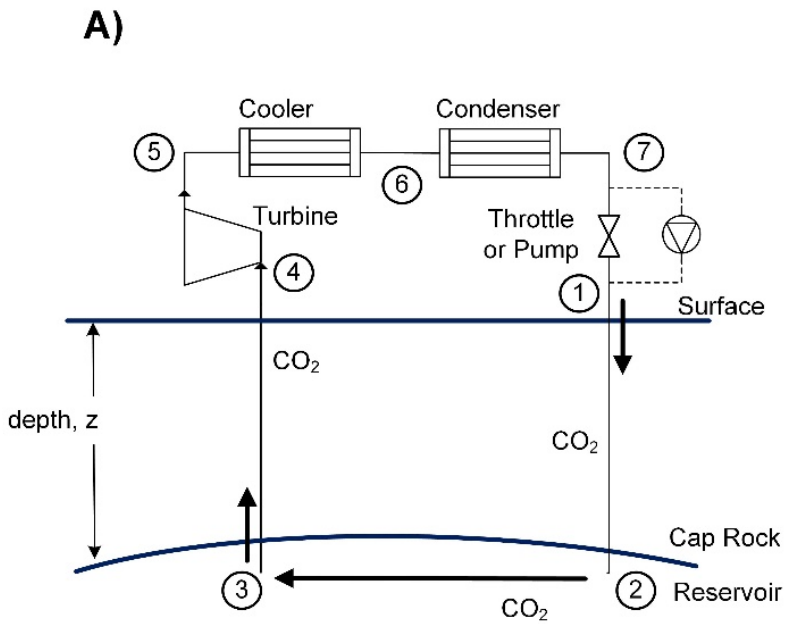

B)

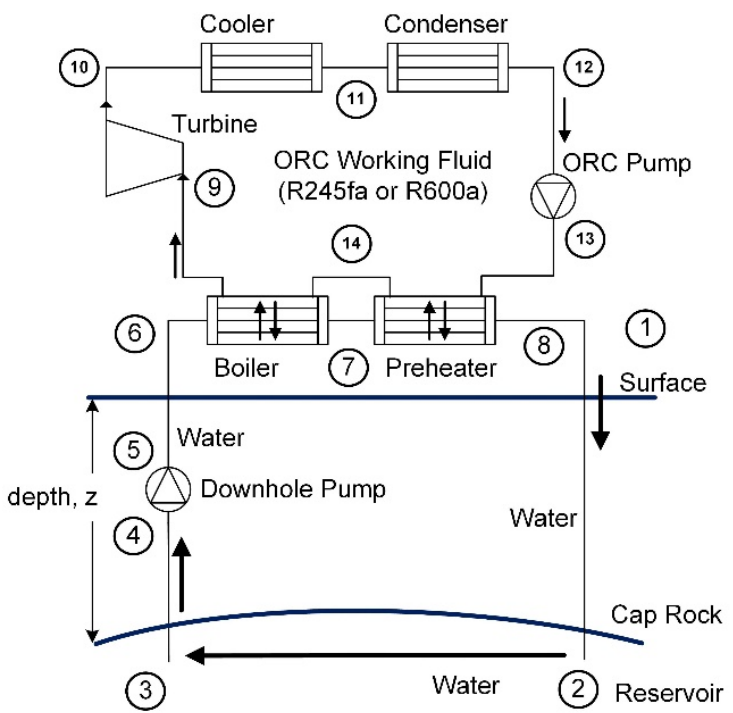

Figure S13: Schematics of two surface plants: $A)$ a $\mathrm{CO}_{2}$-Plume Geothermal (CPG) direct power system, and $B)$ a water-based geothermal system using an organic Rankine cycle (ORC).

A water-based indirect geothermal system uses an organic Rankine cycle (ORC) at the surface to generate electricity from heat (Figure S13B). Indirect systems are a mature technology where the geofluid does not come in contact with the turbo-machinery. Indirect systems are the current state-of-the-art in geothermal power generation, and are the used in both GETEM and GEOPHIRES. Both GETEM and GEOPHIRES implement ORCs through characterizations of unpublished ASPEN simulation results. For instance, GEOPHIRES has built-in equations which calculate electric power and cost as a function of geofluid production temperature. 


\section{S5.2 Organic Rankine Cycle (ORC)}

An organic Rankine cycle is a Rankine cycle using an organic refrigerant, which is common for low-temperature electricity generation. Organic refrigerants, like R245fa or isobutane (R600a), are often preferred within a cycle instead of water because they have higher conversion efficiency at low resource temperatures.

A Rankine cycle has at least four components: heat addition (boiler/preheater in Figure S13B), turbine, heat rejection (cooler/condenser in Figure S13B), and pump. Heat is transferred from the geofluid to the Rankine cycle where it either is converted to useful work in the turbine or rejected as waste heat. The conversion efficiency of the geothermal heat to electricity (thermal efficiency) is governed by the Carnot efficiency, and tends to be $<10 \%$ for low-temperature geothermal (Zarrouk and Moon, 2014).

In genGEO, an organic Rankine cycle (ORC) is used for electricity generating in water-geothermal power plants. The ORC configuration and methodology are identical to that used in Adams et al. (2015), namely, we use a single-pressure, sub-critical ORC with no superheating. An example ORC power cycle used in genGEO is shown in Figure $S 14$ for a $100^{\circ} \mathrm{C}$ geofluid temperature. The water temperature in the counter-flow heat exchanger is overlain in blue in Figure S14. The water outlet temperature from the $\mathrm{ORC}$ is $\sim 62^{\circ} \mathrm{C}$.

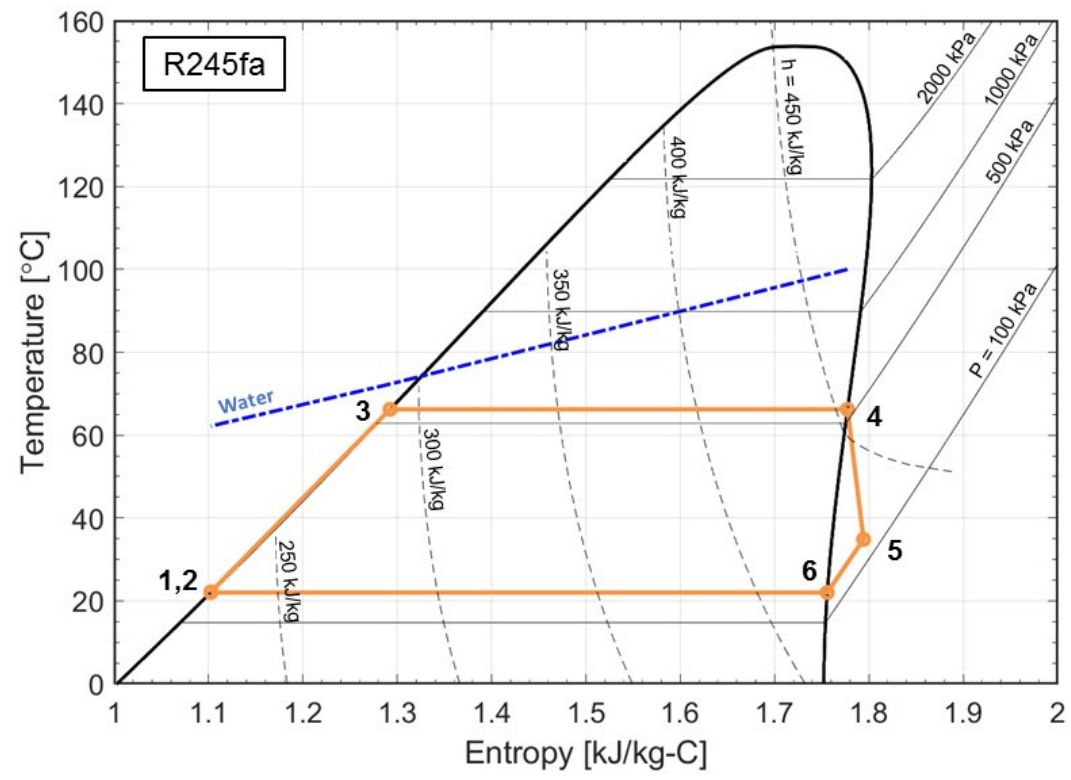

\begin{tabular}{|l|l|l|l|l|}
\hline State & $\begin{array}{l}\text { T } \\
{[\mathrm{C}]}\end{array}$ & $\begin{array}{l}\mathbf{s} \\
[\mathrm{k}] / \mathrm{kg}-\mathrm{K}]\end{array}$ & $\begin{array}{l}\mathbf{P} \\
{[\mathrm{kPa}]}\end{array}$ & $\begin{array}{l}\mathbf{h} \\
[\mathrm{k}] / \mathrm{kg}]\end{array}$ \\
\hline $\mathbf{1}$ & 22.0 & 1.10 & 133 & 229.04 \\
\hline $\mathbf{2}$ & 22.2 & 1.10 & 550 & 229.38 \\
\hline $\mathbf{3}$ & 66.2 & 1.29 & 550 & 289.60 \\
\hline $\mathbf{4}$ & 66.2 & 1.78 & 550 & 454.24 \\
\hline $\mathbf{5}$ & 34.8 & 1.79 & 133 & 433.55 \\
\hline $\mathbf{6}$ & 22.0 & 1.76 & 133 & 421.96 \\
\hline
\end{tabular}

\begin{tabular}{|r|r|r|}
\hline Component & $\begin{array}{r}\text { Heat or } \\
\text { Work }\end{array}$ & $\begin{array}{r}\text { Value } \\
{[\mathrm{kJ} / \mathrm{kg}]}\end{array}$ \\
\hline Pump (1-2) & Work & -0.34 \\
\hline Preheater (2-3) & Heat & 60.22 \\
\hline Boiler (3-4) & Heat & 164.64 \\
\hline Turbine (4-5) & Work & 20.69 \\
\hline Desuperheater (5-6) & Heat & -11.59 \\
\hline Desuperheater (5-6) & Work & -0.19 \\
\hline Condenser (6-1) & Heat & -192.92 \\
\hline Condenser (6-1) & Work & -5.18 \\
\hline Net Work & Work & 14.98 \\
\hline
\end{tabular}

Figure S14: An example R245fa ORC cycle state diagram for $100^{\circ} \mathrm{C}$ geofluid to maximize electricity generation.

The genGEO organic Rankine cycle does not use superheating. Superheating is commonly used in power cycles to guarantee vapor throughout the turbine. However, the shape of the R245fa vapor dome is unusual in that the entropy of saturated vapor decreases at temperatures below $124^{\circ} \mathrm{C}$. As the entropy increases throughout the turbine, the fluid will remain gaseous in the turbine so long as the turbine is constrained to saturated vapor below $124^{\circ} \mathrm{C}$. The isobutane vapor dome has a similar shape and feature. Thus, we instead imposed a maximum boiling temperature constraint for the organic fluid at the temperature with maximum saturated vapor entropy. 
We use both R245fa and isobutane (R600a) as organic fluids in genGEO. R245fa is used to be consistent with previous publications; however R245fa is a more expensive refrigerant than $\mathrm{R} 600 \mathrm{a}$, which is an industry standard. Ultimately, we found the power generation of both refrigerants to be similar, thus we use R245fa in a genGEO ORC, unless stated otherwise.

Similar to genGEO, GEOPHIRES also uses a single-pressure organic Rankine cycle from ASPEN (Beckers and McCabe, 2019). GETEM uses ASPEN power cycle results of an undocumented type. The genGEO single-pressure model is a simple starting point as systems with multiple pressures, and thus boiling points, are more typically deployed in new developments. The genGEO thermodynamic models may be extended to include these system types.

\section{S5.3 ORC Design Optimizations}

An ORC has many design decisions which are made that affect both its electricity generation and cost. There are two ways to optimize ORC design in genGEO: a) to maximize electric power generation per unit geofluid produced from a geothermal resource (Section S5.3.1), or b) to minimize the cost per unit of electricity generated (Section S5.3.2). We compare the results of these optimization choices in Section S5.3.3.

In any ORC design, we set two temperatures depending on the optimization method: the ORC boiling temperature and the heat exchanger pinch temperature difference. The boiling temperature is the temperature where the fluid phase changes from liquid to vapor (States 3 to 4 in Figure S14). The boiling temperature is set by controlling the pump outlet pressure. The heat exchanger pinch temperature difference is the smallest temperature difference in the heat exchanger between the primary and secondary fluids (sometimes called the "pinch point"). In Figure S14, the temperature difference between the water (blue line) and R245fa (orange line) is smallest at State 3 , thus the pinch temperature difference is $5^{\circ} \mathrm{C}$ in that example.

In the following sections, we describe how the ORC boiling temperature and heat exchanger pinch temperature difference are set.

In genGEO, the optimum ORC boiling temperature and heat exchanger pinch temperature difference for a given geofluid production temperature are stored in a lookup table so that this computationally expensive task is not performed with every simulation iteration. However, the code could be modified so this optimization occurs with every iteration.

\section{S5.3.1 Maximize Specific Electric Power}

In this optimization option, the electric power generated, per unit of produced geofluid, is maximized. This is the optimization method of Adams et al. (2015) and GEOPHIRES.

Maximization of electric power is perhaps the easier optimization method to implement as it does not require any costs to be included, so it is often used. Realization of the maximum power is achieved by reducing all heat exchanger temperature differences to the smallest value possible to extract the maximum heat from the produced geofluid. However, a zero pinch temperature difference requires infinite heat exchanger area, and thus infinite cost (Section S3.2.4). Thus, Adams et al. (2015) prescribed a minimum "practical" pinch temperature difference of $5^{\circ} \mathrm{C}$. 
The ORC boiling temperature which maximizes power generation is determined by evaluating the thermodynamic tradeoffs of each temperature. At low boiling temperature, a majority of heat may be extracted from the produced geofluid, however the energy conversion to electricity is at a low efficiency. Thermal efficiency increases with the boiling temperature, as prescribed by the Carnot efficiency. Conversely, at high boiling temperature, the cycle has a higher thermal efficiency, but much of the heat may not be extracted from the produced geofluid. Thus, an iterative method may be used to find the boiling temperature which generates the most power. This process is further described in Section S3 of Adams et al. (2015).

\section{S5.3.2 Minimize Specific Electric Cost}

In this optimization option, the cost of electricity per unit energy generated (i.e. LCOE) is minimized. This is the optimization method of GETEM.

Minimization of electric cost requires that the cost of the entire geothermal system be known. The ORC surface plant can't be cost-minimized by itself. The cost per unit electricity generated by an ORC by itself is minimized by essentially generating zero electricity (i.e. $0 \%$ second-law efficiency), when the heat exchanger pinch temperature difference is maximized. As the secondlaw efficiency (i.e. utilization efficiency) of an ORC is increased, both the electric power and total ORC cost increase. If the non-ORC costs are high, a higher efficiency (and more expensive) power plant may minimize LCOE than when the non-ORC costs are lower. Thus, the non-ORC costs must be also known (i.e. wells, wellfield, etc.). GETEM determines the ORC second-law efficiency to minimize LCOE using an EXCEL macro. However, the specifics of this GETEM optimization are not known as GETEM only provides equations which calculate electric power and cost as a function of second-law efficiency.

In genGEO, the ORC boiling temperature and heat exchanger pinch temperature difference which minimize LCOE are determined for a "test case" and stored in a lookup table. Conversely, the code could be modified so this optimization is performed with every simulation. In the "test case" used in genGEO, the geofluid production rate is $400 \mathrm{~kg} / \mathrm{s}$ and the total non-ORC cost is the cost of two wells drilled to a depth necessary to obtain the ORC inlet temperature given a $15^{\circ} \mathrm{C}$ surface temperature and a $35{ }^{\circ} \mathrm{C} / \mathrm{km}$ geologic temperature gradient. At every geofluid production temperature, the ORC design temperatures are found to minimize the cost per unit electricity generated in this "test case".

\section{S5.3.3 Optimization Results}

The results of the ORC cost minimization as a function of ORC inlet temperature are given in Figure S15 as dashed lines. The ORC operational conditions which result from electricity maximization are given as solid lines in Figure S15.

Figure S15A shows that for low ORC inlet temperatures, the two optimization strategies yield nearly identical results; however, they begin to differ at higher temperatures. For example, the minimum cost strategy has a higher ORC outlet temperature than the maximum power strategy for an inlet temperature of $200^{\circ} \mathrm{C}$. In this case, the cost of removing the remaining low-temperature heat is not worth the value it provides, and the geofluid is reinjected near $\sim 70^{\circ} \mathrm{C}$. Conversely, in the maximum power case, the ORC always removes the maximum possible heat from the geofluid (i.e. an ORC outlet temperature of $27^{\circ} \mathrm{C}$ ). 

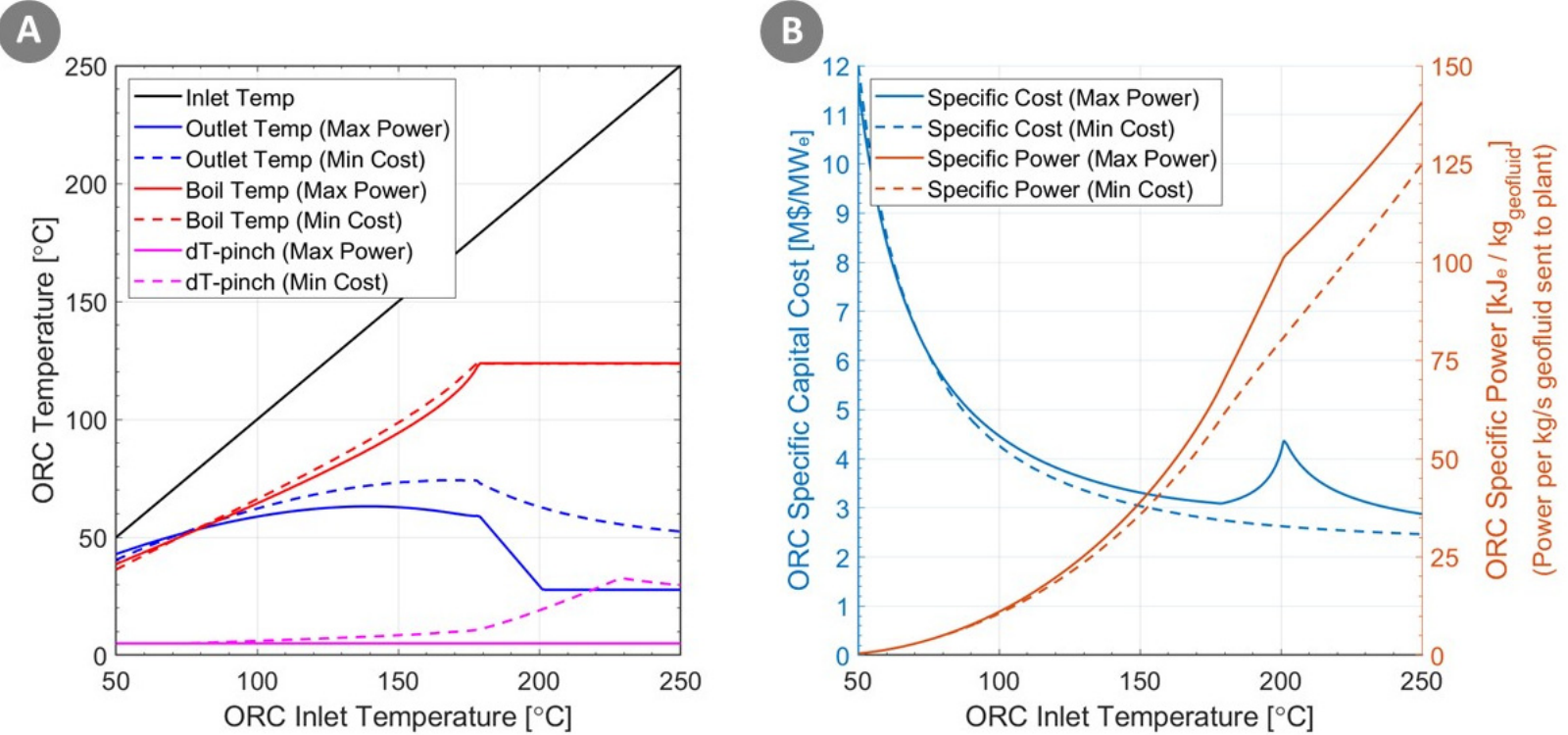

Figure S15: Organic Rankine cycle (ORC) values as a function of temperature of: A) boil and pinch temperatures and B) specific capital cost and specific power.

The lowest geofluid outlet temperature possible from the ORC is the sum of ambient temperature $\left(15^{\circ} \mathrm{C}\right)$, cooling tower approach temperature $\left(7^{\circ} \mathrm{C}\right)$, and minimum heat exchanger pinch temperature $\left(5^{\circ} \mathrm{C}\right)$. When the ORC outlet temperature is this minimum value, no additional heat extraction is possible and electricity generated per unit geofluid is maximized. In Figure S15A, the outlet temperature is greater than $27^{\circ} \mathrm{C}$ at inlet temperatures below $200^{\circ} \mathrm{C}$ for the "Max Power" case because the minimum pinch temperature difference in the heat exchanger is located between the preheater and boiler, instead of at the preheater exit (as is the case in Figure S15A at temperatures above $200^{\circ} \mathrm{C}$ ).

Figure S15B shows the electricity generation per kilogram geofluid produced (i.e. $\mathrm{kJ}_{\mathrm{e}} / \mathrm{kg}_{\text {geofluid }}$ ) and ORC specific capital cost (i.e. surface plant specific capital cost) as a function of inlet temperature. The electricity generation per unit geofluid is sometimes called "ORC Specific Power" or "Brine Effectiveness". The "Utilization Efficiency" or "Second-law efficiency" of the surface plant describe the same concept as ORC specific power, but are instead the ratio of ORC specific power to the maximum possible at that temperature (i.e. exergy available). Figure S15B shows costs for a $10 \mathrm{MW}_{\mathrm{e}}$ plant.

Discontinuities exist in Figure 5B near an ORC inlet temperature of $200^{\circ} \mathrm{C}$ for only the maximum power strategy. In the maximum power strategy, the cost of decreasing the LMTD in the preheater trades off with the benefit of increasing the LMTD in the boiler, resulting in a peak at $200^{\circ} \mathrm{C}$. 


\section{S6. Wellbore Model}

The wellbore model implemented in genGEO is identical to that used in Adams et al. $(2014 ; 2015$; in press), Garapati et al. (2020), and Fleming et al. (2018; 2020), except for the inclusion of heat conduction between the wellbore fluid and the surrounding rock. The heat conduction through the wellbore is found by applying a 1-D analytical solution of radial heat conduction in a semi-infinite solid from Carslaw \& Jaeger (1959) to each element. This is the same method to determine heat conduction as T2Well (Zhang et al., 2011).

The wellbore is numerically solved for pressure, $\mathrm{P}$, (Equation S63) and enthalpy, h, (Equation S64) for each element, $i$. The two relations are identical to that described in Adams et al. (2015), except for the heat loss term, $Q_{L o s s, i}$, in Equation S64, where $\rho$ is the fluid density, $g$ is the gravitational constant, $\Delta z$ is the elevation change, $\Delta P_{\text {Loss }, i}$ is the Darcy-Weisbach frictional pressure loss in each element, and $\dot{m}$ is the wellbore mass flowrate.

$$
\begin{aligned}
& P_{i+1}=P_{i}-\rho \cdot g \cdot \Delta z-\Delta P_{\text {Loss }, i} \\
& h_{i+1}=h_{i}-g \cdot \Delta z-\frac{\dot{Q}_{\text {Loss }, i}}{\dot{m}}
\end{aligned}
$$

The heat exchange between the well and surroundings is given by Equation S65, where $k_{R o c k}$ is the rock thermal conductivity, $T_{w, i}$ is the wellbore wall temperature in the element, and $T_{e, i}$ is the far-field rock temperature at the given element elevation. Only radial heat conduction from the wellbore is considered.

$$
\dot{Q}_{L o s s, i}=\Delta z \cdot 2 \cdot \pi \cdot k_{\text {Rock }} \cdot \beta \cdot\left(T_{w, i}-T_{e, i}\right)
$$

The dimensionless factor $\beta$ accounts for the heat loss change as a function of dimensionless time, $t_{d}$, described in Equation S66. Two relationships for $\beta$ are given depending on their relation to a non-dimensional time of 2.8 (Zhang et al., 2011).

$$
\beta= \begin{cases}\left(\pi \cdot t_{d}\right)^{-0.5}+\frac{1}{2}-\frac{1}{4}\left(\frac{t_{d}}{\pi}\right)^{0.5}+\frac{1}{8} t_{d}, & t_{d} \leq 2.8 \\ \frac{2}{\ln \left(4 \cdot t_{d}\right)-1.16}-\frac{1.16}{\left(\ln \left(4 \cdot t_{d}\right)-1.16\right)^{2}}, & t_{d}>2.8\end{cases}
$$

Lastly, the non-dimensional time, $t_{d}$, is a function of the thermal conductivity of rock, $k_{R o c k}$, the rock density, $\rho_{\text {Rock }}$, the specific heat of rock, $c^{\prime}{ }_{\text {Rock }}$, time, $t$, and the well diameter, $D_{W e l l}$ (Equation S67).

$$
t_{d}=\frac{k_{\text {Rock }}}{\rho_{\text {Rock }} C^{\prime} \text { Rock }} \frac{4 \cdot t}{D_{\text {Well }}^{2}}
$$

The application of heat conduction is further explained in Adams et al. (2020) and implemented in Ezekiel et al. (2020). 


\section{S6.1 Effect of Wellbore Heat Loss}

The effect of the inclusion of wellbore heat loss in genGEO is illustrated in Figure S16. Figure S16 shows the variation in production temperature as a function of mass flowrate for genGEO and other simulators. The reservoir temperature in this base case example (see Table 2 in the main paper) is $102.5^{\circ} \mathrm{C}$. If wellbore heat loss were not included, the water production temperature would also be $102.5^{\circ} \mathrm{C}$ in all cases. The $\mathrm{CO}_{2}$ is less affected by wellbore heat loss-the temperature of $\mathrm{CO}_{2}$ naturally decreases as it expands travelling up the wellbore.

A

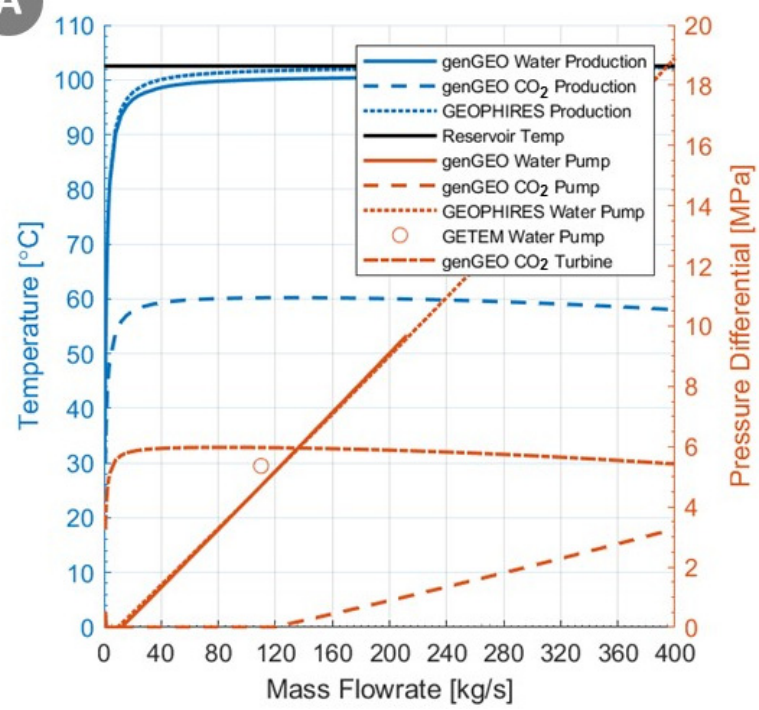

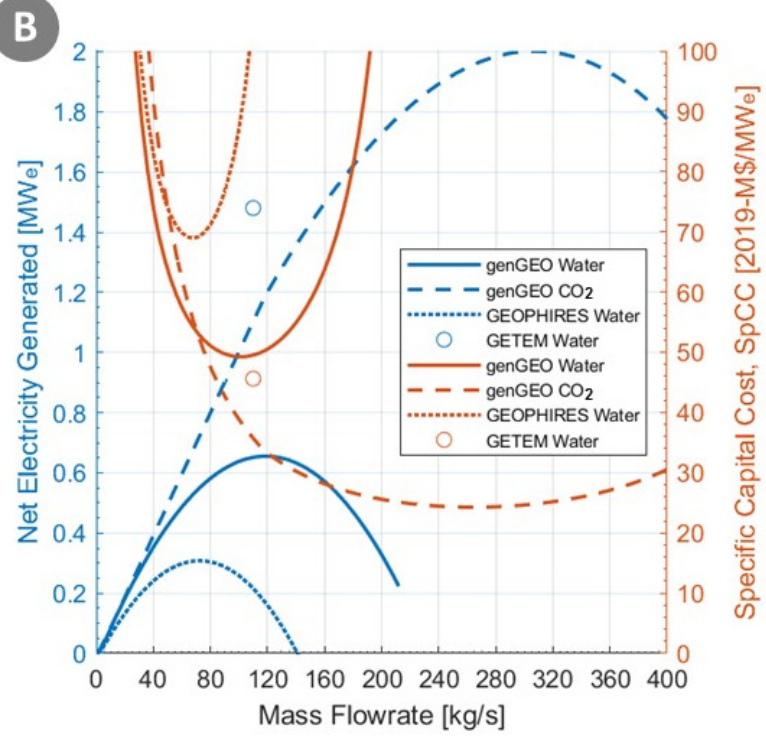

B

Figure S16: A comparison of genGEO, GETEM, and GEOPHIRES simulator results as a function of mass flowrate for: A) wellhead temperature and pump or turbine pressure differential, and B) electricity generated and specific capital cost. Both a genGEO water-based and $\mathrm{CO}_{2}$-based (CPG) system are analyzed. GETEM costs are shown both with and without exploration cost.

Figure S16A shows that well heat loss is negligible above a mass flowrate of $\sim 40 \mathrm{~kg} / \mathrm{s}$. All things considered, the heat flux, $\dot{Q}_{\text {Loss }, i}$, into a well is relatively constant and does not depend on the wellbore mass flowrate (Equation S65). However, the enthalpy change of the fluid due to heat conduction is inversely proportional to the mass flowrate. Thus, we expect the heat loss for any well to begin significantly affecting the fluid temperature below $\sim 40 \mathrm{~kg} / \mathrm{s}$.

In the base-case example of Figure S16, the mass flowrate which minimizes cost for the genGEO water case (Figure S16B) is approximately $100 \mathrm{~kg} / \mathrm{s}$, and much higher than $40 \mathrm{~kg} / \mathrm{s}$. Thus, we can assume the effects of wellbore heat loss are negligible. However, in cases of low transmissivity or pipe diameter, a lower mass flowrate which minimizes cost is expected and the inclusion of wellbore heat loss may be important. 


\section{S7. Geologic Reservoir Model}

The geologic reservoir model provides two important values to the coupled geothermal power plant model of genGEO: 1) the reservoir impedance (Section S7.1), and 2) geofluid production temperature entering the production well (Section S7.2). The reservoir impedance is the reservoir's resistance to flow and is essential to determining the overall flowrate of the system. The surface plant electricity generation is very dependent on the geofluid production temperature as the heat-to-electricity conversion efficiency (i.e. thermal efficiency) is proportional to production temperature.

Both the reservoir impedance and thermal depletion models employ analytical solutions to determine their respective values. This is a primary difference from Adams et al. (2015) which relied on TOUGH2 simulations. In Adams et al. (2015), TOUGH2 simulations were coupled to the well and power plant models in a variety of ways. First, reservoir impedance and temperature depletion curves were fit to TOUGH2 results to be used in power system simulations (Adams et al., 2014; 2015; in press). Later, TOUGH2 simulations were directly coupled to power system simulations (Garapati et al., 2020); however, this proved to be cumbersome.

Ultimately, it was determined that TOUGH2 simulations were not warranted as they incur excessive computational overhead while their results, in our simple reservoir cases, can be estimated with analytical solutions. This switch to analytical solution aligns genGEO with the methodologies of GETEM and GEOPHIRES, though GEOPHIRES additionally allows for integration with TOUGH2.

Consistent with Adams et al. (2015), genGEO assumes a homogeneous, isotropic, porous media reservoir. Alternative reservoir configurations, such as fracture networks or simple linear temperature depletion models can be implemented within the python code, but are not further discussed here.

In simulations that use water as the subsurface heat extraction fluid, the reservoir pore space is assumed to be completely filled with water. When $\mathrm{CO}_{2}$ is used in the subsurface, the reservoir pore space is assumed to be sufficiently filled with $\mathrm{CO}_{2}$ such that only pure $\mathrm{CO}_{2}$ is produced from the reservoir. As the analytical reservoir solutions are one dimensional, buoyancy effects are neglected.

\section{S7.1 Reservoir Impedance Model}

The reservoir impedance is the ratio of the pressure difference between the injection well downhole and production well downhole to the mass flowrate through the reservoir. This value is essential to determine the circulation flowrate of a geofluid, how much pumping is required, the ease at which geothermal heat can be extracted from a reservoir, and ultimately the profitability of doing so.

The 5-spot and doublet (i.e. "source-sink" pair in potential flow terminology) reservoir impedances are derived in Adams et al. (2020). They will be briefly summarized here. 
For a 5 -spot, the reservoir impedance $(\Delta P / \dot{m})$ is given by Equation S68, where $\bar{\mu}$ is the effective viscosity in the reservoir, $\bar{\rho}$ is the effective density in the reservoir, $\kappa$ is the permeability, $b$ is the thickness, $L$ is the well spacing, and $D$ is the well diameter.

$$
\frac{\Delta P}{\dot{m}}=\frac{\bar{\mu}}{\bar{\rho}} \cdot \frac{1}{\kappa \cdot b} \cdot \frac{1}{4} \cdot \ln \left(\frac{4 \cdot L}{\pi \cdot D}\right)
$$

In genGEO, the effective viscosity and effective density are the averages of their respective values at the inlet and outlet fluid states of the reservoir.

For a doublet, the reservoir impedance is given in Equation S69 when $\mathrm{L} \gg \mathrm{D}$, where $e$ is Euler's number.

$$
\frac{\Delta P}{\dot{m}}=\frac{\bar{\mu}}{\bar{\rho}} \cdot \frac{1}{\kappa \cdot b} \cdot \frac{1}{\pi} \cdot \ln \left(\frac{L}{D \cdot e}\right)
$$

The 5-spot reservoir impedance is used for all 5-spot and 5-spot "Shared Neighbor" configurations (Section S8). The source-sink pair impedance (i.e. "doublet") is used for the special case when simulating a lone well pair. Note that the difference in reservoir impedance between the 5-spot and doublet is essentially due to Euler's number in the logarithm, which is relatively small.

\section{S7.2 Thermal Depletion Model}

There are two types of geothermal reservoirs: thermally replenishing and thermally isolated. Thermally replenishing reservoirs are usually connected to deep, high-temperature heat sources via fractures and thus the production temperature of geofluid removed from them tends to be relatively constant. Heat tends to be resupplied to thermally replenishing reservoirs primarily through fluid advection from hot to cold zones. Conversely, thermally isolated reservoirs have no connections to deep heat sources and have only a finite amount of heat to extract, which may be augmented by heat conduction from surrounding geologic layers. Heat depletion is an important consideration in thermally isolated reservoirs.

If first-year electric generation results are desired, both thermally-isolated and replenishing reservoirs will produce approximately the same temperature fluid. First-year generation is assumed in most publications (Adams et al., 2015; Garapati et al., 2020), including the main body of this publication. Thermal depletion over time is considered less frequently (Adams et al., in press), especially because the present-value of electricity generated more than a decade in the future is heavily discounted.

If thermal depletion of a thermally-isolated reservoir is desired, non-dimensionalized depletion curves from Adams (2015) may be used, as is the case in Adams et al. (in press). The nondimensional temperature, $\Gamma$, is a function of the non-dimensionalized reservoir energy, $\Psi$ (see Section 4.2.1.2 in Adams (2015)). The non-dimensional temperature (Equation S70) is the ratio of reservoir production temperature, $T$, less the reservoir injection temperature, $T_{i n j}$, to the initial reservoir production temperature, $T_{\text {initial }}$, less the reservoir injection temperature.

$$
\Gamma=\frac{T-T_{i n j}}{T_{\text {initial }}-T_{\text {inj }}}
$$




\section{S8. Well Pattern and Spacing}

The well placement pattern and spacing describes the way a wellfield is developed in porous media geothermal.

There are two types of well field development types: a large, fully-developed wellfield with an infinite number of repeating well patterns and a single well pattern in an unbounded reservoir. A 5-spot, which is often used in geothermal reservoir analysis (Pruess, 2008; Randolph \& Saar, 2011; Adams et al., 2015), represents a single well pattern within a fully-developed field (Figure S17). This is apparent through the use of no-flow heat and fluid boundary conditions on the 5spot vertical boundaries. Conversely, a single well pattern in an unbounded reservoir has been used in some analyses (Garapati et al., 2015; Garapati et al., 2020; Adams et al., in press), though it is not easily upscaled.

genGEO provides support for both infinite-repeating patterns (i.e. 5-spot) and single patterns (i.e. doublet). Electrical power generation for doublets is limited to a single well pair, while electrical power generation for a 5-spot may be upscaled to the map-view footprint of the reservoir.

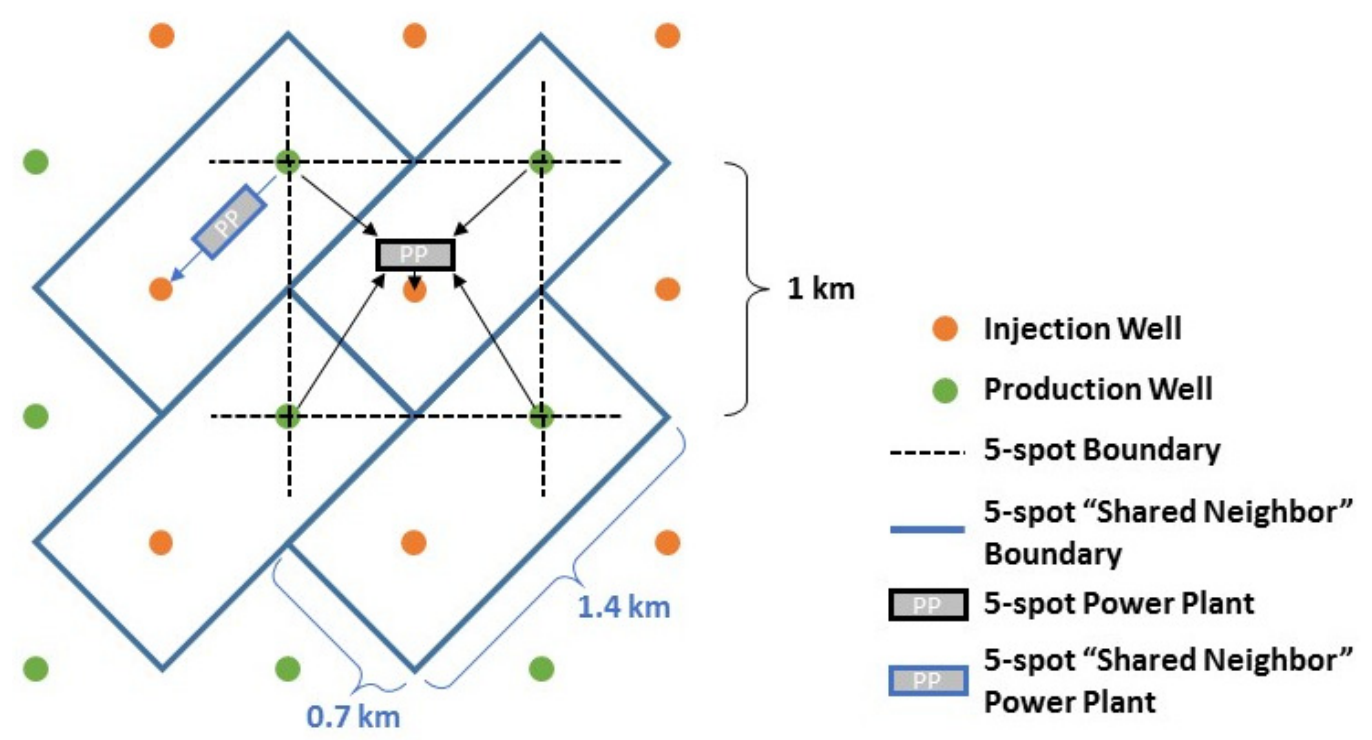

Figure S17: 5-spot Shared Neighbor Well Configuration

A 5-spot consists of a central injection well and four surrounding production wells, as shown by the dashed lines in Figure S17. The inverted 5-spot is square in map-view, with $1 \mathrm{~km}$ length sides, resulting in a $707 \mathrm{~m}$ well spacing.

There are many schemes which could be used to connect the geothermal wells to surface generation plants. Economy of scale may be achieved by routing multiple injection and production wells into a single central power plant. In genGEO, we start with the simplifying assumption that one power plant is constructed for every injection-production well pair (i.e. two wells). 
Each 5-spot generates electricity byway of a single, centrally located power plant. As such, the mass flowrate of each corner production well is split into quarters and distributed to each respective 5-spot power plant. The central plant then combines the four streams and reinjects all the fluid into the central injection well (Figure S17).

As a matter of practicality, it makes little sense to split the flow from four corner wells into quarters, but instead to connect only a single injection and production well, shown by the blue "5-spot Shared Neighbor" rectangles in Figure S17. This reconfiguration does not affect the reservoir pressures, heat, or cycle thermodynamics. However, the "5-spot Shared Neighbor" reconfiguration is useful in terms of cost. It reduces the amount of surface piping to $707 \mathrm{~m}$ and requires only two wells per 5-spot. Thus, when using the "5-spot Shared Neighbor" configuration in genGEO, the reservoir pressures and temperatures are simulated for a 5-spot, but the cost is calculated for a "5-spot Shared Neighbor". 


\section{Acknowledgements}

We thank PSI Engineering of Burnsville, Minnesota, USA for their assistance with $\mathrm{CO}_{2}$ pump quote. We thank Richard Esposito for his insight and thoughtful conversation.

\section{References}

Adams, B.M. (2015). On the power performance and integration of carbon-dioxide plume geothermal (CPG) electrical energy production. Thesis. University of Minnesota. https://conservancy.umn.edu/handle/11299/175183

Adams, B.M., Kuehn, T.H., Bielicki, J.M., Randolph, J.B., \& Saar, M.O. (2015). A comparison of electric power output of $\mathrm{CO}_{2}$ Plume Geothermal (CPG) and brine geothermal systems for varying reservoir conditions. Applied Energy, 140, 365-377. https://doi.org/10.1016/j.apenergy.2014.11.043

Adams, B.M., Kuehn, T.H., Bielicki, J.M., Randolph, J.B., \& Saar, M.O. (2014). On the importance of the thermosiphon effect in $\mathrm{CPG}\left(\mathrm{CO}_{2}\right.$ plume geothermal) power systems. Energy, 69,409 418. https://doi.org/10.1016/j.energy.2014.03.032

Adams, B.M., Vogler, D., Kuehn, T.H., Bielicki, J.M., Garapati, N., \& Saar, M.O. (in press). Heat depletion and its effect on the design and electric power output of $\mathrm{CO}_{2}$ Plume Geothermal (CPG) systems. Renewable Energy. https://doi.org/10.1016/j.renene.2020.11.145

Adams, B.M., Saar, M.O., Bielicki, J.M., Ogland-Hand, J.D., \& Fleming, M.R. (2020). Using geologically sequestered $\mathrm{CO}_{2}$ to generate and store geothermal electricity: $\mathrm{CO}_{2}$ Plume Geothermal (CPG). Proceedings of MIT A+B Applied Energy Symposium, 12-14 Aug, 2020. https://doi.org/10.3929/ethz-b-000444911

Atrens, A.D, Gurgenci, H., and Rudolph, V. (2011). Economic optimization of a $\mathrm{CO}_{2}$-based EGS power plant. Energy \& Fuels, 25, 3765-3775. https://doi.org/10.1021/ef200537n

Baltimore Aircoil Company (BAC). (2020). Product selection software. http://www.baltimoreaircoil.com/english/product-selection-software-public

Beckers, K.F. (2016). Low-Temperature Geothermal Energy: Systems Modeling, Reservoir Simulation, and Economic Analysis. Thesis. Cornell University. https://doi.org/10.7298/X4736NTC

Beckers, K.F., Lukawski, M.Z., Anderson, B.J., Moore, M.C., and Tester, J.W. (2014). Levelized costs of electricity and direct-use heat from Enhanced Geothermal Systems. Journal of Renewable and Sustainable Energy, 6. https://doi.org/10.1063/1.4865575

Beckers, K.F., and McCabe, K. (2019). GEOPHIRES v2.0: updated geothermal techno-economic simulation tool. Geothermal Energy, 7:5. https://doi.org/10.1186/s40517-019-0119-6

Beckers, K.F., and Young, K.R. (2017). Performance, cost, and financial parameters of geothermal district heating systems for market penetration modeling under various scenarios. Proceedings, $42^{\text {nd }}$ workshop on geothermal reservoir engineering, Stanford University, Stanford, California, February 13-15, 2017, SGP-TR-212.

Blumsack, S. (2020). Project decision metrics: Levelized cost of energy (LCOE). Online course lesson for Penn State course EME801. https://www.e-education.psu.edu/eme801/node/560

Borowski, W.S., Shukla, N., \& Rives, J.S.II. (1984). Oil and gas developments in Louisiana gulf coast onshore in 1983. American Association of Petroleum Geologists Bulletin, 68:10, 13701376. https://doi.org/10.1306/AD46192B-16F7-11D7-8645000102C1865D 
Boyd, D.T. (2002). Oklahoma natural gas: Past, present, and future. Oklahoma Geology Notes, $62: 4,143-155$.

Calpine. (2020). Calpine Annual Report, Securities and Exchange Commission Form 10-K. https://www.sec.gov/cgi-bin/browse-edgar?ClK=916457

Carslaw, H.S. and Jaeger, J.C. (1959). Conduction of heat in solids. Second Edition. Oxford University Press.

DiPippo, R. (2015). Geothermal Power Plants: Principles, Applications, Case Studies and Environmental Impact. $4^{\text {th }}$ Edition. Butterworth-Heinemann.

Douglas, J.M. (1988). Conceptual design of chemical processes. New York: McGraw-Hill.

Duc, N.H., Chauvy, F., and Herri, J.M. (2007). $\mathrm{CO}_{2}$ capture by hydrate crystallization-A potential solution for gas emission of steelmaking industry. Energy Conversion and Management, 48, 1313-1322. https://doi.org/10.1016/j.enconman.2006.09.024

Esposito, R.A., Kuuskraa, V.A., Rossman, C.G., and Corser, M.M. (2019). Reconsidering CCS in the US fossil-fuel fired electricity industry under section $45 \mathrm{Q}$ tax credits. Greenhouse Gas Science Technology: 0, 1-14. https://doi.org/10.1002/ghg.1925

EPA (U.S. Environmental Protection Agency). (2008). Geologic $\mathrm{CO}_{2}$ Sequestration Technology and Cost Analysis. Technical Support Document. EPA 816-B-08-009. https://www.epa.gov/sites/production/files/201507/documents/support uic co2 technologyandcostanalysis.pdf

EPA (U.S. Environmental Protection Agency). (2010). Geologic $\mathrm{CO}_{2}$ Sequestration Technology and Cost Analysis. EPA 816-R-10-008.

Ezekiel, J., Ebigbo, A., Adams, B.M., \& Saar, M.O. (2020). Combining natural gas recovery and $\mathrm{CO}_{2}$-based geothermal energy extraction for electric power generation. Applied Energy, 269, 115012. https://doi.org/10.1016/j.apenenergy.2020.115012.

Fleming, M.R., Adams, B.M., Kuehn, T.H., Bielicki, J.M., \& Saar, M.O. (2020). Increased power generation due to exothermic water exsolution in CO2 Plume Geothermal (CPG) power plants. Geothermics, 88, 101865. https://doi.org/10.1016/j.geothermics.2020.101865

Fleming, M.R., Adams, B.M., Randolph, J.B., Ogland-Hand, J.D., Kuehn, T.H., Buscheck, T.A., Bielicki, J.M., \& Saar, M.O. (2018). High efficiency and large-scale subsurface energy storage with $\mathrm{CO}_{2}$. Proceedings, 43rd Workshop on Geothermal Reservoir Engineering, 12-14 Feb, 2018.

Garapati, N., Adams, B.M., Fleming, M.R., Kuehn, T.H., \& Saar, M.O. (2020). Combining brine or $\mathrm{CO}_{2}$ geothermal preheating with low-temperature waste heat: A higher-efficiency hybrid geothermal power system. Journal of $\mathrm{CO}_{2} \quad$ Utilization, 42, 101323. https://doi.org/10.1016/j.jcou.2020.101323

Garapati, N., Randolph, J.B., \& Saar, M.O. (2015). Brine displacement by $\mathrm{CO}_{2}$, energy extraction rates, and lifespan of a $\mathrm{CO}_{2}$-limited $\mathrm{CO}_{2}$-plume geothermal (CPG) system with a horizontal production well. Geothermics, 55, 182-194.

Klein, C.W., Lovekin, J.W., \& Sanyal, S.K. (2004). New geothermal site identification and qualification. A consultant report prepared for the California Energy Commission by GeothermEx, Inc. https://ww2.energy.ca.gov/reports/500-04-051.PDF

Lazard. (2019). Levelized Cost of Energy Analysis - Version $13.0 \quad 2019$. https://www.lazard.com/media/451086/lazards-levelized-cost-of-energy-version-130-vf.pdf. 
Le, V.L., Kheiri, A., Feidt, M., \& Pelloux-Prayer, S. (2014). Thermodynamic and economic optimizations of a waste heat to power plant driven by a subcritical ORC (Organic Rankine Cycle) using pure or zeotropic working fluid. Energy, 78, 622-638.

Levitt, C.J. (2016). Information spillovers in onshore oil and gas exploration. Resource and Energy Economics, 45, 80-98. https://doi.org/10.1016/j.reseneeco.2016.05.003.

Lowry, T.S., Finger, J.T., Carrigan, C.R., Foris, A., Kennedy, M.B., Corbet, T.F., Doughty, C.A., Pye, S., and Sonnenthal, E.L. (2017). GeoVision analysis supporting task force report: Reservoir maintenance and development. Sandia National Laboratories (SNL) Report SAND2017-9977.

Lukawski, M.Z., Anderson, B.J., Augustine, C., Capuano, L.E.Jr., Beckers, K.F., Livesay, B., \& Tester, J.W. (2014). Cost analysis of oil, gas, and geothermal well drilling. Journal of Petroleum Science and Engineering, 118, 1-14. https://doi.org/10.1016/j.petrol.2014.03.012

Mines, G.L. (2016). GETEM User Manual. Idaho National Laboratory, INL/EXT-16-38751. https://workingincaes.inl.gov/SiteAssets/CAES\%20Files/FORGE/inl ext-1638751\%20GETEM\%20User\%20Manual\%20Final.pdf

Moisseytsev, A. \& Sienicki, J.J. (2014). Investigation of a dry air cooling option for an s- $\mathrm{CO}_{2}$ cycle. The $4^{\text {th }}$ international symposium on supercritical $\mathrm{CO}_{2}$ power cycles, Sept 9-10, 2014, Pittsburgh, PA.

National Energy Technology Laboratory (NETL) (2002). Process equipment cost estimation final report. DOE/NETL-2002/1169.

National Energy Technology Laboratory (NETL) (2007). Cost and performance baseline for fossil energy plants: Volume 1: Bituminous coal and natural gas to electricity. Final report. DOE/NETL-2007/1281.

National Energy Technology Laboratory (NETL) (2010). Cost and performance baseline for fossil energy plants: Volume 1: Bituminous coal and natural gas to electricity. Revision 2. DOE/NETL-2010/1397.

National Energy Technology Laboratory (NETL) (2011). Cost estimation methodology for NETL assessments of power plant performance. Quality guidelines for energy system studies. DOE/NETL-2011/1455.

National Energy Technology Laboratory (NETL) (2012). Updated costs (June 2011 Basis) for selected bituminous baseline cases. DOE/NETL-341/082312.

National Energy Technology Laboratory (NETL) (2015). Cost and performance baseline for fossil energy plants volume 1a: Bituminous coal (PC) and natural gas to electricity. Revision 3. DOE/NETL-2015/1723.

National Renewable Energy Laboratory (NREL). 2017. OpenEl: Levelized Cost Calculations. https://openei.org/apps/TCDB/levelized cost calculations.html

National Energy Technology Laboratory (NETL) (2019a). Cost estimation methodology for NETL assessments of power plant performance. Quality guidelines for energy system studies. NETL-PUB-22580.

National Energy Technology Laboratory (NETL) (2019b). Cost and performance baseline for fossil energy plants volume 1: Bituminous coal and natural gas to electricity. NETL-PUB-22638.

Neff, B. (2019). Estimated cost of new utility-scale generation in California: 2018 update. California Energy Commission. Publication Number: CEC-200-2019-500. 
Olson, A., Schlag, N., Patel, K., \& Kwok, G. (2014). Capital cost review of generation technologies: Recommendations for WECC's 10- and 20-year studies. Prepared for the Western Electric Coordinating Council by ethree. https://www.wecc.org/Reliability/2014 TEPPC Generation CapCost Report E3.pdf

Ormat. (2020a). Ormat Annual Report, Securities and Exchange Commission Form 10-K. https://www.sec.gov/cgi-bin/browse-edgar?CIK=1296445

Ormat. (2020b). Ormat Steamboat Field Trip. A virtual field trip at the 2020 Geothermal Rising (formerly Geothermal Resources Council) annual meeting. 16 to 23 Oct, 2020.

Peters, M., Timmerhaus, K., \& West, R. (2003). Heat-Transfer Equipment-Design and Costs. Plant Design and Economics for Chemical Engineers, 5.

Pidaparti, S.R., Moisseytsev, A., Sienicki, J.J., \& Ranjan, D. (2015). Counterflow induced draft cooling tower option for supercritical carbon dioxide Brayton cycle. Nuclear Engineering \& Design, 295, 549-558.

Pruess, K. (2008). On production behavior of enhanced geothermal systems with $\mathrm{CO}_{2}$ as working fluid. Energy Conversion and Management, 49, 1446-1454. https://doi.org/10.1016/i.enconman.2007.12.029

Randolph and Saar. (2011). Combining geothermal energy capture with geologic carbon dioxide sequestration. Geophysical Research Letters, 38, L10401. https://doi.org/10.1029/2011GL047265

Riestenberg, D.E., Koperna, G.J., Pashin, J.C., McLaughlin, J.F., Walsh, P.M., Myers, G.C., Kirkland, B.L., Beckingham, L.E., Ripepi, M., and Esposito, R.A. (2018). Project $\mathrm{ECO}_{2} \mathrm{~S}$ : Characterization of a World Class Carbon Dioxide Storage Complex. $14^{\text {th }}$ International Conference on Greenhouse Gas Control Technologies, GHGT-14, 21-25 October, 2018, Melbourne, Australia.

Sanyal, S.K. (2004). Cost of geothermal power and factors that affect it. Proceedings, twentyninth workshop on geothermal reservoir engineering, Stanford University, Stanford, California, January 26-28, 2004.

Sanyal, S.K., Morrow, J.W., Butler, S.J., \& Robertson-Tait, A. (2007). Cost of electricity from enhanced geothermal systems. Proceedings, Thirty-second workshop on geothermal reservoir engineering, Stanford University, Stanford, California, January 22-24, 2007.

Sanyal, S.K. \& Morrow, J.W. (2012). Success and the learning curve effect in geothermal well drilling-a worldwide survey. Proceedings, Thirty-seventh workshop on geothermal reservoir engineering, Stanford University, Stanford, California, January 30 - February 1, 2012.

Schuster, A., Karellas, S., Kakaras, E., \& Spliethoff, H. (2009). Energetic and economic investigation of Organic Rankine Cycle applications. Applied Thermal Engineering, 29, 18091817.

Sell, B., Murphy, D., \& Hall, C.A. (2011). Energy return on energy invested for tight gas wells in the Appalachian Basin, United States of America. Sustainability, 3, 1986-2008. https://doi.org/10.3390/su3101986

Smith, R. (2016). Chemical process design and integration. West Sussex: John Wily \& Sons.

Thulukkanam, K. (2013). Heat Exchanger Design Handbook. CRC Press.

Zarrouk, S.J. \& Moon, H. (2014). Efficiency of geothermal power plants: A worldwide review. Geothermics 51: 142-153. https://doi.org/10.1016/j.geothermics.2013.11.001 
Zhang, Y., Pan, L., Pruess, K., and Finsterle, S. (2011). A time-convolution approach for modeling heat exchange between a wellbore and surrounding formation. Geothermics, 40, 261-266. https://doi.org/10.1016/j.geothermics.2011.08.003 